Aptamers for Detection and Diagnostics (ADD) is a proposed mobile app acquiring optical data from conjugated quantum nanodots to identify molecules indicating presence of SARS-CoV-2 virus: Why public health and healthcare need smartphone sensors as a platform for early detection and prevention

Shoumen Palit Austin Datta ${ }^{1,2, *}$

${ }^{1}$ Research Affiliate, MIT Auto-ID Labs, Department of Mechanical Engineering, Massachusetts Institute of Technology, Room 35-206, 77 Massachusetts Avenue, Cambridge, Massachusetts 02139

${ }^{2}$ Senior Scientist, MDPnP Medical Device Interoperability and Cybersecurity Labs, Biomedical Engineering Program, Department of Anesthesiology, Massachusetts General Hospital, Harvard Medical School, Partners Research Building, Suite 200, 65 Landsdowne Street, Cambridge, Massachusetts 02139

*Corresponding author (shoumen@mit.edu and/or sdatta8@mgh.harvard.edu)

\title{
ABSTRACT
}

Engineering a biomedical device as a low-cost, non-invasive, detection, and diagnostic platform for surveillance of infections in humans, and animals. The system embraces the IoT "digital by design" metaphor by incorporating elements of connectivity, data sharing and (secure) information arbitrage. Using an array of aptamers to bind viral targets may help in detection, diagnostics, and potentially prevention in case of SARS-CoV-2. The ADD tool may become part of a broader platform approach.

\section{ADD for SARS-CoV-2}

The scale of mortality and morbidity due to SARS-CoV-2 evokes us to explore unconventional approaches to mitigate the risks presented by pandemics. Scientists may be less aware of the discovery of aptamers thirty years ago but the "fit" of aptamers with respect to the molecular biology of the current problem makes it worthwhile to propose new tools. Innovation may arise from the combination of chemistry and molecular biology with sensor engineering and opportunity for data dissemination ${ }^{1}$ to benefit public health ${ }^{2}$ by integrating the principle ${ }^{3}$ of internet of things ${ }^{4}$ (IoT ${ }^{5}$ as a design metaphor).

\begin{tabular}{|l|c|c|c|c|}
\hline & Emergence & Cases & Fatality Rate & Transmissibility \\
\hline SARS & 2003 & 8,098 & $11 \%$ & + \\
\hline MERS & 2011 & 2,519 & $34 \%$ & + \\
\hline SARS-CoV-2 & 2019 & $>\mathbf{5 0}$ million & $0.5-1 \%$ Est & +++ \\
\hline SARS-CoV-3? & $? ?$ & $? ?$ & $? ?$ & ?? \\
\hline SARS-CoV-4? & $? ?$ & $? ?$ & $? ?$ & ?? \\
\hline
\end{tabular}

Table 1: Is the eight ${ }^{6}$ year interval between SARS, MERS and COVID-19 just an unrelated coincidence? 


\section{Aptamers for Detection and Diagnostics (ADD)}

Single stranded (ss) DNA aptamers (ssRNA ${ }^{7}$ are equally useful ${ }^{8}$ but susceptible to degradation by ribonuclease) bind with specificity to SARS-CoV- $2^{9}$ proteins (Nucleocapsid, Spike, Nsp1).

Aptamers are conjugated with carbon or cadmium quantum (QT) nano-dots. If there are viruses $(1,10$, $100,1000)$ in a sample (sputum, saliva) at a detectable level, then it triggers QT.DNA (QTD) conjugated complex to transmit optical property change (EIS or electrochemical impedance spectroscopy is another option for signal transduction). An optical signal transduction mechanism may offer low cost data acquisition, enabling billions of people to use $\mathrm{ADD}$ (detection tool) at home or anywhere (AHA). The end-user must have access to the "QTD" conjugate (distributed by health departments in hamlets, towns and cities). QTD (product) may be a slurry in a tube labeled as "CoV-2-DETECTION \& DIAGNOSIS" (C2DD). It remains to be investigated if inclusion of endo-b-N-acetylglucosaminidases $\left(\right.$ ENGases $\left.^{10}\right)$ in the slurry may be necessary to expose the binding sites by partially removing the $\mathrm{N}$-glycan coat if the viral Spike protein is the target (Figure 20). Imagine C2DD as a tube of lip balm or similar form factor. For supply chain and logistics, it will reduce operational cost of distribution if C2DD may be shipped as a tamper-proof sterile vial without the need for cold supply chain or special storage to extend shelf-life.

First, the end-user uses her smartphone holo-lens "QTD" app (may not be limited to Microsoft, others who can/may develop are Apple, Google, Baidu, Tencent) to take an image of the C2DD vial/tube without sample (no virus). Priming (tuning) step is critical to establish a baseline for signal transduction and app-embedded data analytics engine to set the system to "without virus" ground state to obtain an optical "ground zero" (baseline will be different for EIS). Open question for instrumentation is the need for UV activation (for traditional nanodots) to record the shift (valence electron transfer). Can the app be configured to perform the activation and record the photoluminescence change? Using visible light to activate and coupling activation/quenching with the app needs innovative chemical/device engineering.

Second, the end-user spits (or adds a small volume saliva or sputum using a swab/spoon) in the test tube (vial). There is room for controversy in this step but it is the easiest non-invasive procedure.

Third, end-user uses her smartphone holo-lens "QTD" app to record optical change (as soon as possible after adding saliva/sputum). Perhaps similar to bar code or EPC or QR code scanning.

Fourth, end-user uses her smartphone holo-lens "QTD" app to record optical changes every 5 minutes for $30 \mathrm{~min}$ (from the time of adding the sample). There will be questions about ENGase activity, binding kinetics of the aptamer, signal to noise ratio ([filtering algorithms (Kalman ${ }^{11}$ filter), error correction], activation/quenching issues, damping of signals due to interference from host proteins, salinity and pH of mucus-mucin/saliva/sputum sample (any or all could jeopardize binding and signal). 


\section{ADD Digital Data Design}

Baseline versus change over time will appear as a plot in the app (analytics, Figure 1, uses basic machine learning (ML) tools, for example, SVM or support vector machine). Fool-proof visualization by generating a "traffic signal" visual [green oval (NO virus detected); red oval (virus detected); yellow oval (inconclusive/ambiguous)]. Data gathered by the smartphone app (if enabled by user) to be transmitted to national centers of epidemiology (eg CDC in USA, ECDC in EU) and local hospitals (the choice will be user-dependent). Allowing collection of anonymized data may be one alternative (without recording IPv6/IPv4 addresses) but pros/cons to be considered for the greater good, public safety and privacy ${ }^{12}$.

This app is a "frontline" detection tool which may be used everyday or each week, At Home or Anywhere (AHA), by individual users. The "C2DD" vial has no therapeutic value. Positive results (red oval - virus detected) may have to be re-confirmed using lab tests (PCR, mAbs) in a clinic or hospital. C2DD PRODUCT and associated SERVICE "QTD" app if combined, are data-informed tools. It does not offer or guarantee further testing or treatment. Distribution and pricing of the hypothetical C2DD product and proposed pay-per-use (PAPPU ${ }^{13}$ ) service for QTD will be debated by corporations. Free distribution of C2DD and a micro-payment model (pay-per-use) for the "QTD" app is advocated.

Users may hide or selectively control data/information sharing as well as access to surveillance data (data from daily screening for infection by the infectious agent in question). Secure sharing of surveillance data by users (citizen science) is recommended to generate a robust and representative status of the community or infected demographics in the region in terms of molecular epidemiology.

In general, data from molecular epidemiology is critical for resource-constrained healthcare supply chains to optimize planning (humanitarian logistics), allocate human resources (medical professionals) and organize transportation of materials to the geographic areas where assistance is needed, the most.

Citizen science ${ }^{14}$ efforts are germane for the efficacy of healthcare systems in case of widespread infections (epidemics/pandemics). The tools which makes citizen science possible and effective may be viewed as global public goods. Similar systems for animal surveillance (farms, cattle, poultry, meat) are necessary to reduce infection in domestic animals (pets) and from crippling the food supply chain.

Components of the ADD system (QTD, C2DD) including mobile data collection, information arbitrage and public health applications are not limited to SARS-CoV-2 but is a platform approach which includes digital design elements illustrated ${ }^{15}$ in Figure 1. Citizen science supported public health may immensely benefit from detection of viruses, bacteria, fungi, prions or any infections agent as long as an aptamer (oligonucleotide based on the idea ${ }^{16}$ of an "anti-sense" approach ${ }^{17}$ ) may bind a small molecule or a macromolecule (peptides or proteins) with sufficient specificity, sensitivity and selectivity to generate credible data which may be distributed in real-time to inform and initiate subsequent steps. 


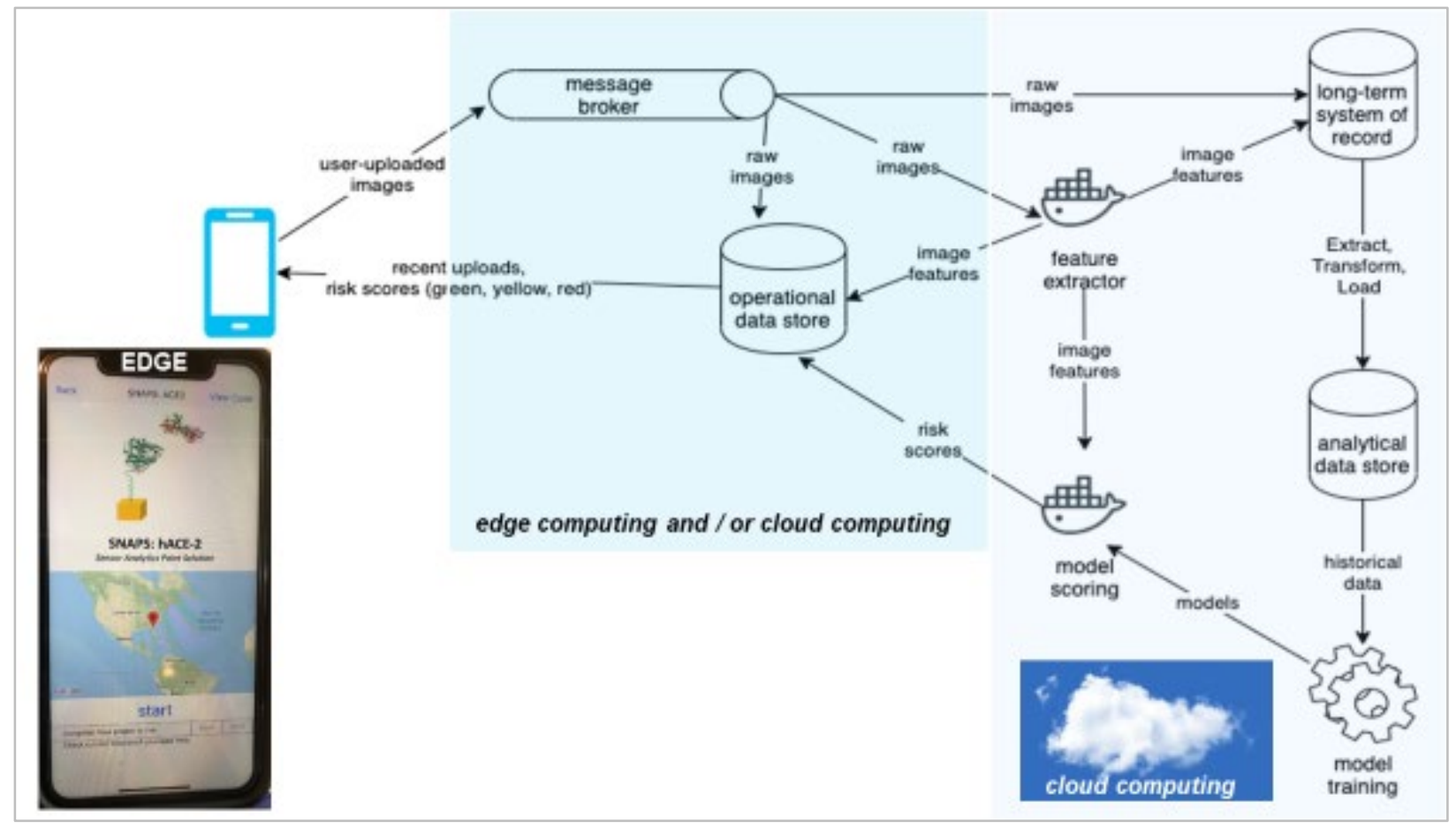

Figure 1: ADD system also includes data acquisition, analytics and data distribution which includes elements of the concept referred to as internet of things (IoT) which is a "digital ${ }^{18}$ by design" metaphor. Cartoon shows the potential path of raw data from the hypothetical binding between a sensor and a target ${ }^{19}$ molecule. Raw data from signal transduction due to binding activity is transmitted and acquired at the "edge" by the smartphone. The raw data is "processed" using tools either at the edge (embedded operations in the smartphone) or data may be uploaded to the cloud. Post-cloud computing analytics is returned to the edge device for display within an ADD application portal on the smartphone. The choice between edge versus cloud computing is a function of infrastructure (availability of wireless bandwidth, at the edge). The user may observe a difference in the time that it takes to process the data and display information (delayed visualization due to latency, function of bandwidth and speed).

Data scoring and processing is recommended due to variability of systems. ADD proposes the use of aptamers but other alternative arrays (see section 6) which may use the general approach (above) may "weigh" the information based on probability of false positive / false negative outcomes from tests ${ }^{20}$ (separate from false positives / false negatives in machine learning ${ }^{21}$ models). Assigning weighted risk to data and running other analytics can be performed on the mobile device (smartphone) or in the cloud, depending on access to and quality of telecommunications infrastructure. Cloud computing could add latency ${ }^{22}$ between upload and display of information or prediction, depending on availability, reliability and connectivity to the internet. Several regions of the world still lack sufficient access to the internet ${ }^{23}$. 
Scoring, processing and assigning risk within the analytical engine may benefit from machine learning (ML) tools to create a set of models or rules, to be described by and agreed on by experts. The system may scan and screen the image or data from the holo lens app (optical signal) to compare with these models or rules. Assigning an "image risk score" (IRS) may influence the presentation of the raw data where the "traffic signal" "red" may be provided with a sub-text containing a confidence score or include a qualitative comment (likely presence of virus) associated with a Likert-type ${ }^{24}$ indicator/scale.

In any procedure, enabling the IRS to influence the raw data must be stringently controlled. Models or rules must be agreed by global experts whose credibility may be above question. Hence, these models and rules must stay outside the realm of testing services or labs or groups that are involved with creating systems, for example, ADD. It is preferable if model scoring (assigning risk score to an upload) runs on a platform which is not influenced by the local operator or the mobile user. The smartphone uploading the data may use a "tool" that applies the IRS engine residing in a secure infrastructure in a public cloud (FDA, NIH, NSF, CDC, ECDC) using appreciable level of cybersecurity (eg. Microsoft Azure, Amazon AWS). The smartphone must have the permission and physical availability to wireless internet or mobile data network to remotely access analytical tools in the cloud, such as, the IRS engine.

One alternative is to install (and update) the data scoring models/rules (IRS engine) in the ODS (operational data store, see Figure 1). The 'message broker' receives uploads and sends them to the ODS, which serves "hot" data to the app. ODS database is tuned for rapid reads, and serves requests made by the mobile app (only recent uploads and metadata about those uploads, including "risk scores").

Risk scores are generated from models which are trained from historical data relevant to the test in question (using aptamer or antibody or other molecules, for example, hACE2). There must be access to sufficient statistical data from each type of test to create a credible risk score. If the model is based on bad data (garbage in), the risk score and IRS engine will spew bad information (garbage out). The model's responsibility to assign "risk score" impacts the "traffic signal" and could alter the outcome. Model training ${ }^{25}$ requires vast quantities of historical data, curated and pooled across multiple users who used the test and verified their outcome. If the binding was positive it must be corroborated by $\mathrm{PCR}^{26}$ or another test with even higher specificity to confirm the result from the binding test using ADD tool.

Model-building is an iterative exercise that requires lab data from testing to be evaluated by credible scientists before data scientists can use it (curate?) to train ML models, which are error prone ${ }^{27}$. In model scoring, a model (in the IRS engine) is called to act on the uploaded (input) data. This analysis generates a prediction, displayed on the smartphone as information or recommendation for the user. The outcome the user views depends on the design choices made in ML model ${ }^{28}$ training. It is absolutely central that model scoring requires "features" (characteristics germane to model/analysis). Creating features ${ }^{29}$ is the task of a team of specialists (scientists collaborating with data experts). Harvesting 
feature vectors and data relevant to the feature is the task of feature extractors. It may be provided by humans or we may use automated ${ }^{30}$ feature ${ }^{31}$ selection/extraction ${ }^{32}$ to generate features from raw data.

\section{Beyond ADD}

Scientific and engineering challenges to design ADD must embrace trans-disciplinary activities. But, no new physics is necessary. ADD may be available to billions, as a low-cost mobile AHA (at-home) product linked to IoT-type service app. The user experience is related to the service, not the product. The convergence of hardware and software with science and engineering as well as analytics and machine learning to meaningfully ascend the DIKW pyramid (data, information, knowledge, wisdom) is key to creating any detection platform where other tools and devices may upload data using open data APIs and standards-compliant data interoperability $\left(\mathrm{DDS}^{33}\right)$ tools to aggregate or explore cumulative analytics, integrated with other systems, for example, geographic information systems ${ }^{34}$ or GIS.

In the broader spectrum, ADD is an embryonic element of a potential global health surveillance platform (GSP) which may be pivotal as an early warning signal for humans and animal farms. Lessons from tsunami detection are sorely missing from public health policy discussions. Implementation of GSPs are neither a part of any local public health strategy nor on the agenda of precision population health management organizations (CDC, ECDC, WHO).

An important element of the global health surveillance platform (GSP) may include data from non-invasive profiling, referred to as "pay-per-pee" healthcare, which may be instrumental in molecular profiling for longitudinal studies on health and wellness ${ }^{35}$. GSPs may try not to dwell on genomics ${ }^{36}$ (DNA) and expression ${ }^{37}\left(\mathrm{RNA}^{38}\right)$ in imprecision ${ }^{39}$ medicine but include proteomics because gene expression is insufficient unless the functions are implemented by proteins. Aptamers ${ }^{40}$ in proteomic profiling (GWAS ${ }^{41}$, metabolomics) and other applications ${ }^{42}$ including ADD may benefit from synergistic integration to help predict status of health (collected papers ${ }^{43}$ provide select applications of aptamer).

Genomics is a "snapshot" (static structure of the infrastructure) and transcriptomics (RNA, GTEx) is an indicator of expression, which is data, but data may not (always) contain information. Proteins bind ${ }^{44}$ in a myriad of ways ${ }^{45}$ and translates data to usable information to maintain standard dynamic operating procedures (physiology, homeostasis, metabolomics).

Proteomics is a "time series" but its analysis over time may be interrupted due to feasibility and logistics of implementing programs like pay-per-pee healthcare, not to mention the complexity involved in extracting sense, often cryptic, from thousands of protein profiles, over time. Static protein profiles using NMR and mass $\operatorname{spec}^{46}$ tools only capture snapshots. Can proteomics make sense ${ }^{47}$ of a cytokine storm as markers of counter-anti-inflammatory response ${ }^{48}$ even before the infectious agent is detected? Perhaps it is utopian to expect proteomic profiling as a daily practice in healthcare and home-health. 


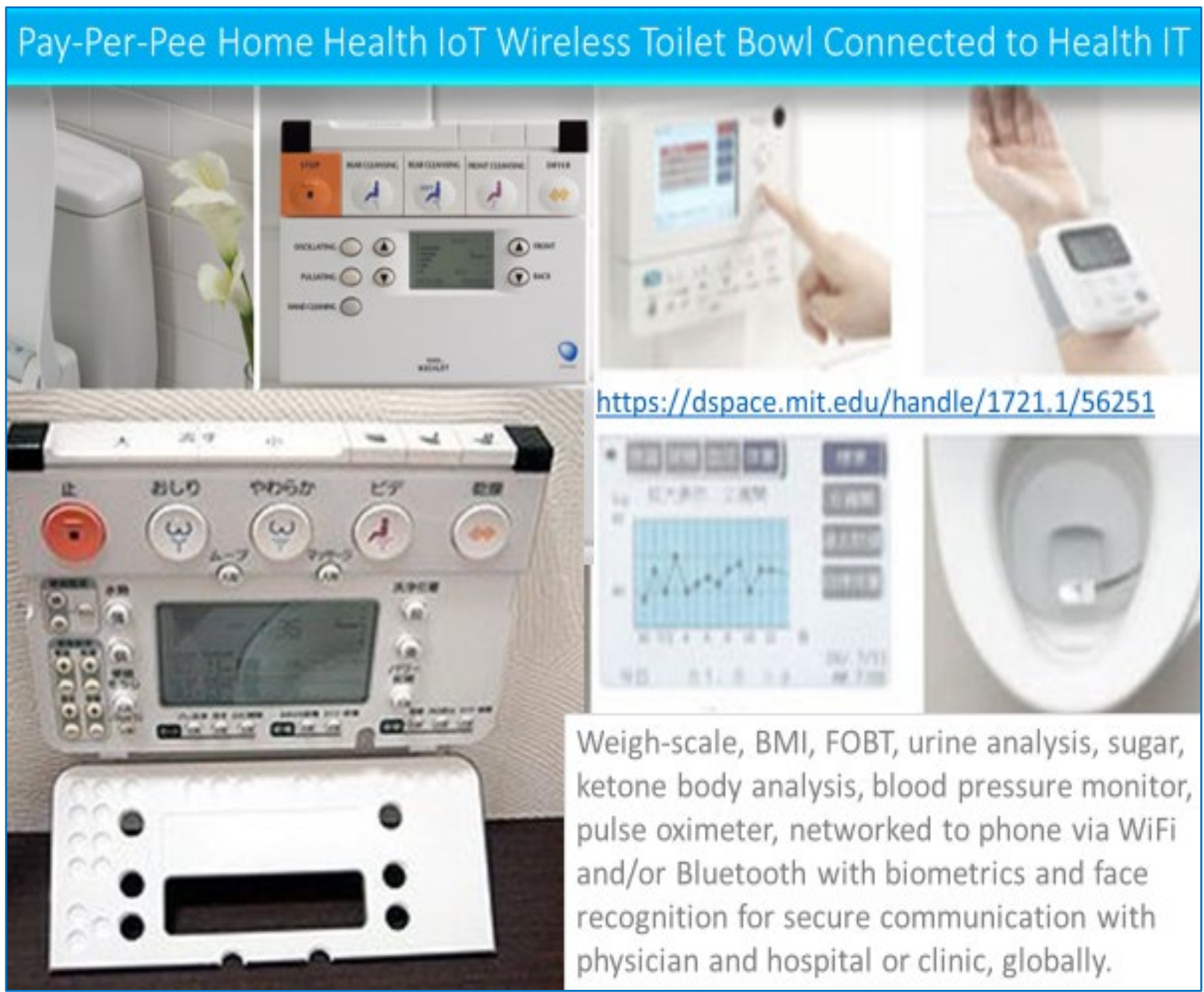

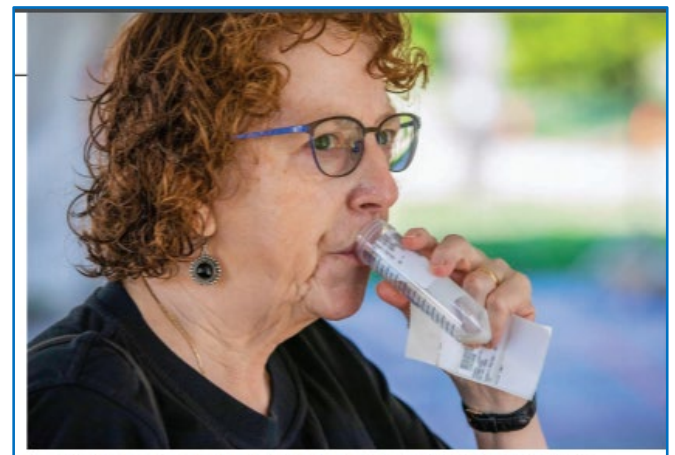

\section{COVID-19}

\section{Spit shines for easier} coronavirus testing

Tests using saliva are cheaper and faster than those with nasal swabs-and can be just as accurate
Figure 2: (Top) Pay-per-pee healthcare may provide time series data for precision medicine. (Left) "Collection of saliva samples by patients themselves negates the need for direct interaction between health care workers and patients. This interaction is a source of major testing bottlenecks and presents a risk of nosocomial infection. Collection of saliva samples by patients themselves also alleviates demands for supplies of swabs and personal protective equipment. Given the growing need for testing, our findings ${ }^{49}$ provide support for the potential of saliva specimens in the diagnosis of SARS-CoV-2 infection." 


\section{Prevention follows Detection and Diagnostics}

If viewed ${ }^{50}$ as non-classical antibodies ${ }^{51}$ then the role of aptamers vastly exceeds that of detection. It spills over into prevention, perhaps as an alt-vaccine, albeit non-immunogenic. Identifying aptamers that can detect viral proteins in saliva implies that the aptamers may also bind the same protein (albeit with altered kinetics ${ }^{52}$ ) if administered topically (nasal spray, throat spray, soft-mist inhaler). Protecting the naso-pharyngeal area by saturating it with aptamers which binds (irreversibly?) to proteins from respiratory viruses (SARS) may be a preventative measure. Asymptomatic ${ }^{53}$, pausisymptomatic and COVID-19 patients clearly expressing symptoms associated with SARS-CoV-2 may continue application of the aptamer cocktail to reduce the spread of infection by disabling (?) nascent virions. Aptamers preventing the spike protein (S1 RBD) of SARS virion from attaching to the ACE-2 $2^{54}$ viral receptor protein of uninfected cells may slow down the infection and development of COVID-19.

It follows that aptamers can also bind to any or all viral proteins not only in the extracellular space but also inside the cell. Delivering a portfolio of functional aptamers inside the cytosol must face the challenges posed by bio-availability and toxicity due to the potential for perturbing functions of essential ${ }^{55}$ cellular proteins. Creating aptamers as alt-vaccines for any infecting organism (virus, bacteria, fungi, prion) which uses a protein in its lifecycle may be an ( 30 year) old idea. Will the use of aptamers gain greater prominence in global public health practices, as a low-cost global public goods tool to contain the current and future epidemics and/or pandemics, worldwide, in humans and animals?

Single stranded RNA or ssDNA aptamers are not linear "tapes" but 3-dimensional shapes as illustrated by the discovery of tRNA ${ }^{56}$ by Paul Zamecnik, Mary Louise Stephenson and colleagues at MGH, HMS. Publication of the discovery of tRNA by Zamecnik in 1958 catalyzed an array of milestones including the discovery of mRNA by Brenner ${ }^{57}$ and $\mathrm{Gros}^{58}$ as well as the lac operon model of feedback inhibition by Jacob and Monod ${ }^{59}$, all three published in 1961. The role of proteins in regulation ${ }^{60}$ emerged as central to physiology and metabolism. In transcription, translation and replication ${ }^{61}$ the binding between proteins and nucleic acids acted as a "switch" (mechanism of action). The notion ${ }^{62}$ of aptamers $^{63}$ germinated $^{64}$ in 1990 but it drew on knowledge from binding between oligonucleotides and proteins. Aptamers may be $20-60^{65}$ oligonucleotides or more. Binding specificity ${ }^{66}$ of an enriched pool may be orders of magnitude different $\left(K_{d}\right)$ between a nearest neighbor or an analog. Sequential steps ${ }^{67}$ are necessary from a starting sample (for example, $9 \times 10^{14} \mathrm{ssDNA}$ oligonucleotides) to arrive at an enriched pool of aptamers (19 ssDNA aptamers). The process has evolved ${ }^{68}$ in complexity ${ }^{69}$ and unique structures may be involved ${ }^{70}$ in conferring specificity. In many applications ${ }^{71}$ of aptamers ${ }^{72}$ the debate also involves issues pertaining to trust and doubts ${ }^{73}$ due to the constant demand for increasing accuracy and precision with respect to sensitivity, selectivity and specificity, in detection and diagnostics. 
Current and future ${ }^{74}$ application ${ }^{75}$ of aptamers include chemistry ${ }^{76}$, chemotherapy $^{77}$, food ${ }^{78}$ safety, diagnostics ${ }^{79}$, antibodies ${ }^{80}$, alt-vaccines ${ }^{81}$, imaging ${ }^{82}$ and different ${ }^{83}$ types $^{84}$ of biosensors $^{85}$. ADD as a detection tool for SARS-CoV-2 proposes aptamer-based sensors (aptasensors) to detect SARS-CoV-2 proteins. When an aptamer binds with the target, the signal (data) will be transduced and captured by a mobile device. Analytical tools will process data and display information on smartphones (Fig 1). Data dissemination will follow according to user preferences, to inform public health authorities or hospitals.

Optimism for aptamers as detection tools ${ }^{86}$ extend to SARS-CoV-2 due to the detection of SARS-CoV (etiologic agent of 2008 SARS epidemic) C-terminal of N (nucleocapsid) protein at a concentration as low as 2 picograms $/ \mathrm{mL}$ using a $\mathrm{RNA}^{87}$ aptamer in a nanoarray. Tests using saliva ${ }^{88}$ may be unsuitable for RNA $^{89}$ aptamers due to presence of ribonuclease ${ }^{90}$ (RNase). DNA aptamers previously shown to bind to the N protein of SARS-CoV $\left(\mathrm{K}_{\mathrm{d}} 4.93 \pm 0.3 \mathrm{nM}^{91}\right)$ also ${ }^{92}$ binds to the N protein of SARS$\mathrm{CoV}-2$. The N protein ${ }^{93}$ of SARS-CoV-2 shares $91 \%$ sequence homology with the N protein ${ }^{94}$ of SARS$\mathrm{CoV}$ but is less similar $(16 \%-38 \%)$ with $\mathrm{N}$ protein from the other 5 known human coronaviruses. Thus, detection ${ }^{95}$ of $\mathrm{N}$ protein in saliva using an aptamer-based ADD aptasensor is possible. Aptamer-based technologies ${ }^{96}$ directed toward SARS-CoV-2 Spike protein are gaining ${ }^{97}$ momentum ${ }^{98}$. Blocking ${ }^{99}$ the $S$ protein from attaching to hACE-2 may perturb viral entry and prevent ${ }^{100}$ the spread of infection. Aptamers created against the $\mathrm{S} 1 \mathrm{RBD}^{101}$ may block binding to hACE-2 (internally) or serve as a detection tool (external ADD aptasensor) to test saliva/sputum for SARS-CoV-2. Other ${ }^{102}$ SARS-CoV-2 targets ${ }^{103}$ including Nsp $1^{104}$ may be less accessible in saliva because they are synthesized after viral entry. But, during the burst cycle, when new virions are released, viral proteins inside the host cell may be exposed. The targets are not limited to external viral proteins (spike, nucleocapsid, envelope proteins; Figure 4).

Signal transduction and data acquisition follows detection. In addition to EIS (electrochemical impedance spectroscopy ${ }^{105}$ ) signals, optical signals are preferred because data acquisition using cameras and apps in smartphones are feasible in locations where resources may be limiting. Protein ${ }^{106}$ detection ${ }^{107}$ by conjugating aptamers with quantum dots ${ }^{108}$ is a tried ${ }^{109}$ and true ${ }^{110}$ process ${ }^{111}$ which may be the optical signal (data) for this system. Changes in optical characteristics due to binding may be captured by cameras on mobile phones or HoloLens ${ }^{112}$ app in smartphones may scan the saliva sample (think barcode or $\mathrm{QR}^{113}$ code scan). Cameras (sensors) associated with the holo-lens (Kinect ${ }^{114}$ ) can scan the "field" and collects data to create a digital geometry ${ }^{115}$ (digital model, 3D image). For ADD, HoloLens tools required for holographic functions ${ }^{116}$ may be unnecessary, for example, accelerometer (speed of movement), gyroscope (tilt, orientation) and magnetometer (compass). Optical data captured from saliva containing testing vials will be analyzed (machine learning tools; see Figure 1) followed by visualization of information on the mobile device and (secure) information arbitrage, if authorized. 


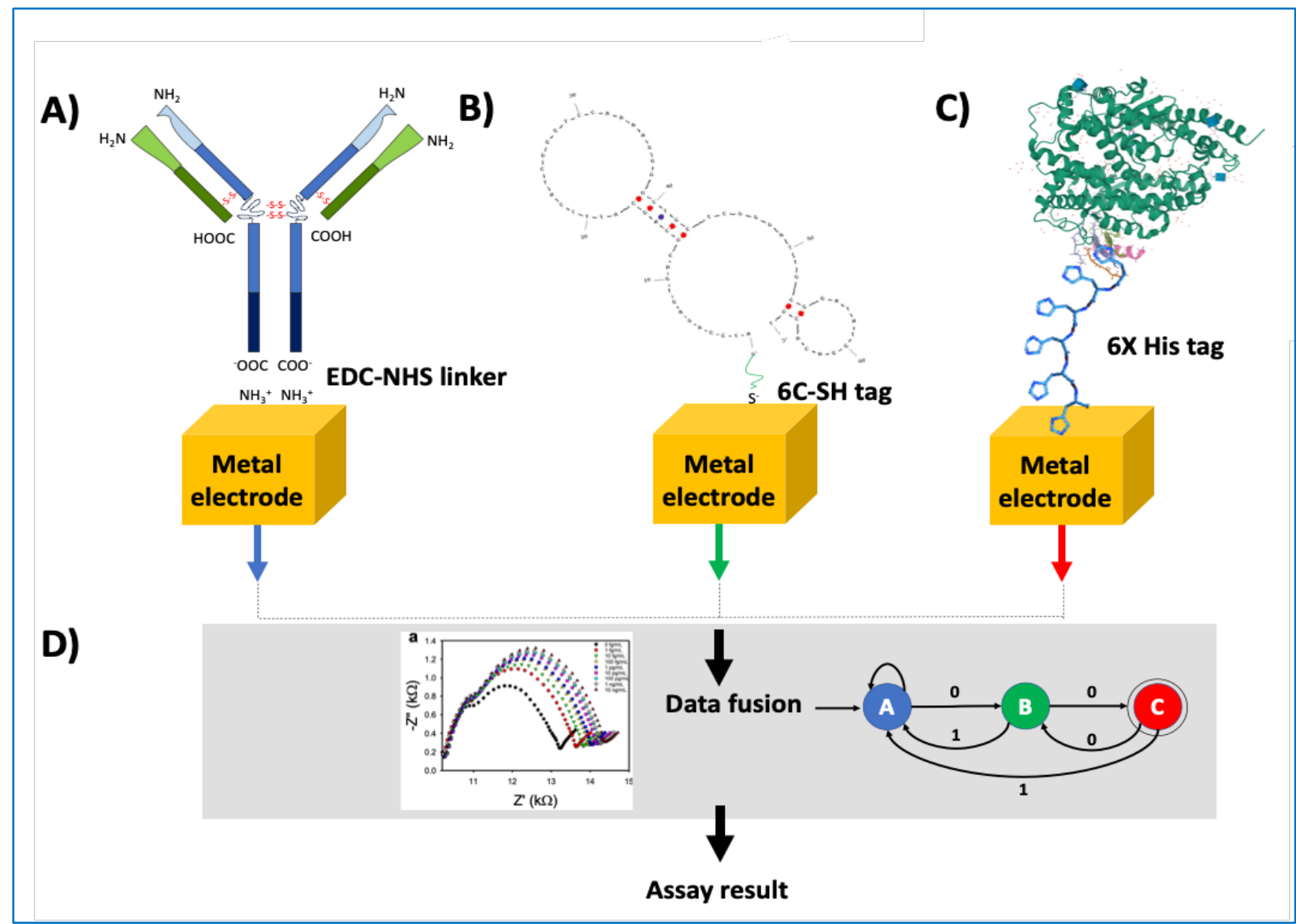

Figure 3: Multiplexed ${ }^{117}$ Detection Tool for SARS-CoV-2. Upper panel presents potential recognition and detection chemistries. The data (fusion, middle panel) will be analyzed and assay results displayed (bottom). The data and information will be displayed on a mobile device (see cartoon in Figure 1). Three distinct binding targets for SARS-CoV-2 spike protein RBD are presented in sections A, B (ADD) and C. In (A) RBD-antibody (SARS-CoV-2 strain specificity) is functionalized with EDC-NHS chemistry to metal (gold, $\mathrm{Au}$ ) nanoparticles (or may be attached/adsorped on laser inscribed graphene, LIG).

In (B) single-stranded DNA aptamers with thiol linker is adsorbed to metallized LIG (ADD aptasensor). In (C) histidine-tagged human ACE2 is adsorbed to metallized LIG. (D) Binding elicits signal (EIS, impedance spectroscopy) which is transduced to a mobile device. Data acquisition is followed by "hot" data upload to embedded tiny database (tinyDB ${ }^{118}$ ) in the device (ODS in Figure 1). Analytics may be executed on the device (embedded logic, machine learning tools) or uploaded to cloud server. The data fusion (model scoring) step may be necessary to make sense of the data, in combination, to provide not only raw data (results from A, B and C) but information, extracted from data and processed according to a simple SNAPS ${ }^{119}$ paradigm to convey the meaning of the outcome, to inform the non-expert end-user. 
Interpretation of data may be necessary due to the caveats of target binding and recognition. The specificity of the antibody used in the tool may not bind or bind with lower affinity $\left(\mathrm{K}_{\mathrm{d}}\right)$ with viral target protein (Spike protein) due to mutations in the epitope which generated the immunoglobulin (IgG). Lack of binding or lower affinity of binding can interfere with signal generation and failure to log signal over noise. Thus, individuals carrying SARS-CoV-2 may fail to test positive (false negative) if the viral variant possesses mutations preventing the antibody (A) to bind with the mutated Spike protein. Other factors (temperature, $\mathrm{pH}$, salinity) may also interfere with signal (see "model scoring” in Appendix).

In (B), binding with the aptamer is highly specific but it depends on precisely which oligonucleotide (sequence of the ssDNA from an enriched pool) binds to which part of the Spike protein. For ADD, one aptamer may bind to the RBD (receptor binding domain) of the SARS-CoV-2 Spike protein. The length of the RBD (primary sequence) used in screening and enriching for the aptamer(s) may influence the shape (structure) of the RBD during selection phase. The complementarity of the shape of the RBD and the secondary/tertiary structure of the ssDNA complex is key to the binding specificity and affinity. If the test sample contains the whole Spike protein (includes RBD) as well as fragments (peptides with different lengths of amino acid sequence) which may or may not contain the $\mathrm{RBD}$ then the binding to the aptamer may fluctuate (widely) because the primary sequence of the protein may influence the secondary and tertiary structural outcome. The latter may change the configuration of the $\mathrm{RBD}$ in a given fragment and prevent binding to the aptamer, generating a false negative. If a sample contains other proteins and peptides, it is possible that the $3 \mathrm{D}$ configuration of an arbitrary protein or protein fragment could mimic or compete, albeit partially, with the RBD, and elicit a signal by binding with the aptamer, even if the binding is ephemeral due to reduced affinity (false positive result).

Binding of the Spike protein RBD to the immobilized hACE2 protein target $(\mathrm{C})$ is probably the weakest link in this tripartite approach. Presence of mutations, dynamic or modified configuration and the effect of the environment (temperature, $\mathrm{pH}$, salinity) may perturb binding and corrupt the signal.

Error correction and data curation may be necessary to prevent data corruption (false negative, false positive, limit of detection) to improve the information and recommendation for end-users. If the confidence in the raw data from each element is high, then the data may be responsibly combined (after data scoring, image risk score) to display the information with an assigned degree of confidence which may be more than the sum of the parts (positive, negative, false positive, false negative). The strategy from data acquisition and display vs information and recommendation must reduce risk, optimize level of precision and accuracy to maximize the value of the information for the user and/or the community. Of greater concern is the accumulation of errors, which when aggregated (time series data from ADD used as a surveillance tool), may generate spurious results with respect to the status of the population. 


\section{Array of Targets}

The ADD approach for detection of infectious agents is based on targets identified from the biology and/or lifecycle of the organism and its interaction with the host (humans, animals). The RBD (receptor binding domain) of the Spike protein from SARS-CoV-2 and the human ACE2 cellular receptor (in bats, rats, pangolins and related animals in the phylogenetic tree; reviewed in reference 9) are under intense scrutiny. But, exploring the biology of SARS-CoV-2 reveals other equally potent targets. Developing drugs, antibodies and aptamers may benefit from a brief review of the viral biology. For SARS-CoV-2 detection alone, there are at least two other external proteins which may serve as targets for binding to aptamers, the M protein and the E protein in addition to S protein (Figure 4).

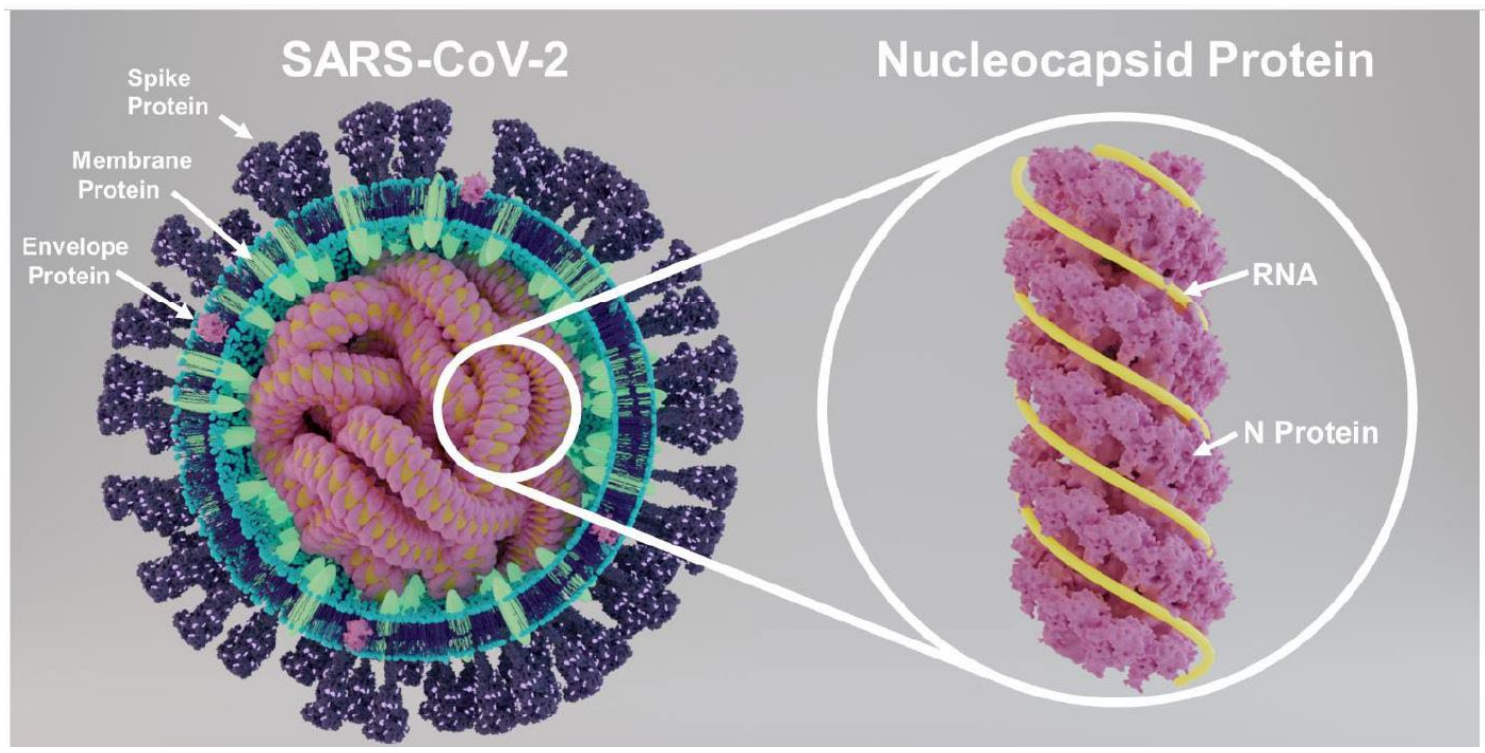

Figure 4: ssRNA genome of SARS-CoV-2 is longer compared to other RNA viruses (HIV, Influenza, Zika, Ebola; see Figure 16). It is encased in a nucleocapsid core $\left(\mathrm{N}\right.$ protein $\left.{ }^{120}\right)$ and resides inside the virus. External surface of the virus is studded with S (spike), M (membrane) and E (envelope) proteins.

The receptor binding domain (RBD) of the Spike protein appears to make the first contact with the human cellular receptor ACE2 (angiotensin converting enzyme 2). Disrupting this event is the Holy Grail for preventing the virus from entering the cell. The mechanism by which Spike protein facilitates viral entry is not merely due to the recognition (between $\mathrm{RBD}$ and $\mathrm{ACE} 2$ ) but a cascade of events that begins after successful binding. The events that follow result in fusion of the viral envelope with the cell membrane, thereby allowing the viral genetic material (+ssRNA) to be delivered inside the cell in order to create progeny viruses. Fusion is mediated by the fusion machinery and fusion peptide sub-segments of Spike S2 protein which includes a step resembling a "jack-in-the-box" toy ${ }^{121}$. These segments of the Spike protein are better conserved and occupy a distinctly different part of the Spike protein (Figure 5). 


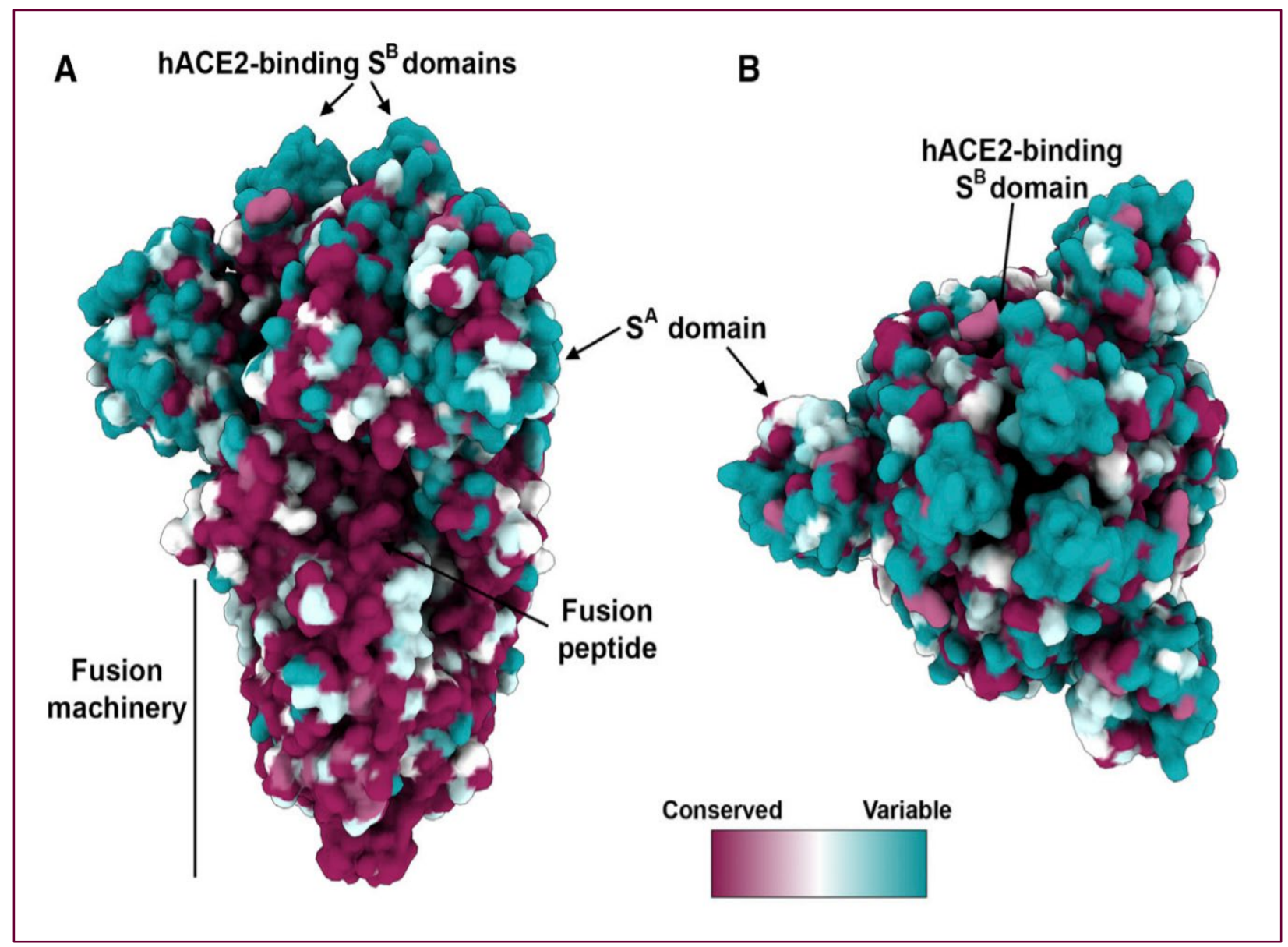

Figure 5: Sequence conservation ${ }^{122}$ of sarbecovirus S glycoproteins plotted on the SARS-CoV-2 Spike protein structure [viewed from the side (A) and top (B)]. The receptor binding domain (RBD S1) is separate from the region of the Spike S2 protein necessary to initiate viral entry. The latter is better conserved (fusion machinery, fusion peptide) and perhaps better targets for ADD aptasensors.

The better conserved segment of the Spike protein may offer valuable epitopes ${ }^{123}$ and potential binding sites for aptamers (unless glycan moieties interfere). In addition to the RBD (which appears to be more variable), the conserved portions of the S2 subunit responsible for fusion (fusion machinery, fusion peptide) are likely targets for aptamer binding. It remains to be seen if reagents (monoclonal antibodies, aptamers) aimed at the fusion specific domain of the S protein can disrupt viral entry and serve as tools for detection as well as prevention.

Interfering ${ }^{124}$ with the human cellular proteins ACE2 and TMPRSS2 (which are viral targets) to prevent viral binding may not be prudent. Reagents directed against proteases, usually non-specific, may perturb physiological functions essential for homeostasis. The events which follow after the viral Spike protein docks with the human ACE2 protein are illustrated (Fig 6 copied from Scientific American ${ }^{125}$ ). 


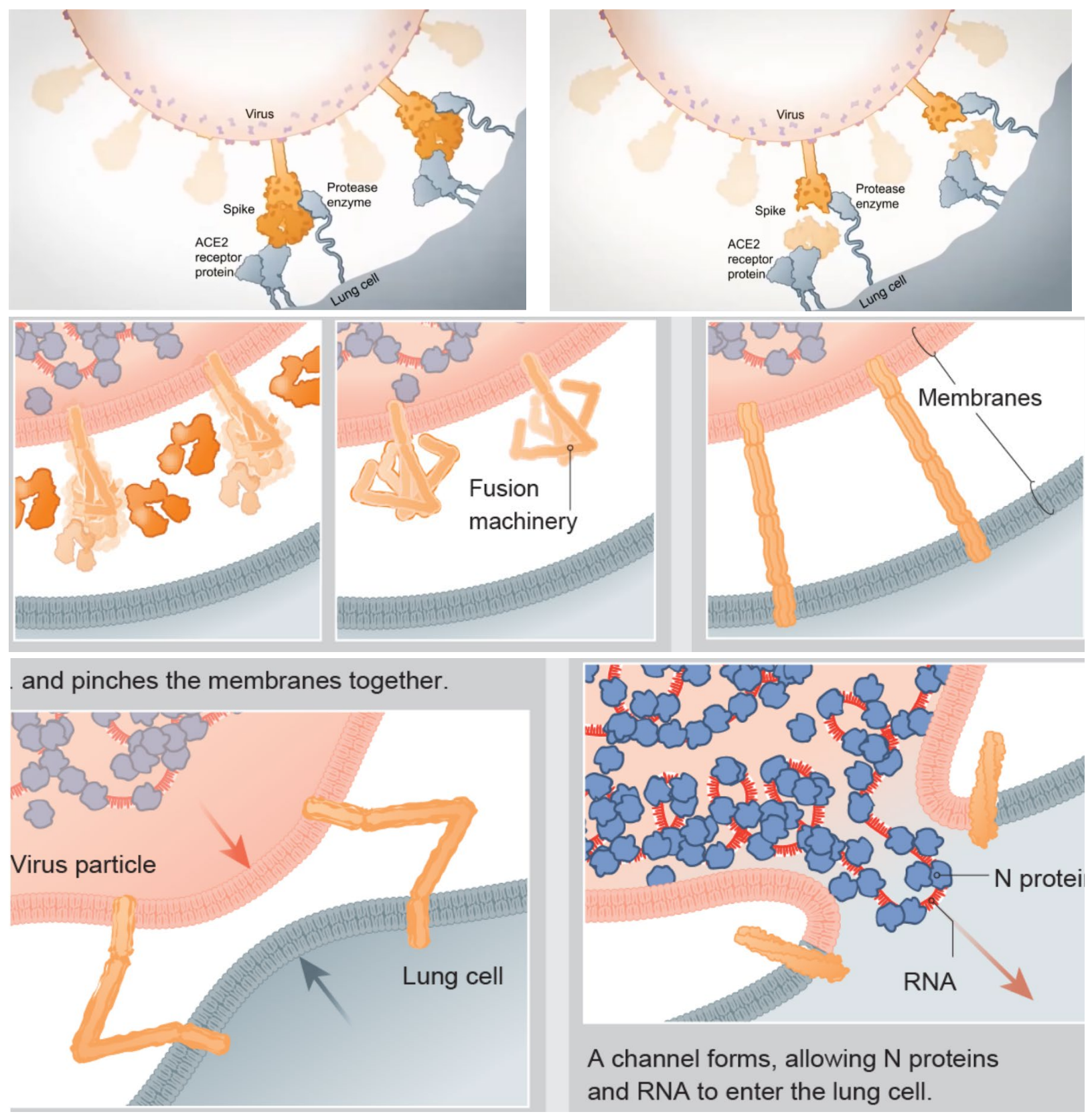

Figure 6: Cascade of events ${ }^{126}$ leading to viral entry into host lung cell identifies the "jack-in-the-box" mechanism as a pivotal tool used by the fusion machinery of the Spike protein to deliver the viral RNA inside the host cell. Selectively disabling the fusion machinery of the Spike protein is an attractive target for aptamers and other reagents. If available, the latter may not only detect and diagnose but prevent infection, even if virus particles may have already reached the human apical surface ${ }^{127}$ area. Superior region of the lungs are more vulnerable to infection due to higher number of hACE2 receptors. The number of hACE2 decreases from superior to inferior. Lower part of the lungs have less ACE2 and TMPRSS2 proteins, corroborated by the observation that these genes are expressed at a higher level in upper nasal epithelial tissue compared with bronchial and small airway epithelial brushings ${ }^{128}$. 
The +ssRNA of SARS-CoV-2 (positive strand serves as mRNA) generates at least 27 or more viral proteins by creatively manipulating the host translational machinery. Theoretically, any or all viral proteins could serve as targets for anti-viral ${ }^{129}$ strategies. Virus-encoded proteases ${ }^{130}$ are distinct ${ }^{131}$ from cellular proteases and may serve as good ${ }^{132}$ targets. The viral protease ${ }^{133} 3$-chymotrypsin-like protease ${ }^{134}$ or 3 CLpro $^{135}$ aka $\mathrm{M}^{\text {pro }}$ is encoded by Nsp5 and appears ${ }^{136}$ to cleave (see "scissors" in Figure 7) essential viral proteins from "polyproteins" generated from translation of open reading frame (ORF) $1 \mathrm{a}$ and $1 \mathrm{~b}$ (Fig 7). Papain-like protease ${ }^{137}$ PLpro (ORF 1a, Nsp3 ${ }^{138}$ ), cleaves ${ }^{139}$ proteinaceous post-translational (ref 131) modifications on host proteins to evade host anti-viral immune responses. Nsp $1^{140}$ suppresses host translation by cleaving cell $\mathrm{mRNAs}{ }^{141}$ and competes ${ }^{142}$ with mRNAs for binding to human $40 \mathrm{~S}$ ribosomal mRNA channel ${ }^{143}$ (as well as $43 \mathrm{~S}, 80 \mathrm{~S}$ subunits). Type $1^{144}$ interferon $^{145}$ (IFN-1) response ${ }^{146}$ is modulated by Nsp1, Nsp 6 and Nsp13, which interferes indirectly with IFN-1 by suppressing the phosphorylation and/or nuclear translocation of other cellular molecules ${ }^{147}$ involved in catalyzing the IFN-1 response.

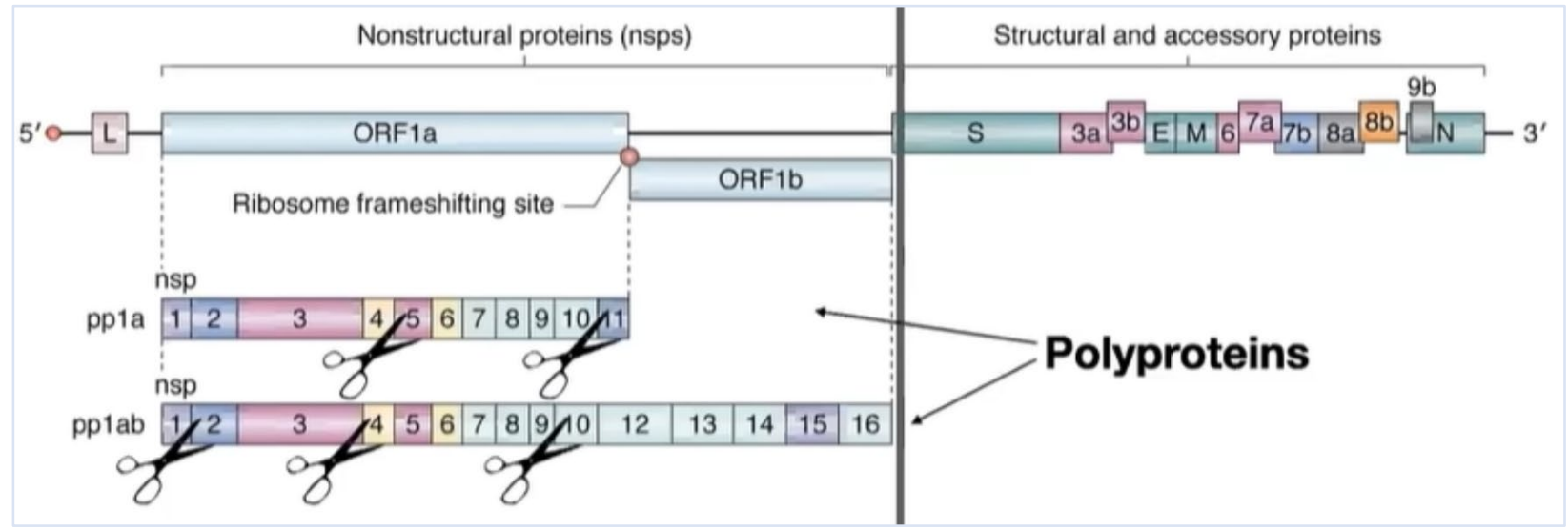

Figure 7: (Top) SARS-CoV-2 genome ${ }^{148}$ encodes nonstructural proteins (nsp), structural and accessory proteins. Nsps are encoded by ORF1a \& ORF1b generating pp1a (nsps 1-11) or pp1ab (nsps 12-16). The structural and accessory proteins are synthesized by translation of their respective sub-genomic mRNAs. (Bottom) Translational repression (Kamitani et al) and binding to 40S ribosome (Thoms et al) by Nsp1.

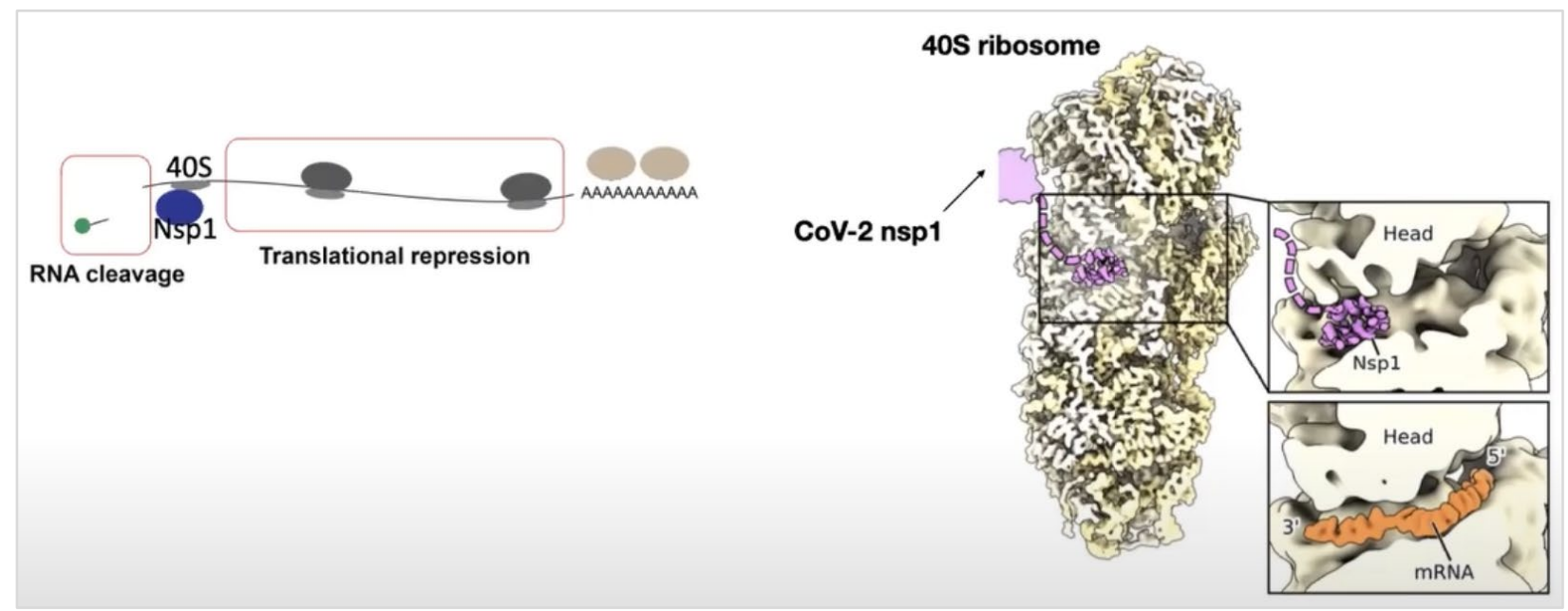




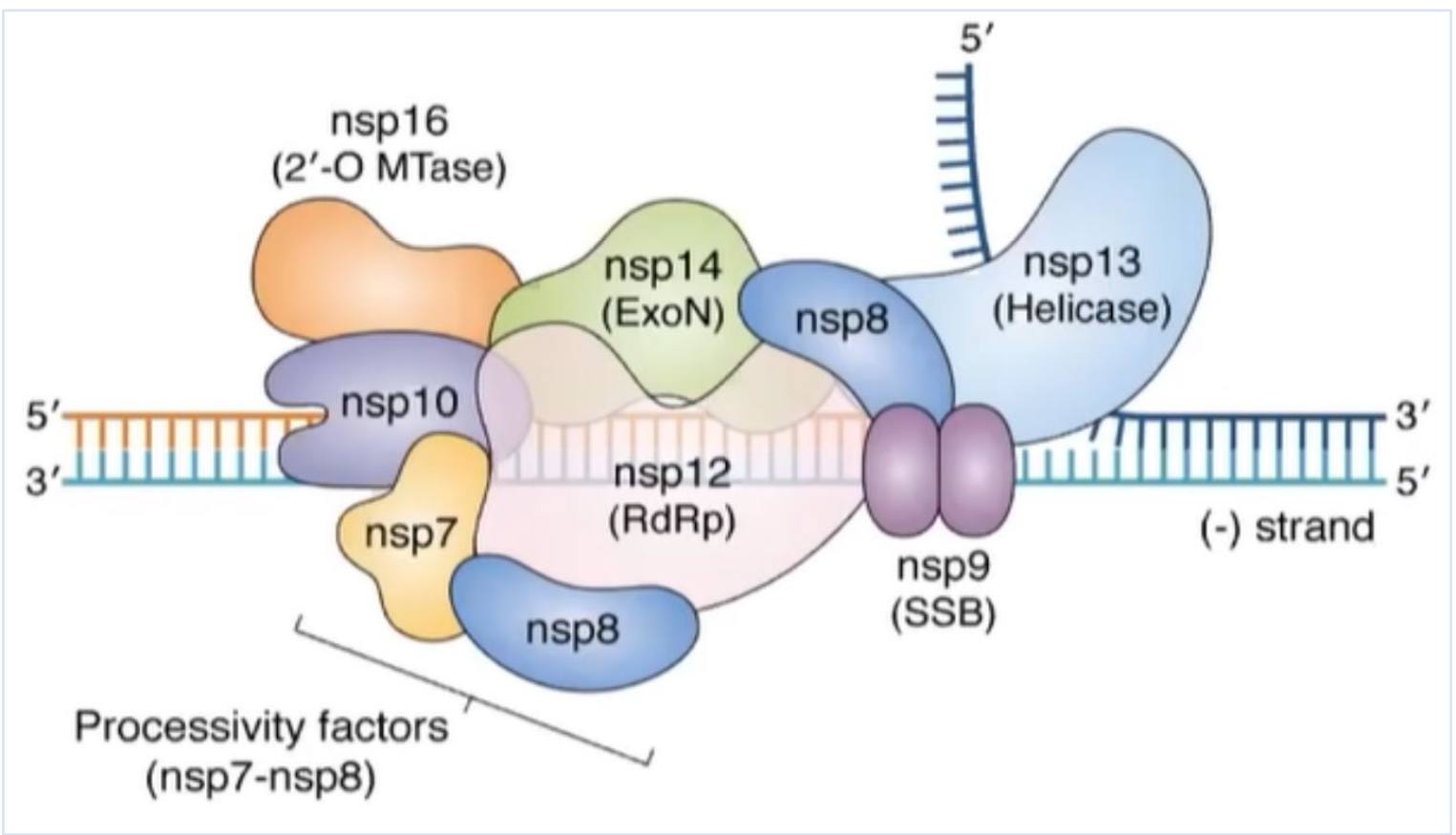

Figure 8: The positive sense (+ss) RNA genome is translated by the host translation machinery to make polyproteins that are co-translationally cleaved by proteases (PLpro/Nsp3 and 3CLpro/Nsp5) encoded in the polyprotein to generate components of RdRp or RNA dependent RNA polymerase (Hartenian and Nandakumar et al). The RdRp complex uses the genome as a template to generate negative sense subgenome and genome length RNAs, which are in turn used as templates for synthesis of positive sense full length progeny genomes and subgenomic mRNAs. Each and/or any protein factor in this complex may be a target for anti-viral reagents, for example, aptamers, antibodies, small molecules and inhibitors.

The conundrum and complexity presented by an abundance of anti-viral targets, a variety of strategies and potentially many cell types susceptible to infection, adds to the pharmaceutical dilemma where the problems of bio-availability, cross-reactivity and toxicity may force a solution to extinction. Viral proteins are distinct but structural homologies and overlapping functional issues are non-trivial.

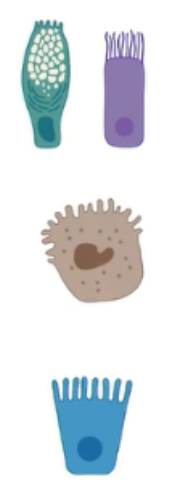

$$
\begin{aligned}
& \text { Nose: } \\
& \text { Goblet Sells } \\
& \text { Ciliated Cells }
\end{aligned}
$$

Lung:

Type II Penumocytes

Gut:

Adsorptive Enterocytes

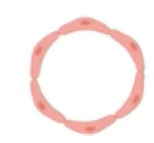

Circulation:

Endothelial Cells

Heart:

Cardiac Myocytes

CNS:

Olfactory neurons
Figure 9: Identification of ACE2 receptors on many other cells (humans). The SARS-CoV-2 virus is not only a respiratory virus or results only in pneumonia. It is causing systemic diseases presenting a vast array of symptoms and acuity. 
The medical chaos due to our lack of understanding of the biological minutiae of SARS-CoV-2 is not completely without a silver lining, albeit bleak. The ray of "hope" emanates from ExoN (Figure 8) the protein produced from Nsp14 segment of ORF1b (see Figure 7). It appears that SARS-CoV with inactivated ExoN is growth impaired and mutates at a much higher level ( $>20$-fold ${ }^{149}$ higher, see right panel in Figure 10). SARS-CoV with one of the longest genomes (see Figure 16) among common RNA viruses (HIV, Influenza, Rhino, Ebola) abhors errors ${ }^{150}$ in replication (not corrected in other common RNA viruses with low fidelity RNA replication). High fidelity replication has enabled SARS-CoV to maximize its genome size (see Figure 16) using RNA-dependent proof reading system, repair and error correction implemented by Nsp14-ExoN (there are Nsp14 homologs in other viruses). Lack of error correction in humans $\mathrm{s}^{151}$ may result in disease, dysfunction and death, even due to point mutations.
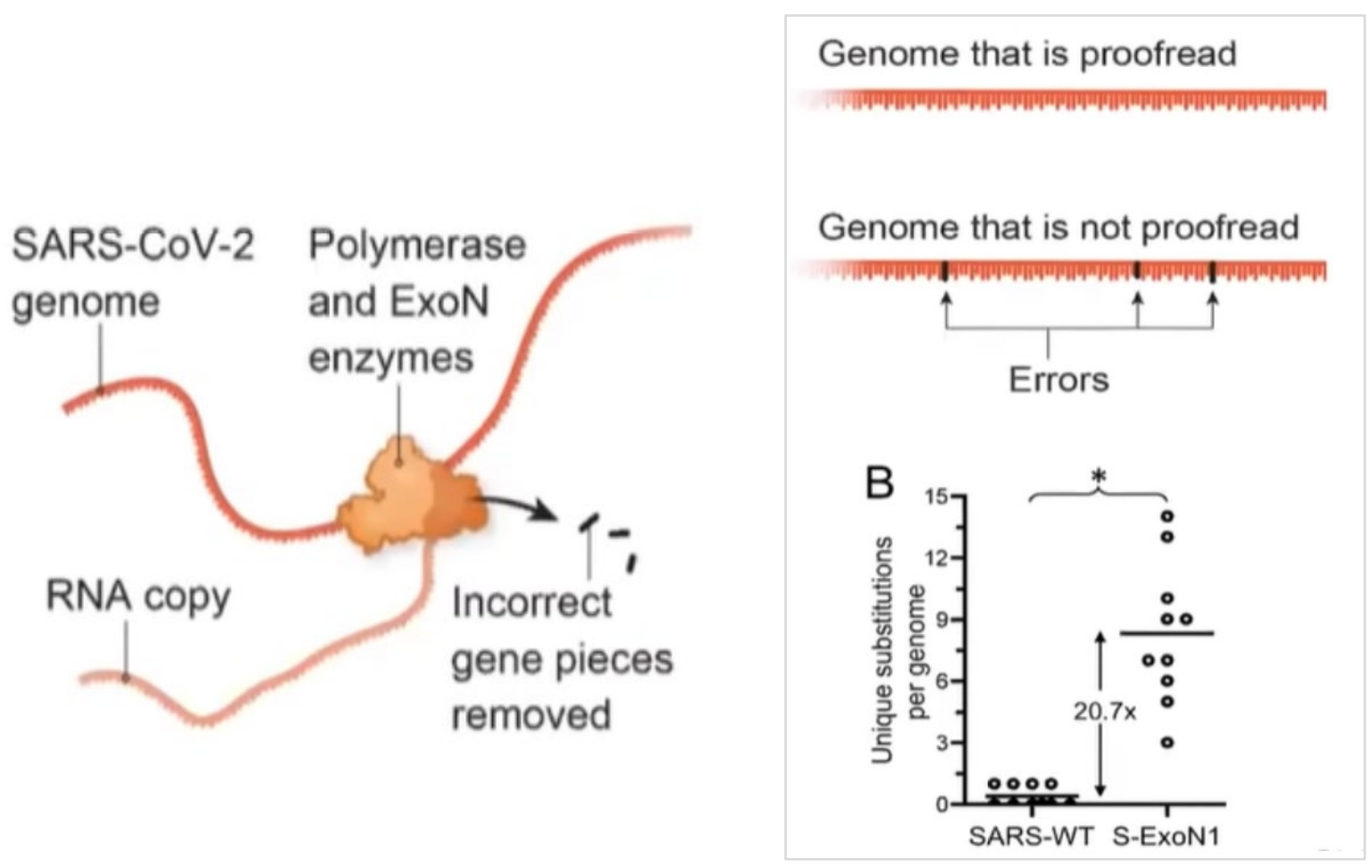

Figure 10: Mutated or inactivated Nsp14-ExoN results in $>20$-fold increase (Eckerle et al 2010) in genomic errors (B, right panel). ExoN in RdRp of SARS-CoV-2 enables error correction (left panel).

Error correction in SARS-CoV-2 may have implications for optimizing target selection for antiviral strategies. The choice of the receptor binding domain in subunit 1 (S1 RBD) of the SARS-CoV-2 Spike protein, therefore, may be incomplete as a target (Figure 3). It appears that the fusion machinery and the fusion peptide (FP) region of the Spike protein (subunit 2) is better conserved and will continue to remain better conserved due to the error correction mechanism (see Figure 10). Hence, sub-segments within subunit S2 of S protein may be better targets. The obvious caveat in this discussion is whether the chosen sub-segments in S2 may be sufficiently exposed or available to bind with the anti-viral molecules. 
A

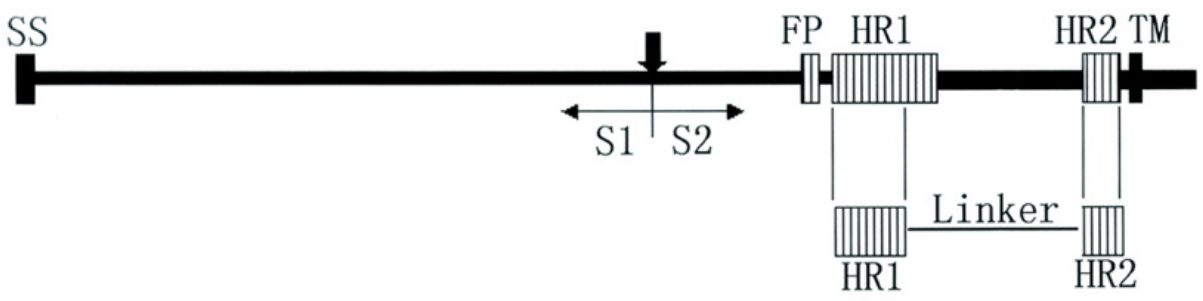

HR1 ENQKQIANQFNKAISQIQESLTTTSTALGKLQDVVNQNAQALNTLVKQLS

Linker LVPRGSGGSGGSGGLEVLFQGP

HR2 DVDLGDISGINASVVNIQEEIDRLNEVAKNLNESLIDLQEL

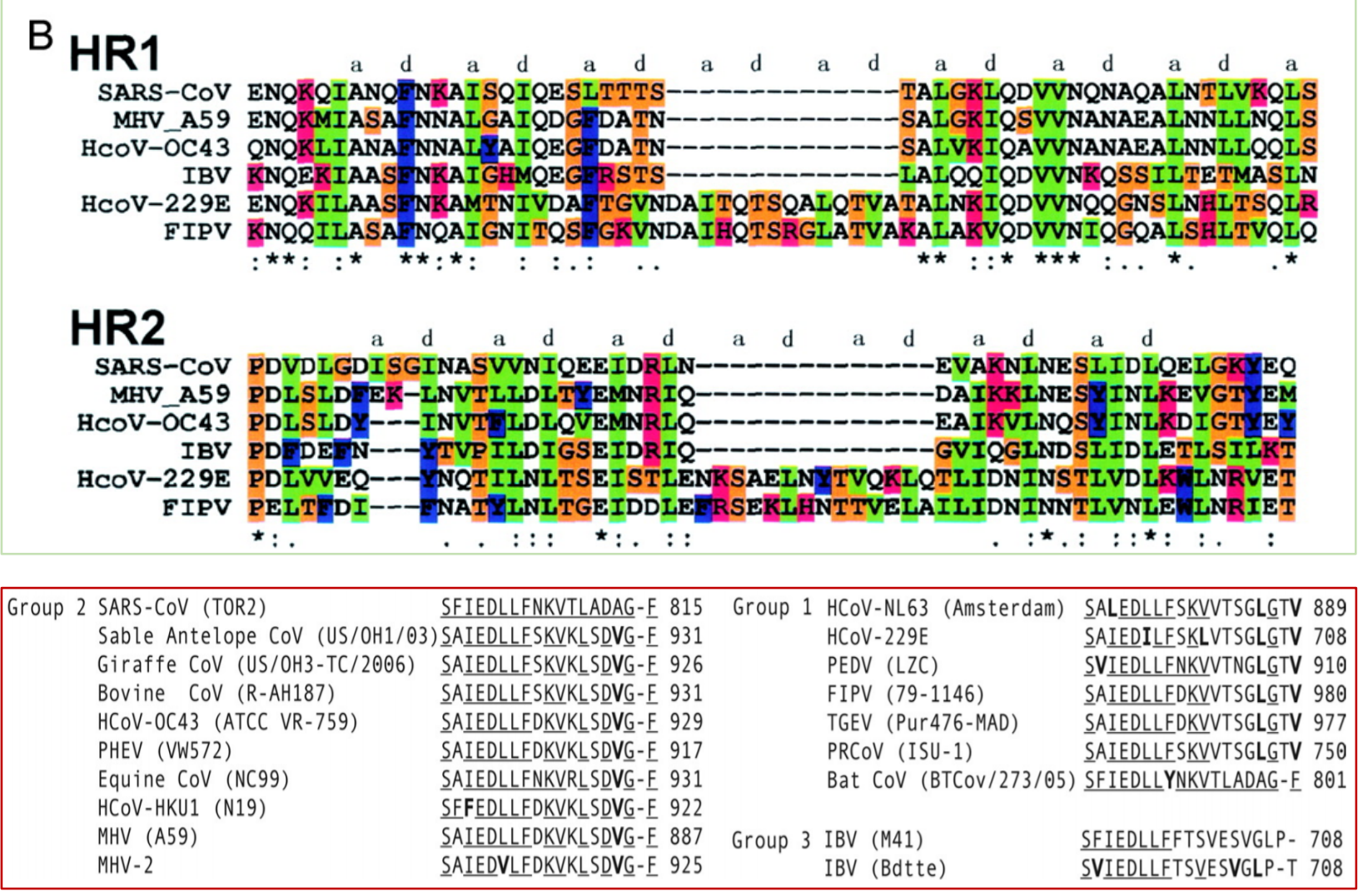

Figure 11: S protein (trimer) consists of 2 structurally noncovalently linked domains, S1, contains RBD (receptor binding domain) and S2 contains the fusion machinery and the fusion peptide ${ }^{152}$ (FP). Site of proteolytic cleavage $\rightarrow$ vertical arrow. S2 contains 2 HR (heptad repeat) ${ }^{153}$ regions HR1 $(898-1005)$ and HR2 (1145-1184) connected by 22-amino acid linker (LVPRGSGGSGGSGGLEVLFQGP). Hydrophobic residues ( $\mathrm{a}$ and d positions in heptad repeat regions) are conserved. SS (N-terminal signal sequence), TM (transmembrane domain, C terminus), FP (fusion peptide, bottom ${ }^{154}$ ), IBV (infectious bronchitis virus), FIPV (feline infectious peritonitis virus), MHV (murine hepatitis virus - murine coronavirus). 


\section{Discussion}

Could we detect SARS-CoV-2 in saliva, prevent ${ }^{155}$ membrane fusion and block viral entry ${ }^{156}$ with the same aptamer or another type of molecule based ${ }^{157}$ on the better conserved S2 of the SARS-CoV-2 Spike protein? Could we detect SARS-CoV-2 in saliva of asymptomatic individuals without COVID-19? ADD may use better targets for its aptasensors beyond RBD S1 and hACE2. ADD can be accomplished, as suggested by the evidence from creation of $\operatorname{DeMEA}^{158}$ (but it uses high cost microfluidics ${ }^{159}$ ).

Even if ADD is successfully engineered to be a low-cost biomedical device for non-invasive detection, dissemination of $\mathrm{ADD}$ and other systemic surveillance tools will still depend on communityspecific economics of technology ${ }^{160}$ to facilitate diffusion and adoption. Bringing data and information together to make sense and extract foresight (uncertain of the value of hindsight ${ }^{161}$ ) will be a challenge which new initiatives ${ }^{162}$ must address. Diffusion of the tool to vulnerable communities will be restricted unless the end-to-end system is cost-effective at a level where it is sustainable for repeated use, preferably daily, as a surveillance tool for humans, pets and farm animals.

Data when transformed into usable information may deliver value for the greater good, for the greatest number. ADD is one small surveillance tool but it isn't enough. Healthcare cannot be a kneejerk reaction to epidemics and pandemics. Continuous monitoring (even for high risk individuals) may remain a mirage in view of the disproportionate socio-economic imbalance. While we must ADD up to address the crisis ${ }^{163}$ at hand, we must also utilize this disaster as an opportunity to deploy profiling as a healthcare staple. Other tools, for example, wastewater ${ }^{164}$ analysis ${ }^{165}$ may offer transparency ${ }^{166}$ and guide public health strategies regarding elements the community must address, in advance, to prevent meltdown of health services. When an emergency presents itself we must not disintegrate into quagmire.

Precision medicine and precision public health may benefit if we probe the broader question of physiological status as expressed by proteins but further complicated by our microbiomes ${ }^{167}$. Isolated snapshots of data may be rate-limiting for communities under economic constraints. But, convergence of data from ADD along with multiple levels of profiling ${ }^{168}$ (DNA, RNA, protein, $\mathrm{RDW}^{169}$ ) as well as environmental ${ }^{170}$ and wastewater ${ }^{171}$ data $^{172}$, if included ${ }^{173}$, may augment the value of information, which could be catalytic for medicine ${ }^{174}$, in general, if aggregated and shared between open ${ }^{175}$ platforms.

Analytical skills necessary to deconstruct the data and reconstruct its meaning, relevant to the individual and/or the community, may pose a rather insurmountable barrier in terms of tools and/or human resources. The ill-informed inclination is to hastily pursue a "quick and dirty" version (perhaps shoddy, yet masquerading as good enough) without a long term view or a vision that embraces a sense of service, science for the good of society and access to global public goods for all. It goes without saying that one shoe does not fit all. It is obvious that ADD is not enough to better prepare for the future ${ }^{176}$. 


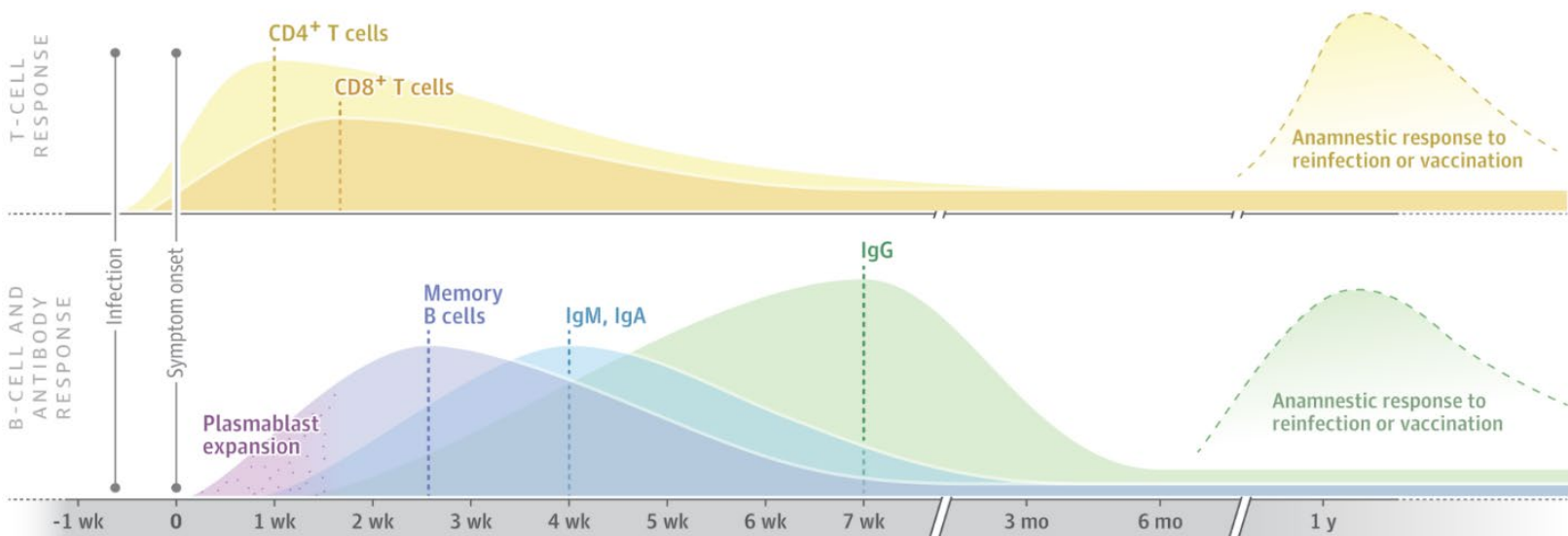

Figure 12: Serum from a significant percentage of patients (one third) recovering from COVID-19 have low viral neutralizing activity. Depending on the acuity of the infection, patients may or may not follow standard immune profile (top ${ }^{177}$ ). Low variation (Fig 10) in SARS-CoV-2 Spike protein is good news but mutations, D614G (middle panel and bottom) may still complicate ${ }^{178}$ the immune response and expected anamnestic response to reinfection or use of classical ${ }^{179}$ approaches ${ }^{180}$ to vaccination.
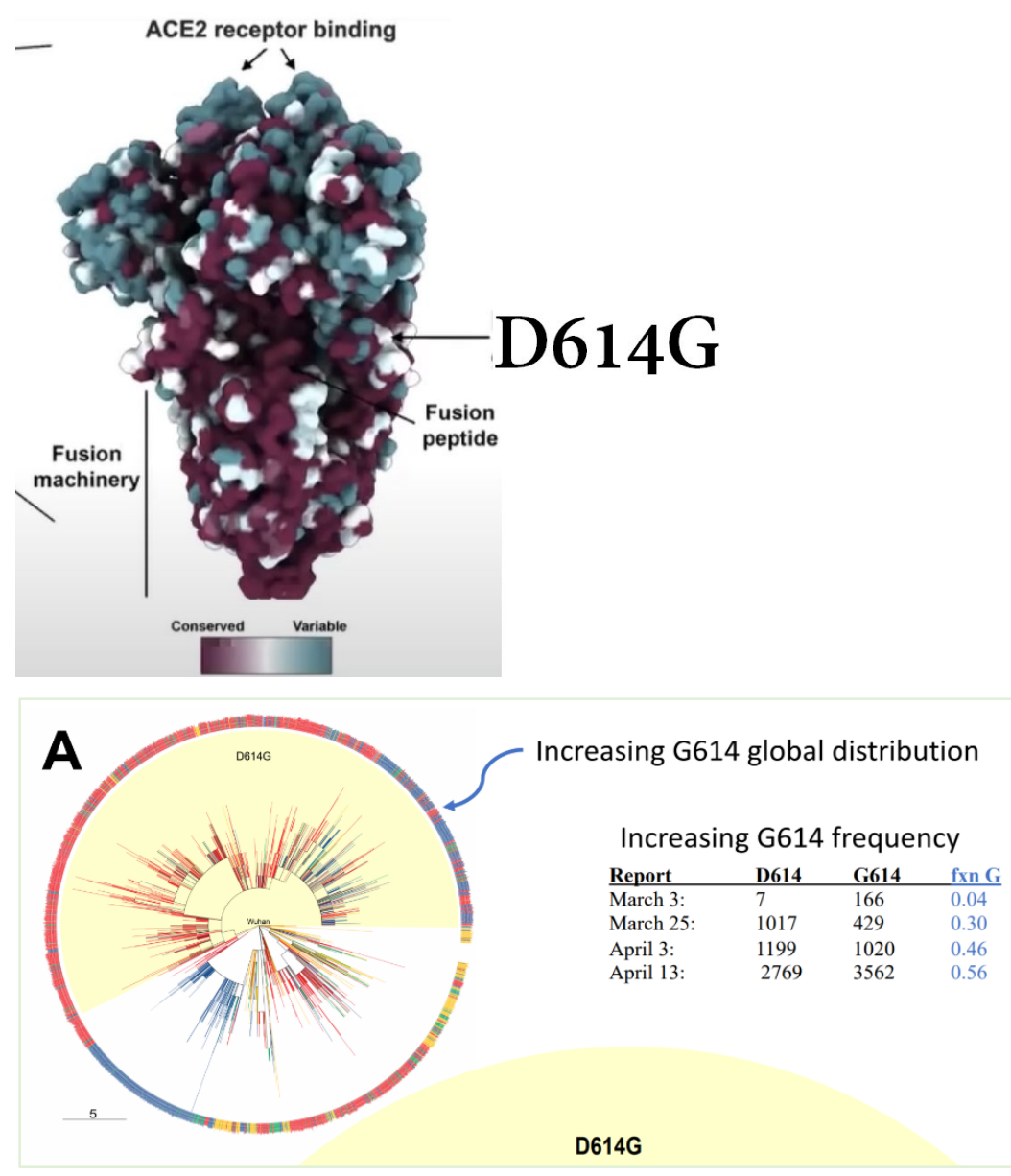

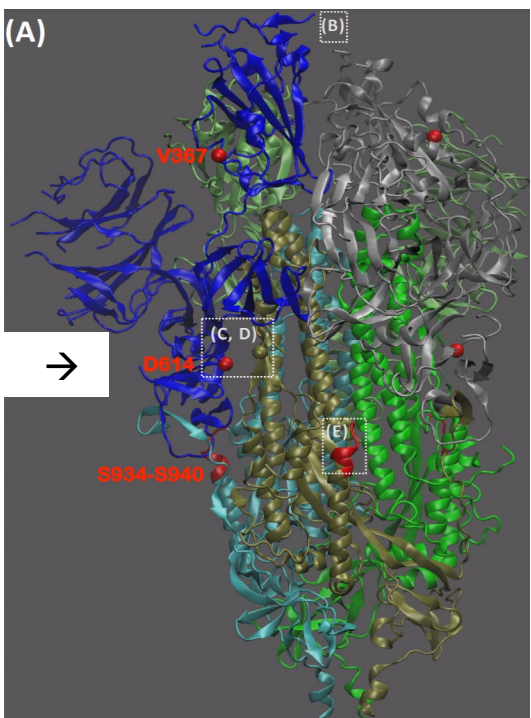

If immunity from traditional vaccines are uncertain ${ }^{181}$, can we supplement with alt-vaccines (which are non-immunogenic, for example, aptamers), to better prepare for low-cost and rapid ${ }^{182}$ response to public health during future epidemics / pandemics? 
9. Complexity of the biomedical scenario, socio-economic catastrophe and the public health crisis Since 1980's the HIV epidemic has infected $\sim 76$ million people ${ }^{183}$ ( $\sim 1 \%$ of the global population) and almost half are dead ( $\sim 33$ million AIDS related deaths, disease caused by HIV) and currently the other half is still living or struggling with the disease. Yet, the thrust for HIV vaccine pales compared to the warp speed vaccine development collaboration ${ }^{184}$ against SARS-CoV-2, which erupted in 2020 as the COVID-19 pandemic. Is it because SARS-CoV-2 is irreverent and indiscriminate in infecting humans?

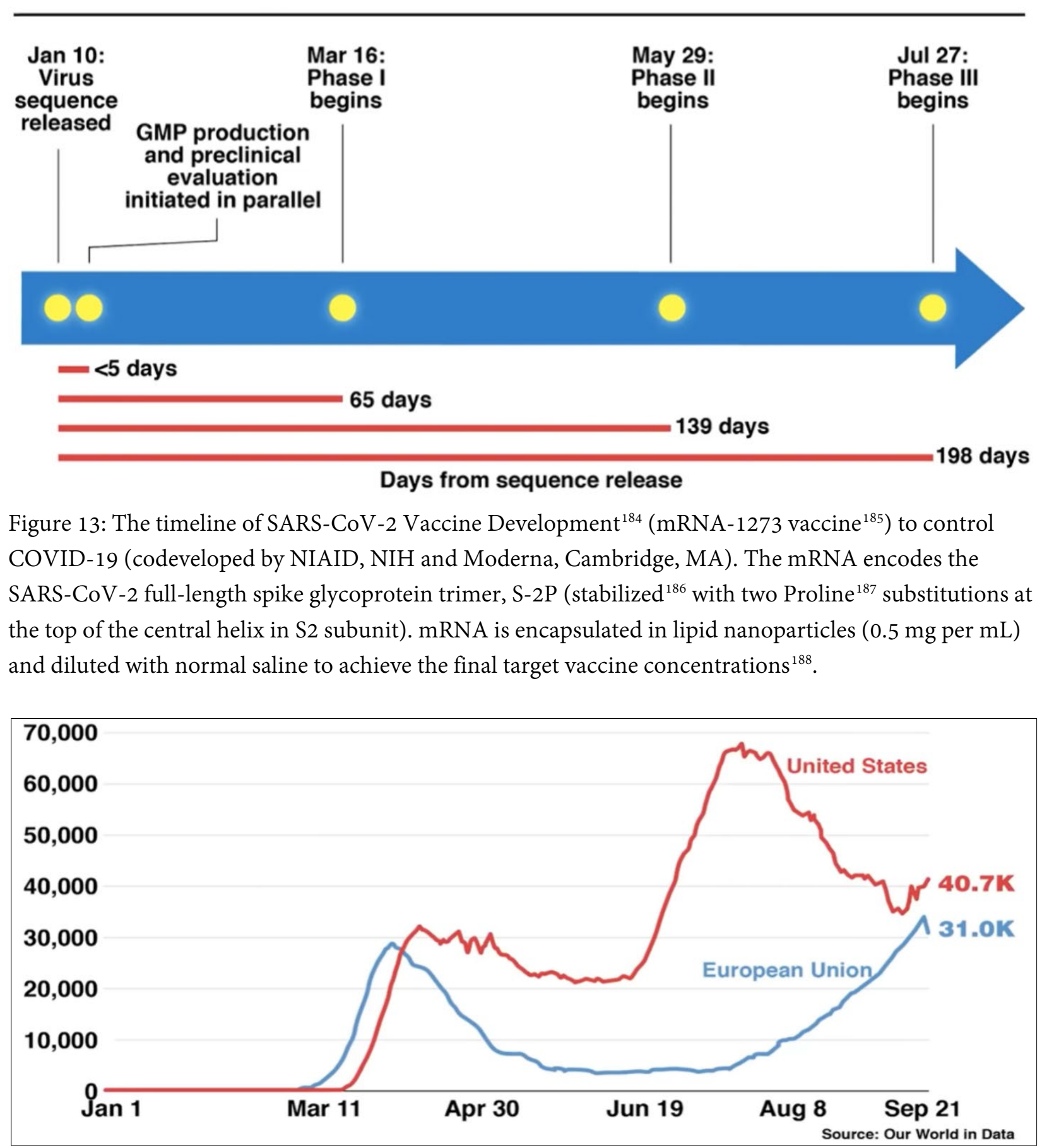

Figure 14: 7-day rolling average of new COVID-19 cases $^{189}$ from January through September 21, 2020. 
Coronaviruses have long co-existed with humans and animals. Error correction (Figure 10) has made the genome of the coronavirus one of the largest among viruses (Figure 16). What does it mean? Compared to diseases ${ }^{190}$ due to relatively unknown viruses ${ }^{191}$, and despite the flu pandemic $\sim 100$ years ago, the coronavirus, in less than six months, has changed, perhaps permanently, global thinking, trends and technology. Tobacco Mosaic Virus (TMV) was discovered around $1890-1892^{192}$ but after more than 100 years ${ }^{193}$ of virus discovery, we have just now acknowledged the threat to global health from viruses. Understanding the molecular basis of virulence is the single most important questions in basic biology which must be investigated by the best and brightest, if we ever expect to mitigate the risk from viruses.

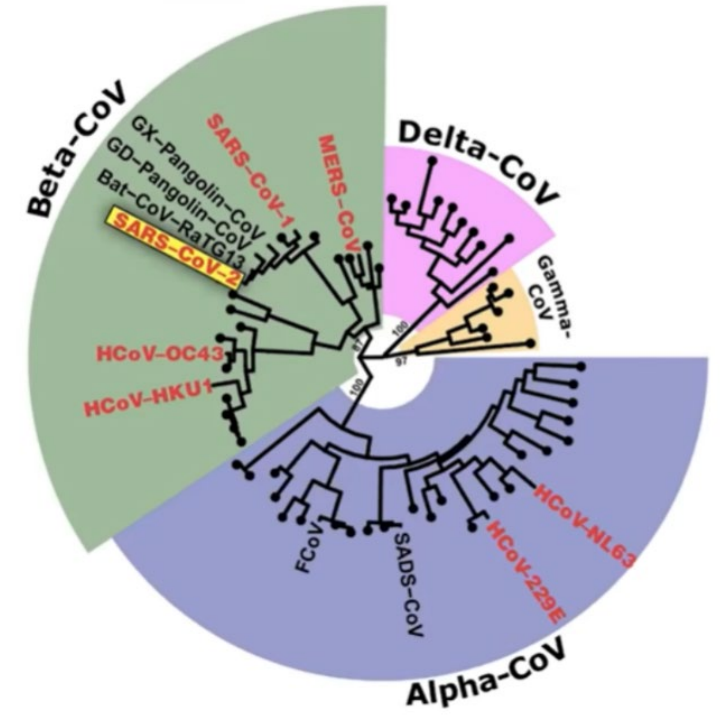

Figure 15: Coronavirus phylogenetic tree. Human coronaviruses (courtesy of S. M. Gygli, NIAID) ${ }^{194}$

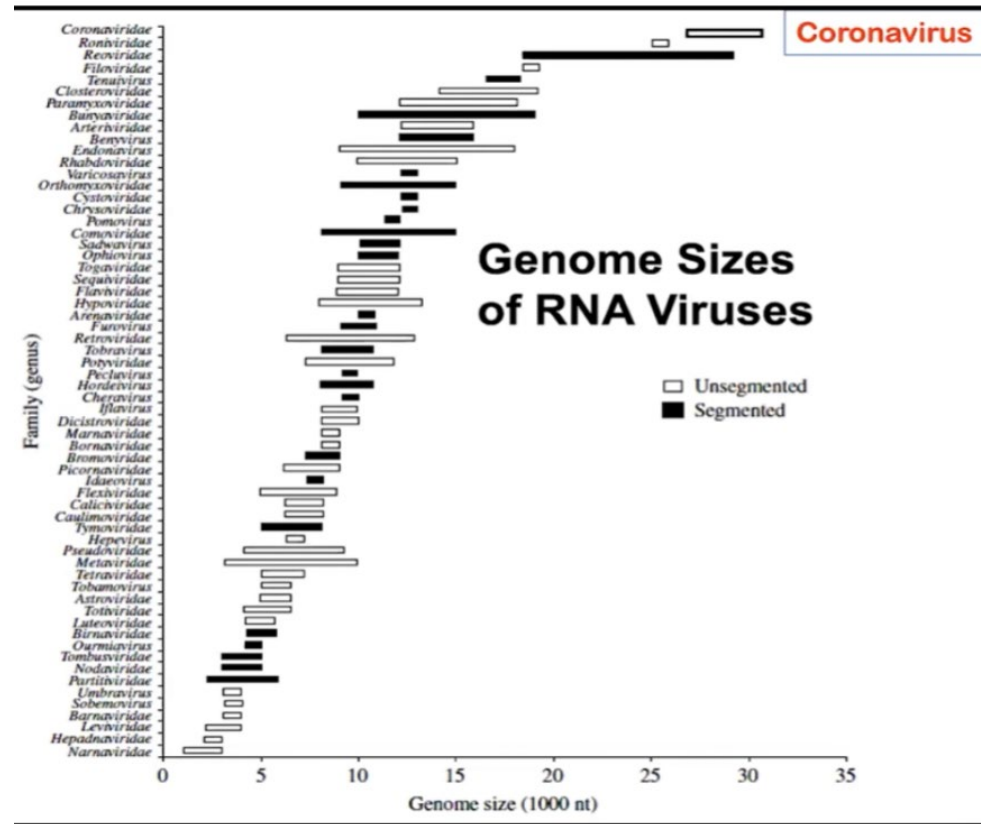

Figure 16: Coronavirus pandemic wasn't really expected ${ }^{195}$ according to at least one global expert ${ }^{196}$. The coronavirus has the largest RNA genome. Is it just a coincidence or is there any bio-medical correlation? 
While we still remain clueless about what constitutes virulence, the genome size does not offer any solace or solution. New evidence about Neuropilin-1 as a host factor ${ }^{197}$ which facilitates cell entry ${ }^{198}$ further thickens the plot. The deep quagmire ${ }^{199}$ about R0 and $k^{200}$ for COVID-19 defies epidemiological models ${ }^{201}$ but prefers apocryphal Pareto ${ }^{202}$ principles which suggests that $80 \%$ of new infections may be caused by only $20 \%$ (or less - 10\% - see Figure 17 and reference 216) of the infected individuals. Are these individuals a high risk group due to inborn errors of immunity caused by mutations of genes involved in regulation of type I and type III interferons ${ }^{203}$ (IFN)? How many more genetic factors may underlie the differentiation between super-spreaders ${ }^{204}$ vs sub-spreaders for SARS-CoV-2 ? If the latter is true then how valuable is generalizing infection dynamics ${ }^{205}$ from communities as a prediction tool for overall public health, advance planning and use as early warning ${ }^{206}$ for cautionary preparation?

In future, genomic analysis may enlighten us if there are polymorphisms ${ }^{207}$ which may partially account for this differentiation. It may be worth digressing to note that some individuals may be more susceptible to leprosy, caused by Mycobacterium leprae. Genes ${ }^{208}$ associated with leprosy include HLA (human leukocyte antigen) proteins. Analysis of eleven HLA genes in 1155 Vietnamese individuals revealed 4 leprosy-associated independent amino acid variants [HLA-DR $\beta 1$ positions 57 (D) and 13 (F), HLA-B position 63 (E) and HLA-A position $19(\mathrm{~K})$ ] which comprised 2 pairs of linked genes, with one set conferring susceptibility [HLA-DR $\beta 1$ and HLA-A] and one being protective ${ }^{209}$.

The demographics of infection by SARS-CoV-2 may be due to genetic ${ }^{210}$ determinants $^{211}$ and individual outcomes ${ }^{212}$ may be determined by our genes ${ }^{213}$ as well as epigenetic factors which may be mapped to biomarkers ${ }^{214}$. At this point it is unclear whether the etiologic agent of this 2019 coronavirus pandemic should be referred to as SARS-CoV-2 where SARS imply severe acute respiratory syndrome.

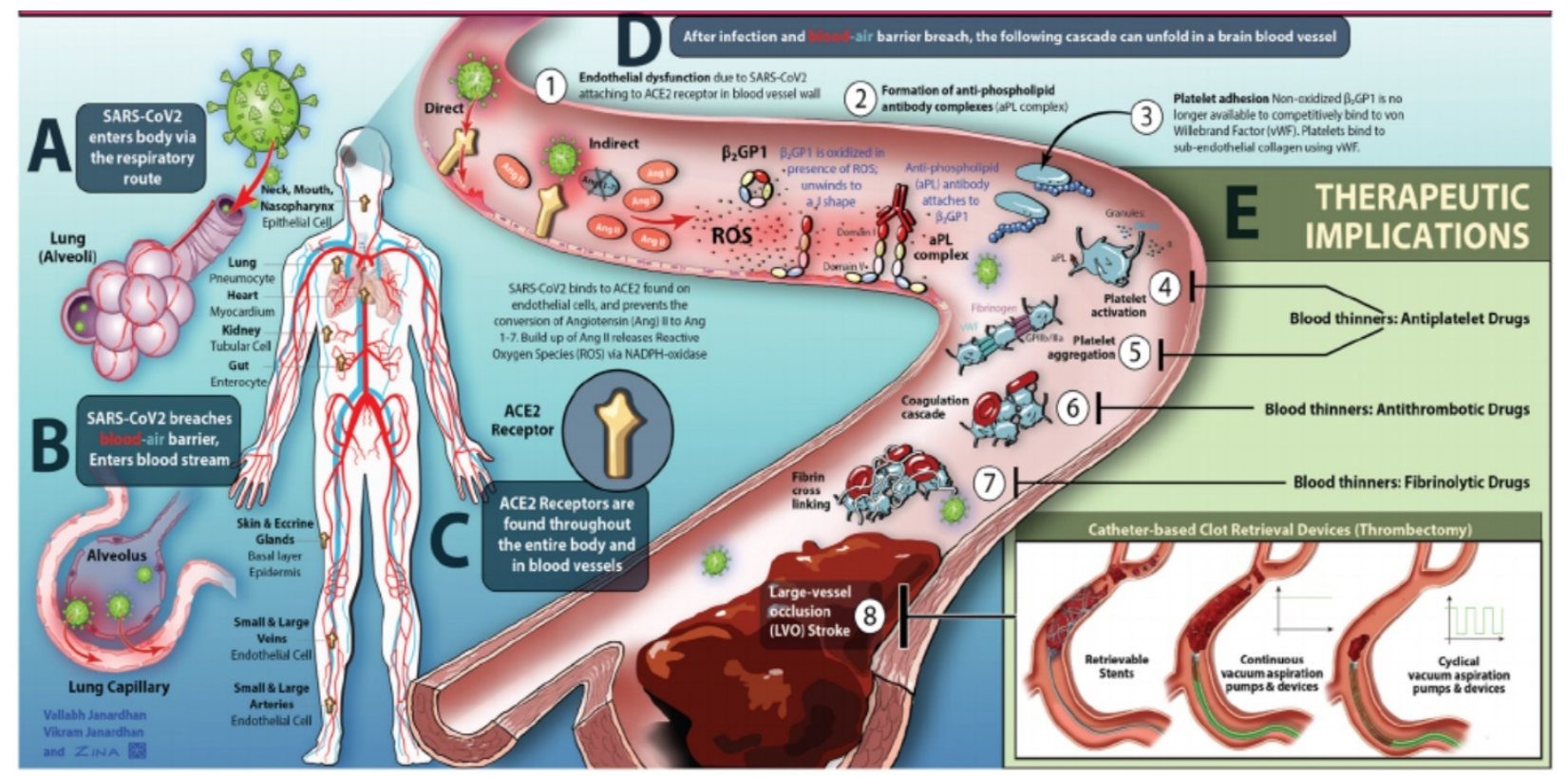

Figure 17: What is COVID-19? Respiratory illness? Blood clotting disorder ${ }^{215}$ ? Cardiovascular disease? Autoimmune disease? Opportunistic "killer" for ( 10\%) patients with severe COVID-19 pneumonia and high titers of autoantibodies ${ }^{216}$ against different types (type I IFN- $\alpha 2$ and IFN- $\omega$ ) of interferons? 


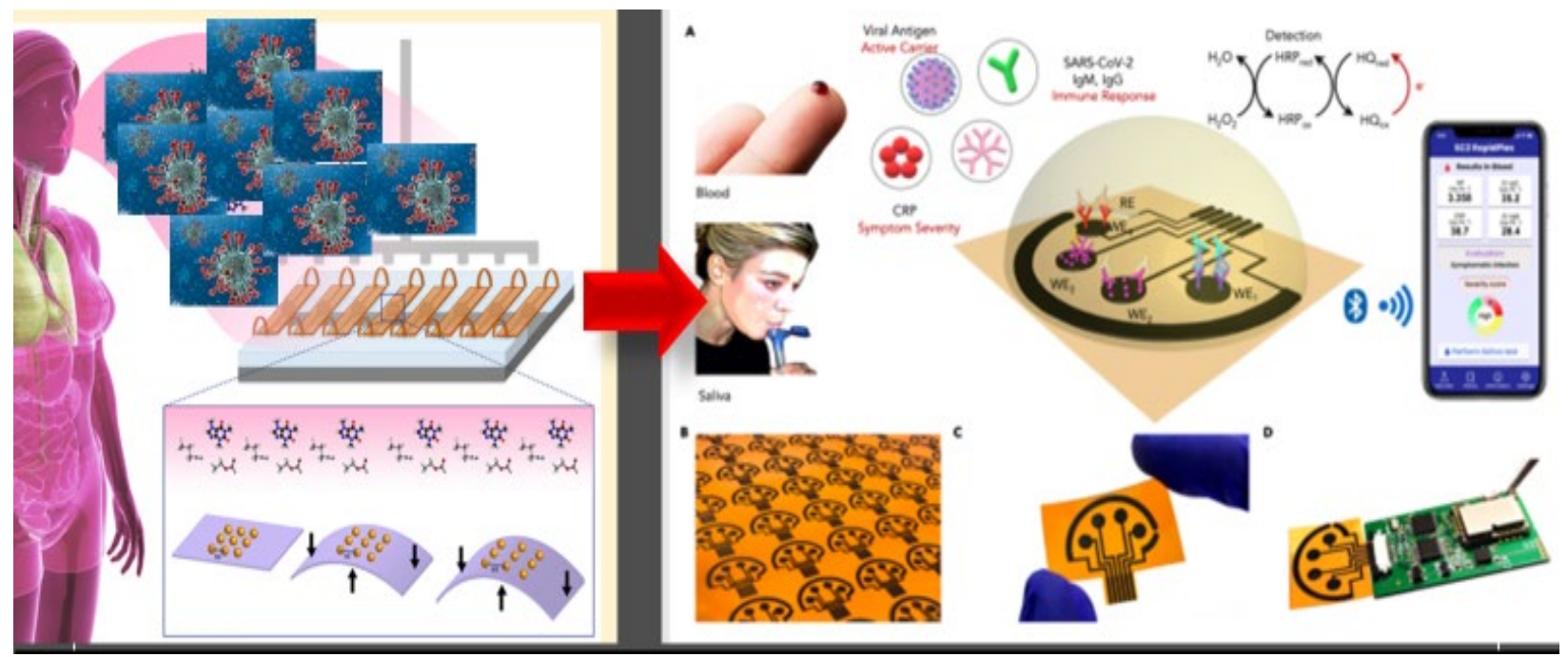

Figure 18: Hypothetical ${ }^{217} 5^{218}$ cent $^{219}$ déjà $v u$ graphene sensor (RIGHT) detects SARS-CoV-2 antigens. Can smartphone detection ${ }^{220}$ adapt $^{221}$ to other ${ }^{222}$ sensors $^{223}$ (LEFT) to detect ${ }^{224}$ SARS-CoV-2 in exhaled ${ }^{225}$ breath ${ }^{226}$ by mouth? More evidence we need to use masks? Smartphone ${ }^{227}$ "breathalyzer" for malaria ${ }^{228}$ ? Can it serve ${ }^{229}$ as a global surveillance tool (for humans and animals) to bridge the chasm of inequity?

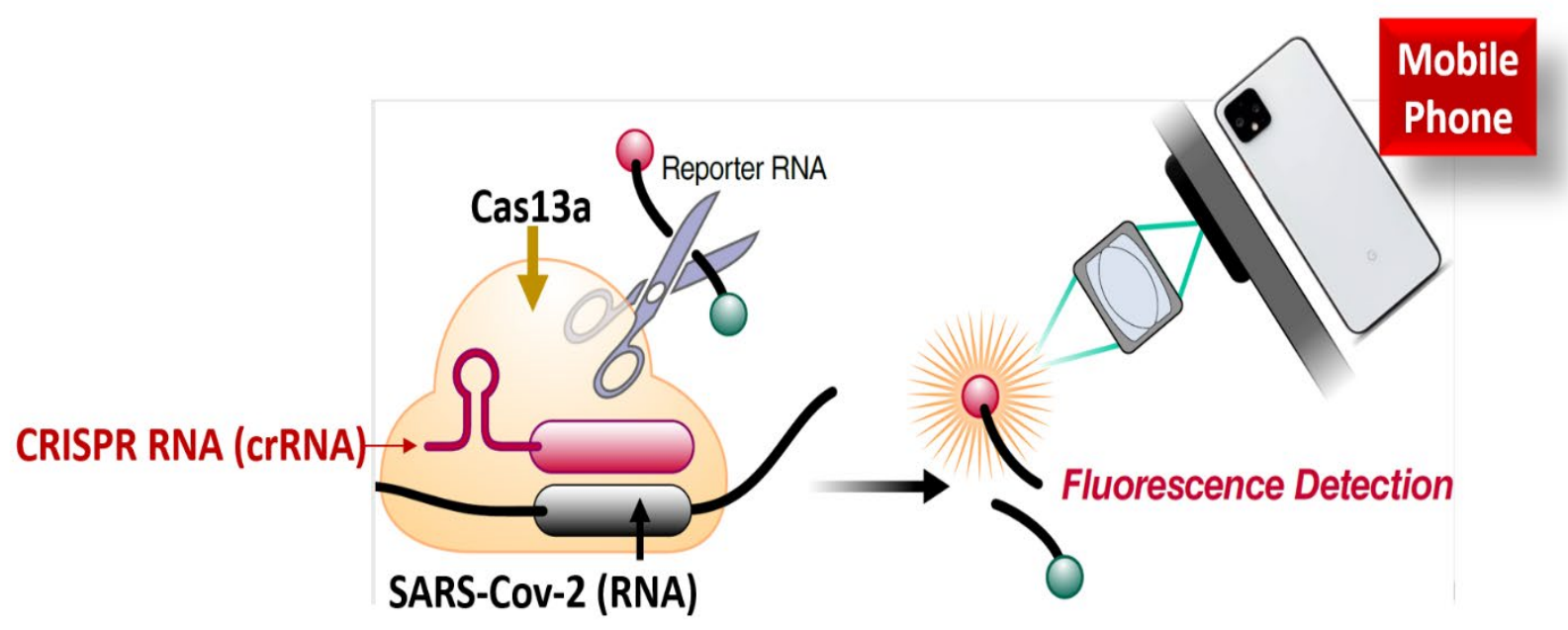

Figure 19: Detection of one copy RNA per $\mu \mathrm{L}$ (microL) from SARS-CoV-2 $2^{230}$ with mobile phone camera. Cas13a (C2c2) is complexed with a CRISPR RNA (crRNA) containing a programmable spacer sequence (red tube) to form a nuclease-inactive ribonucleoprotein complex (RNP). When the RNP binds to a complementary target RNA, it activates HEPN (higher eukaryotes and prokaryotes nucleotide-binding domain) motifs of Cas13a that then indiscriminately cleaves surrounding ssRNAs. Target RNA binding and subsequent Cas 13 cleavage activity can therefore be detected with a fluorophore-quencher pair linked by an ssRNA, which will fluoresce after cleavage by active Cas13. Ott et al used the SARS-CoV-2 nucleocapsid $(\mathrm{N})$ gene as the template (detection target) to create an array of crRNA spacer (red tube). 
The socio-economic fall-out from the stochastic spread of infection and non-deterministic trends affecting certain countries, select groups (race, ethnicity) and underserved clusters, may be an example of "writing on the wall" we are slow to acknowledge. The cost of testing 100,000 individuals in the US approximate $\$ 6$ million. If 30 million tests are performed weekly it would require an additional $\$ 75$ billion and adding the cost of contact tracing might bring the total to approach $\$ 100$ billion $^{231}$.

The "writing" says that the NIAID-Moderna mRNA-1273 vaccine or any other safe and effective vaccine against SARS-CoV-2, when it may become available in 2021 or later, may still be out of reach for billions of people. CRISPR ${ }^{232}$-based tests may be promising ${ }^{233}$ in the future (see Figure 19). BinaxNOW $\$ 5$ test $^{234}$ is at hand but may not be feasible for daily use in communities under economic constraints. The case of Hepatitis- $\mathrm{C}^{235}$ is an example how even after nearly 50 years, anti-viral drugs are not within the buying power of billions of people.

Death, destruction and the decay of civilization ${ }^{236}$ may continue and may continue to amplify in certain regions of the world, long after the pandemic. If the current pandemic is substantially contained by the end of 2021, then the aggregated loss from mortality, morbidity, mental health conditions, and direct economic losses in the US alone is conservatively estimated at $\$ 16$ trillion $^{237}$. The US economy is about a quarter of the global economy ${ }^{238}$, hence, extrapolation suggests that losses due to this pandemic may be an estimated $\$ 64$ trillion, globally (about $80 \%$ of the global GDP ${ }^{239}$ ).

This mundane proposal is an elusive quest for an alternative path, albeit temporary and vastly incomplete, perhaps through the use of aptamers (or other variations based on oligonucleotides ${ }^{240}$ ) to partially bridge the chasm of inequity ${ }^{241}$ and cushion the blow from the mortality and morbidity, yet to be witnessed. Healthcare is a pillar (FEWSHE - food, energy, water, sanitation, healthcare, education) of life and living but it is prudent to avoid indulging in any illusion or delusion because neither aptamers nor vaccines or CRISPR tools, irrespective of their respective efficacies, are a panacea for the restoration of civilization, even if this pandemic subsides in a few years. The quintessential ingredients for public health and global rejuvenation are scientific credibility, color-blind magnanimity and ethical leadership.

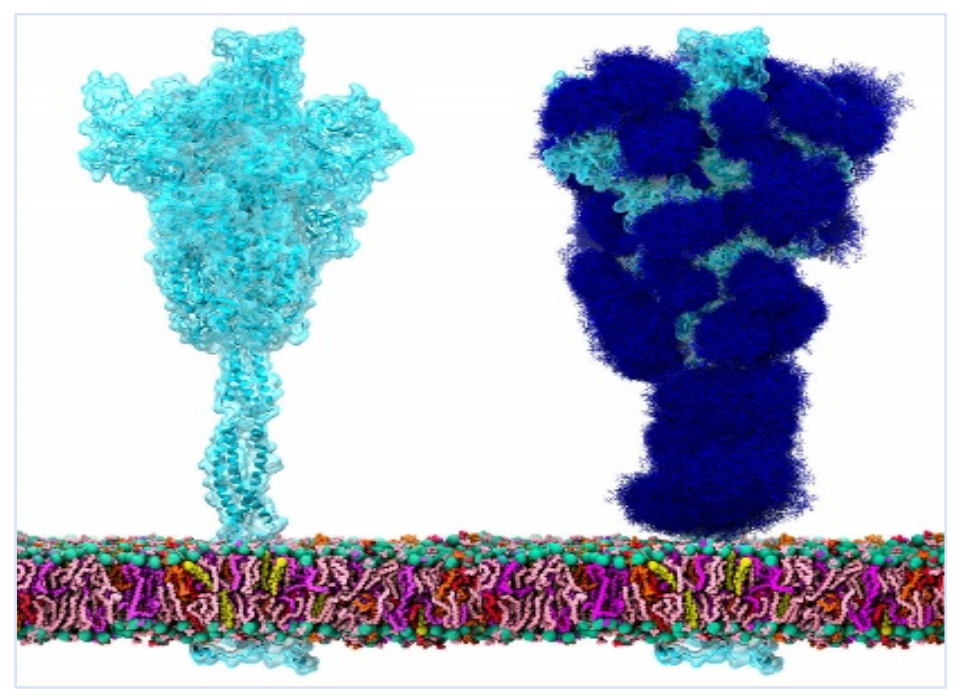

Figure 20: Similar to HIV, SARS-CoV2 Spike protein uses a $\mathrm{N}$-glycan shield $^{242}$ to thwart the host immune response (coating of $\mathrm{N}$-glycans in cobalt blue, right). Mutations ${ }^{243}$, inborn errors of the immune system and other factors may make SARSCoV-2 endemic ${ }^{244}$. Thus, it behooves us to explore other risk mitigation strategies. Anti-sense oligonucleotides, mini protein inhibitors ${ }^{245}$ and aptamers (this proposal) are alternatives. 


\section{Post-Pandemic Public Health and Healthcare: Broad Spectrum use of Sensors with Smartphones}

Transaction $\operatorname{cost}^{246}$ of humans-in-the-loop detection or surveillance ${ }^{247}$ is often astronomical ${ }^{248}$ and the burden of $\operatorname{cost}^{249}$ for public health and heathcare systems is prohibitive even for affluent nations. For resource constrained communities, the mortality and mobidity due to lack of access to primary care must be reduced. Can we effectively combine the ecosystem of sensors, smartphones and data informed decision analytics to deliver usable information at the point of care or point of need, in near real-time?

In general, part of the solution may be found in remote sensing and imaging tools (oil and gas pipelines $^{250}$, leaves ${ }^{251}$, tree $^{252}$ canopy $^{253,254}$, radiation ${ }^{255}$ ). SEE or “sense everything everywhere" (paintbased computation ${ }^{256}$, sensors in fabrics ${ }^{257}$ ) was a 'touchy-feely' mantra at the turn of the millenium buoyed by the principle of ubiquitous ${ }^{258}$ computing ${ }^{259}$ but stumbled in practice due to the $\operatorname{cost}^{260}$ of computation ${ }^{261}$. Vinton Cerf's "I P on Everything" ${ }^{262}$ (I pee on everything) was the witty clarion call for embedding the IPv6 ${ }^{263}$ standard ${ }^{264}$ in all things ${ }^{265}$ to enable "bit dribbling" between "digital" objects. These ideas were preceded by "tangible bits" ${ }^{266}$ from Hiroshi Ishi ${ }^{267}$ and the "atoms to bits" paradigm ${ }^{268}$ of "Internet 0 " from Raffi Krikorian ${ }^{269}$ and Neil Gershenfeld ${ }^{270}$ followed by the origins ${ }^{271}$ of internet of things ${ }^{272}$ by Sanjay Sarma ${ }^{273,274}$ and others ${ }^{275}$. The borborygmi of radio frequency identification (RFID) and standardization of the electronic product code $\left(\mathrm{EPC}^{276}\right)$ shifted the thinking from stationary goods and products with static bar codes to dynamic digital objects which can be unqiuely identified in any process or supply chain and tracked and traced digitally between any number of transactions, globally.

Project Oxygen ${ }^{277}$ offered extraordinary insight into the art of the possible ${ }^{278}$ and represented a consilience and confluence ${ }^{279}$ of ideas but it was cost-prohibitive for real world applications, circa 2000. With decreasing cost of computation ${ }^{280}$, memory ${ }^{281}$, data storage $\mathrm{e}^{282}$ and transmission ${ }^{283}$, these streams, which were occasionally bubbling since Isaac Asimov's ${ }^{284}$ Sall ${ }^{285}$ in 1953, turned into a raging river bursting its banks. The convergence of these tools with initial thoughts about the networked physical world ${ }^{286}$ were far more than the sum of the parts. It exploded to become the inescapable tsunami of IoT $^{287}$ which has infected every domain. The anastomosis ${ }^{288}$ of IoT with cyberphysical systems ${ }^{289}$ $\left(\mathrm{CPS}^{290}\right)$ has penetrated almost every field from asteroids to zeolites and engulfed them within the new ${ }^{291}$ laissez-faire world of DIKW ${ }^{292}$ hierarchy. The mobile smartphone represents the grand conduit for the aggregated dissemination of distributed facets emanating from the DIKW pyramid. The mobile platform appears to be the global choice to access and implement all and any service which is possible, via the smartphone, in some form or the other, where the ubiquitous device serves as the platform for information ${ }^{293}$ arbitrage.

$\mathrm{ADD}$ is a recognition element and a tiny part of this landscape. ADD enables the sensor, data is captured, analyzed, communicated and visualized on a smartphone. It may detect infectious molecules relevant to SARS-CoV-2 in saliva and nasal swabs for early detection to prevent the spread of the virus. This principle is applicable to any infectious agent as well as any physiological molecule of interest (see Figure 21). The potential of developing a "breathalyzer" (identifying molecules in breath, see Figure 18) may make it easier to detect any molecule or molecules which are either volatile or lighter than air. 
Based on the idea of swappable, modular, flash drives, sensors-on-a-chip in the form factor of flashdrives are not hypothetical but frontrunners as potential tools for dealing with infectious ${ }^{294}$ diseases. Cameras, accelerometers (speed, movement), gyroscopes (tilt, orientation), magnetometers (compass), lidars (range, depth sensing from reflected laser signal), GPS and other "sensing" tools are increasingly "standard" with smartphones. These "detectors" makes it possible to use multiple mediums and phases for detection of signals from molecules, changes in dipole moments (electro-magnetic field) and perhaps even perturbation ambient electromagnetic waves (transmission and capture of reflected radio waves).

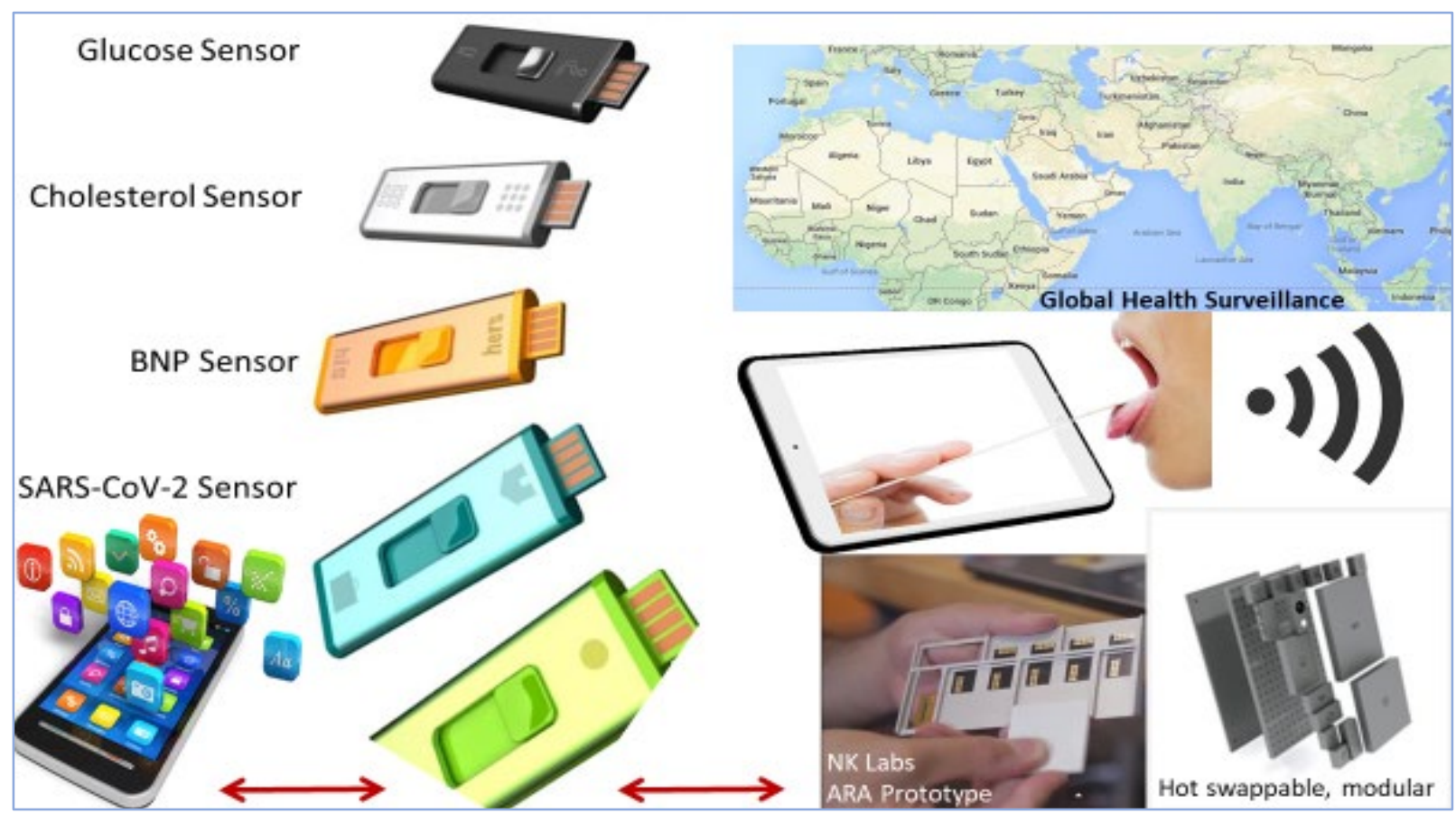

Figure 21: Billions of users in underserved geographies may access limited health services by using ${ }^{295}$ ubiquitous tools that does not require installation of new infrastructure and re-uses "mobile lifestyle" devices to partially bridge the scarcity of resources. Smartphones may be catalytic for delivery of service, remote monitoring ${ }^{296}$ and health surveillance, not restricted to infectious diseases but as physiological probes for health and homeostasis or detecting onset of disequilibrium (BNP, Brain Natriuretic Peptide).

Using information arbitrage to better contain the pandemic is the thrust of ADD. Expanding this principle as a routine for public health and healthcare, in general, is not a leap of imagination but natural progression. It bears reiteration that data informed decision analytics (DIDAS) must embrace sensor data plus smartphone (SDS) applications not as "pilot" projects but science in the service of society to catalyze the SENSIBLE system (SENSors and Information arbitrage via moBiLE system). The marriage of DIDAS with SDS in the affluent world is a matter of social acceptance of SENSIBLE but the penchant for profit-first and lack of leadership are holding us back. In the rest of the world the barrier to diffusion of life-saving tools are, albeit with exceptions, greed, pursuit of unethical profitability, cost or paucity of infrastructure (engineering, energy, telecommunications) and rampant inequity in social cohesion. 
One milestone for smartphone-based health surveillance may be the non-invasive ${ }^{297}$ glucose $^{298}$ monitoring ${ }^{299}$ system which the healthcare system failed to aggressively adopt ${ }^{300}$ despite significant ${ }^{301}$ advances $^{302}$. The chest-thumping about diabetes pandemic ${ }^{303}$ continues in parallel with avoidance of available $^{304}$ solutions $^{305}$. Cholesterol ${ }^{306}$ monitoring ${ }^{307}$ using smartphones ${ }^{308}$ may be a preventative measure for adults at increased risk for a slew cardiovascular diseases, a few of which may not show symptoms.

Decades after the discovery of atrial natriuretic peptide ${ }^{309}$ (ANP, 1981), brain or B-type natriuretic peptide ${ }^{310}$ (BNP, 1987) and C-type natriuretic peptide ${ }^{311}$ (CNP, 1990), we still do not have SENSIBLE monitoring for BNP even though BNP sensors ${ }^{312}$ including an aptamer-based ${ }^{313}$ sensor for BNP-32 and cardiac Troponin I are available. These and other ${ }^{314}$ biomarkers (CRP5/CRP6, TNF $\alpha$ ) are indicators of cardiovascular dysfunction including congestive heart failure (CHF) and state of the patient after myocardial infarction, in addition to other conditions. BNP and other markers are key to risk stratification, diagnosis, prognosis, disease monitoring, titration of therapy, and identification of therapeutic targets for cardiovascular disease. Brain Natriuretic Peptide concentrations $>400 \mathrm{pg} / \mathrm{mL}$ and N-terminal (NT) pro-BNP $>400-900 \mathrm{pg} / \mathrm{mL}$ (age related) are prognosticators of congestive heart failure. Analysis of 48,629 patients ${ }^{315}$ of acute decompensated heart failure found linear correlation between BNP levels and in-hospital mortality. Failure of BNP to decline during hospitalization predicts death or rapid re-hospitalization. However, BNP levels of 250 picograms per $\mathrm{mL}(\mathrm{pg} / \mathrm{mL})$ or less during discharge predicts potential for survival. Accelerating availability of sensors ${ }^{316}$ and transforming innovations ${ }^{317}$ to SENSIBLE systems for prevention of cardiovascular disease should neither suffer from paralysis due to analysis nor asphyxiated by the rancour over margin of profitability.
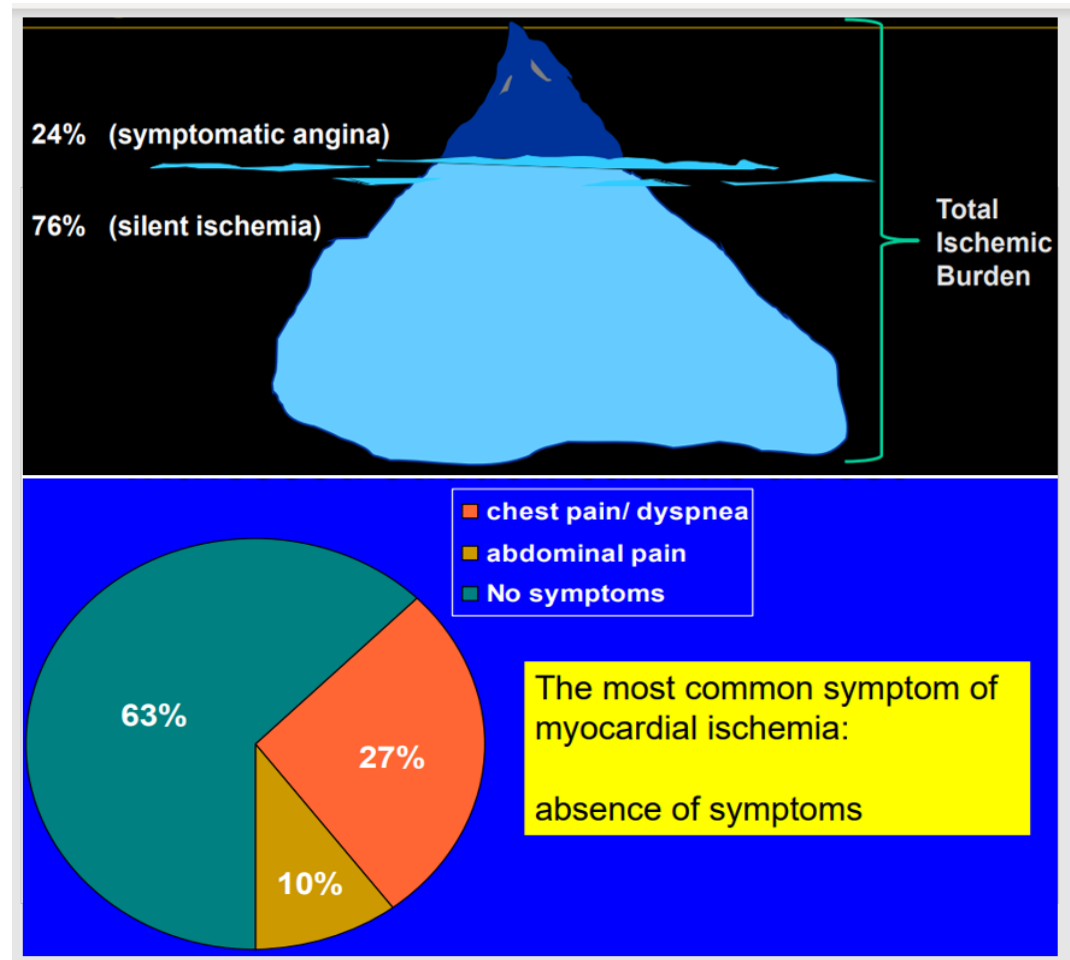

Figure 22: Tip of the Ischemic Iceberg ${ }^{318}$ hides $>63 \%$ of the individuals who lack symptoms but are increasingly at risk for CVD, ischemia, myocardial infarction, congestive heart failure. BNP and other biomarkers may reduce the risk using the SENSIBLE system. We know these facts ${ }^{319}$ for $\sim 40$ years. Yet, the proponents of prevention policies wear that perpetual unctuous grin assimilating both the promises of a television evangelist and the sympathies of a funeral home director of marketing. 

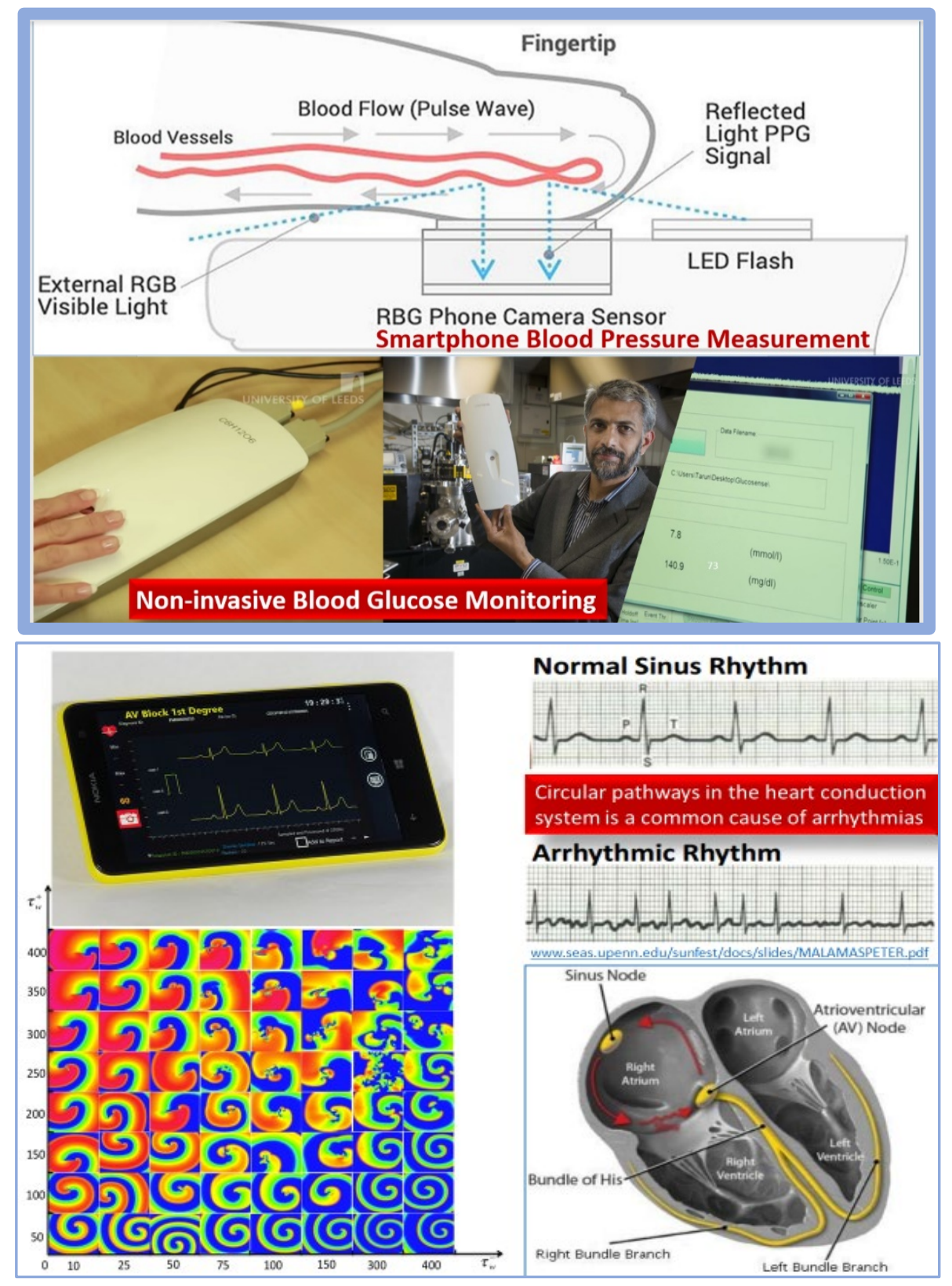

Figure 23: Smartphone cameras, LEDs, LiDARs and a FEAST ${ }^{320}$ of signal transduction tools (optical, Raman spectroscopy, electrochemical impedance spectroscopy, surface plasmon resonance) are now available as data carriers. Cartoon (top) shows smartphone-based blood pressure ${ }^{321}$ and non-invasive blood glucose ${ }^{322}$ monitoring ${ }^{323}$. The SENSIBLE system may be used to estimate blood cholesterol level, hemoglobin ${ }^{324,325,326}$ and uric $^{327}$ acid $^{328}$ as indicators of health, albeit imperfect. Data from smartphone based optic disc ${ }^{329}$ exam, photoplethysmography ${ }^{330}$, electrocardiograph for arrhythmias ${ }^{331}$ (see bottom panels), general ECG ${ }^{332}$, heart ${ }^{333}$ rate, respiratory ${ }^{334}$ rate (reflection of radio waves), pulse oximetry ${ }^{335}$ and other vitals, collectively, may create precision physiology portfolios (open data source interoperability). 
It is likely that hundreds of papers are published weekly on sensors, many of which may be adapted/adopted as a part of the SENSIBLE family. Biosensing using mobile devices at the point of use is a staple, for example, in the food industry (spoilage, contamination, security), soil, water, agriculture, manufacturing, chemical industry, transportation, energy, etc. But, lack of open data and restrictions on data interoperability makes the transformation of data to information quite difficult. Scientists are eager to drill deeper to develop yet another sophistcated sensor but the real-world user is in quest of answers at the point of use, and does not have the luxury to deal with numbers, compilers and programmers.

This discussion about the cacophony of available sensors is an embarrassment of riches from decades of research and development scattered as parts, in silos or locked by patents. The form and functional orchestration and integration necessary for sensors to contribute to precision physiology requires cross-pollination of ideas. Multi-disciplinary teams are necessary to create end-to-end working SENSIBLE systems which can be synchronized, if authorized, as a part of the public health information system. If that data is shared in real time, it may reduce mortality, morbidity, cost to society, decrease the burden on emergency medical professionals, and actually aid in preventing dysfunction. If this data is anonimized to serve molecular epidemiology, it may help precision public health and channel benefits to the community by revealing the environmental conditions or instances which need additional attention.

A plethora of brilliant experts with deep knowledge can fill any university hall but few have the breadth of ideas which, if synthesized, synergized and integrated, may helps to address or even solve a real problem in the public domain where non-experts are the end users. Solutions based approach must combine depth with breadth to deliver the fruits of science to society as global public goods. The latter may be missing in the academic context where chronic search for scholastic erudition is the norm. The concept of essential products and services as global public goods may not be appetizing in the corporate context due to their perpetual penchant to promote profit and profiteering, first. The cleavage between purpose and profit needs a new bridge and a new breed of thinkers and leaders with altruistic traits.

The laser-focus of biomedical professionals on saving the lives of those affected by COVID-19 and the public health community on preventing the spread of infection by SARS-CoV-2 is the only path, at present, to lift us out of the quagmire of the raging pandemic. Yet it may be crucial to use this disaster as a global opportunity to strengthen public private partnerships (academic-industry-government) for the ubiquitous deployment of global tools for early detection and prevention, not only for pandemics, but for public health and healthcare, in general. It is an enormous task and requires global leadership.

Ubiquity of smartphones is the available SENSIBLE platform to create at least one bridge over the chasm separating the haves from have nots. Inextricably linked economies of the under-developed, developing and developed nations makes it imperative that the leadership for global public health must be agnostic of prejudice. Trans-disciplinary cooperation and collaboration between corporations must rise above conventional economics ${ }^{336}$, narcissism, egocentricity and personal wealth creation. We need an overwhelming force for good, for a greater purpose, for the greatest number ${ }^{337}$ (of people). 


\section{Concluding Comments}

The complexity of the physiological dysfunctions associated with the SARS-CoV-2 pandemic calls for multiple routes for detection, prevention and therapy. ADD is a tool for detection and perhaps an alternative approach to treatment that does not depend on the immune system due to reported heterogeneity of response, partially based on individual genetic constitution or inborn genetic errors.

From a public health perspective, the global diffusion of smartphones as ubiquitous devices is an opportunity to use smartphones for detection of the spread of any infectious agent. ADD is one tiny subcomponent of the proposed SENSIBLE system. Realization of the SENSIBLE system is a difficult task. The deployment of the SENSIBLE system, with ADD and other sensor components, is an essential task.

The caveat in this line of thinking is the over-emphasis on the sensor and the SENSIBLE system as if the value proposition is undeniable. The latter is true for the affluent economies of the world but detection without follow-up is an exercise in futility. The latter is common in communities under economic constraints where tools to detect (SENSIBLE system) are impotent because there are very few resources to attend to the public health or healthcare need identified by the SENSIBLE system. Just because the user can detect the presence of mercury in drinking water does not mean that the user has another alternative source of drinking water in under-served or dystopian communities. Is it more or less psychologically debilitating to drink water or consume food if the user is cognizant that the water is contaminated with mercury ${ }^{338}$ or the food is laced with bacteria ${ }^{339}$ beyond the level of food safety?

Incongruity between the pursuit of science, implementation of the fruits of science and science as a measurable service to society is a conundrum beyond the horizon of tools and technology, for example, the SENSIBLE system. Entrepreneurial innovation can create SENSIBLE but implementing SENSIBLE requires leadership imbued with a sense of the future, especially for low-income countries with ultra-low per capita disposable income. In the absence of charity, SENSIBLE for public health and healthcare must carry with it a pay-per-use price tag which may be a micro-payment or even a nano-payment but still it must be a non-zero payment for the system to be sustainable and survive long enough to deliver value.

Ephemeral gimmicks demonstrating SENSIBLE in geographies with GDP which may be less than an average household income in Europe is a deliberate act to deceive, dressed up in a marketing ${ }^{340}$ garb by the glib, the smug and the smarmy. Enabling a SENSIBLE future and making it sustainable for most segments of the community, in greatest numbers, is a mission for a visionary leader who radiates the aura that kindness is a strength, not a weakness, humility is a virtue, not a lack of knowledge, that agreeing to disagree is a mark of civility ${ }^{341}$ and dignity, not a character flaw, that fear is not a tool for maiming diversity, speech or peace, that progress of civilization is development of the freedom ${ }^{342}$ to act on remediable injustices ${ }^{343}$ and lift many boats, not a few yachts. The best man for that job is a woman. 
APPENDIX

32. ADD is in the MIT Library https://dspace.mit.edu/handle/1721.1/128017 (will be uploaded to ChemRxiv, too). 


\section{APPENDIX - Brief Description of the Components ${ }^{344}$ for SARS-CoV-2 ADD Decision System (Fig 1)}

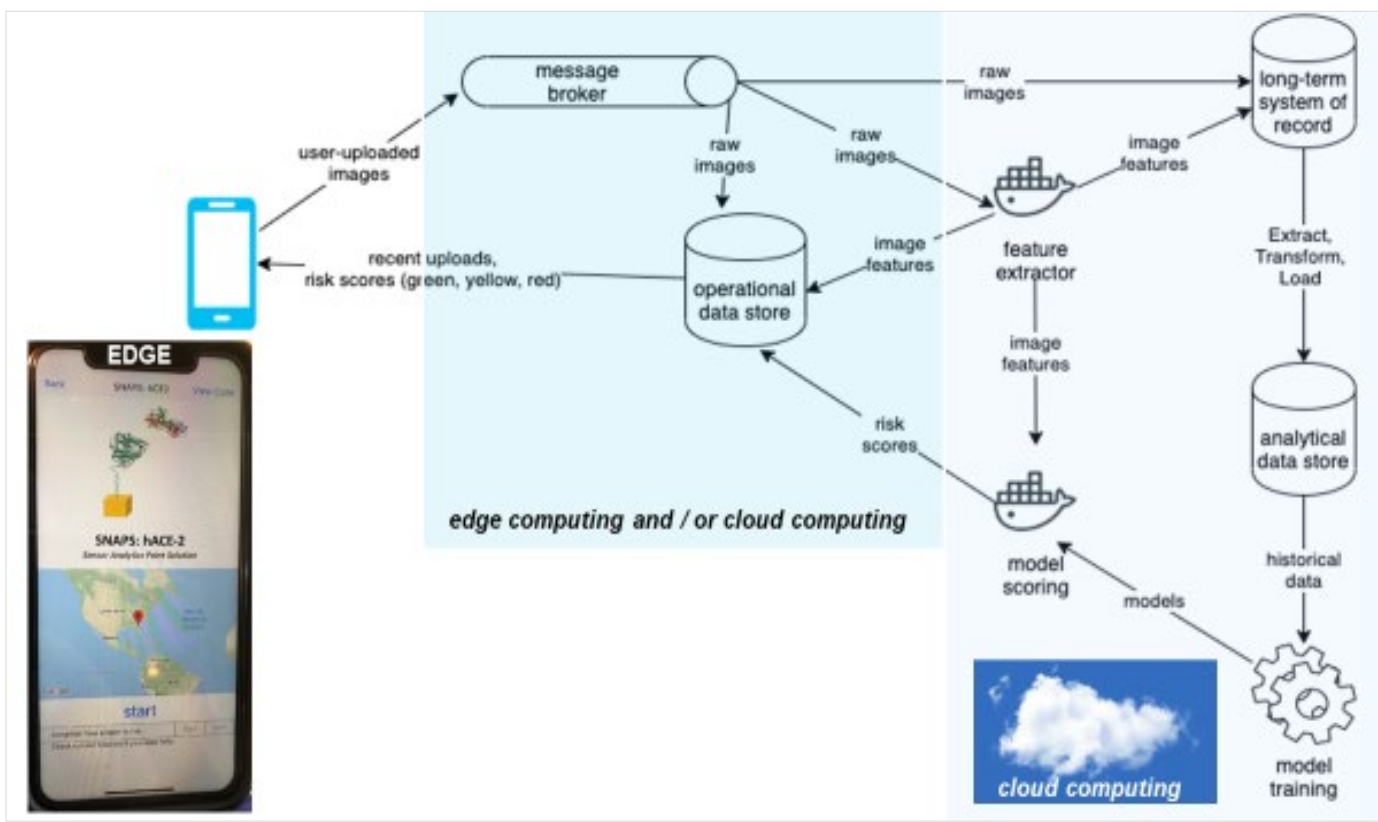

\section{Message Broker}

When users upload images (the data after scanning with the HoloLens app or equivalent mobile tool), the mobile application (on their phones) writes messages with the image content and other metadata to a message-broker, which may be cloud-based message queuing $\left(\mathrm{MQ}^{345}\right)$ protocol (open source software). The message broker allows devices to quickly offload data and confirm "sent" to a user (if cloud based), thereby decoupling the user experience from the data store (even if it uses a temporary tinyDB on the device, if the network is unavailable to access the cloud in real-time at the point of use). Messages can be queued in topics and the system may enable autoscaling (as usage of the application increases, more users can be provisioned, process user uploads and get them stored). The uploads (data) are also sent by the message broker to the feature extractor and long-term storage database (may use the batch upload option when device is proximal to a high bandwidth gateway which can offer access to cloud services).

\section{Operational Data Store}

The message broker transfers uploads to ODS (Operational Data Store ${ }^{346}$ ), which may be a cloud-based managed service or part of the tinyDB on the device, if cloud is inaccessible at the point of use. ODS must be able to store image data (supports binary blog column type) alongside time-index numerical and character data. It is intended to only serve "hot" (nascent) data to the application. Older data may be evicted (batch uploaded to cloud managed facilities) to optimize on-device service and prevent data amplification. ODS is tuned for fast random reads and serves requests made by mobile app when users view recent uploads and additional metadata about those uploads, including "risk scores". ODS is optimized for fast writes and high efficiency time-series queries. 


\section{Feature Extractor}

Extracts additional metadata from images/data uploaded from the mobile app (uploads it to the longterm system of record ${ }^{347}$ which includes raw data uploaded from the application, similar to "master data" in $\mathrm{ERP}^{348}$ ). Feature Extractor may convert the uploaded image into a numeric matrix ${ }^{349}$ or create hash table or representation of a region ${ }^{350}$ and correct for differences in resolution (for example, variation due to pixel density of cameras on different smartphones). Feature ${ }^{351}$ vectors $^{352}$ may be maintained in the long-term system of record. It may be written to the operational data store to enable extraction/selection ${ }^{353}$ of incoming data (uploads from message broker) relevant to these feature vectors.

\section{Long-term System of Record}

Mobile applications may never access data directly from this data store ${ }^{354}$. Interactive-speed queries to this data store may not be supported. When necessary, objects stored in this "record" may be extracted and the data is loaded into an analytical data store. For object stores, this operation may be accomplished using query-over-files engines ${ }^{355}$. The thorniest problem that ferments within long-term data record is the inaccuracy of "accurate" data and the diabolical mayhem from "big data" if it is sourced and stored.

\section{Analytical Data Store}

Scientists and data experts will need historical data (from uploaded samples) to train task-specific ${ }^{356}$ machine learning (ML) models to assign risk scores to samples. Analytical data store (ADS database ${ }^{357}$ ) may be populated with data from the long-term system of record using scheduled batch data uploads.

\section{Model Training}

In model training ${ }^{358}$, a statistical model is built from historical data. Models should be serializable ${ }^{359}$ representations of the program generated by ML training. Serialization is essential for interoperability on different platforms. It is key to create composable models where models from different groups can be deconstructed to sub-elements which can be reconstructed to compose a new model (which may be greater than the sum of parts). Serialization enables the process of translating a data structure or object state into a format that can be stored or transmitted and reconstructed. Proprietary software vendors obfuscate or encrypt serialized data to prevent access. Standard architectures such as CORBA ${ }^{360}$ define the serialization formats in detail to enable open access.

\section{Model Scoring}

In model scoring, a model is called on input data, the model processes the input data and generates a prediction. The structure of this code depends on the design choices made during model training. For reliability of deployment, model scoring may run in a container ${ }^{361}$ (an unit of software) which contains code (and all its dependencies) that uses a model to produce predictions on new input data. If model scoring runs in a container then the model can be arbitrary code in the developer's language ${ }^{362}$ of choice. Model scoring requires features created previously by the feature extractor (feature selection is critical). 


\section{REFERENCES}

${ }^{1}$ Subirana, Brian, et al. "Hi Sigma, Do I Have the Coronavirus?: Call for a New Artificial Intelligence Approach to Support Health Care Professionals Dealing with the COVID-19 Pandemic.” April 2020. http://arxiv.org/abs/2004.06510 and https://arxiv.org/ftp/arxiv/papers/2004/2004.06510.pdf ${ }^{2}$ Massachusetts General Hospital (2020) New Tool Can Detect COVID-19 Outbreaks in US Counties. https://www.massgeneral.org/news/press-release/New-tool-can-detect-covid-19-outbreaks-in-uscounties and https://analytics-modeling.shinyapps.io/outbreakdetection/

${ }^{3}$ Engels, D. W., et al. "Networked Physical World: Automated Identification Architecture." Proceedings. The Second IEEE Workshop on Internet Applications. WIAPP 2001, IEEE Comput. Soc, 2001, pp. 76-77. doi:10.1109/WIAPP.2001.941872 https://ieeexplore.ieee.org/document/941872

${ }^{4}$ Sarma, Sanjay, Brock, David and Ashton, Kevin (2000) The Networked Physical World: Proposals for Engineering the Next Generation of Computing, Commerce \& Automatic-Identification. White Paper WH-001. October 1, 2000. MIT Auto-ID Center, Massachusetts Institute of Technology. https://cocoa.ethz.ch/downloads/2014/06/None_MIT-AUTOID-WH-001.pdf ${ }^{5}$ Susan Symington, William Polk and Murugiah Souppaya (2020) Internet of Things (IoT) Device Network-Layer Onboarding and Lifecycle Management. NIST Cybersecurity White Paper (Draft). https://nvlpubs.nist.gov/nistpubs/CSWP/NIST.CSWP.09082020-draft.pdf ${ }^{6}$ Chinese Numerology https://en.wikipedia.org/wiki/Chinese_numerology

${ }^{7}$ Shambhavi Shubham, Jan Hoinka, Soma Banerjee, Emma Swanson, Jacob A. Dillard, Nicholas J. Lennemann, Teresa M. Przytycka, Wendy Maury and Marit Nilsen-Hamilton (2018) A 2'FY-RNA Motif Defines an Aptamer for Ebolavirus Secreted Protein. Nature Scientific Reports 2018 Aug 17; 8(1):12373 doi: 10.1038/s41598-018-30590-8 https://www.ncbi.nlm.nih.gov/pmc/articles/PMC6098113/pdf/41598_2018_Article_30590.pdf ${ }^{8}$ Jakub Ptacek, Dong Zhang, Liming Qiu, Sven Kruspe, Lucia Motlova, Petr Kolenko, Zora Novakova, Shambhavi Shubham, Barbora Havlinova, Petra Baranova, Shi-Jie Chen, Xiaoqin Zou, Paloma Giangrande, Cyril Barinka. Structural basis of prostate-specific membrane antigen recognition by the A9g RNA aptamer. Nucleic Acids Research, gkaa494. https://doi.org/10.1093/nar/gkaa494 ${ }^{9}$ Datta, Shoumen (2020) CITCOM - An Incomplete Review of Ideas and Facts about SARS-CoV-2 https://dspace.mit.edu/handle/1721.1/128017 and https://dspace.mit.edu/handle/1721.1/111021 ${ }^{10}$ Fairbanks, Antony J. "The ENGases: Versatile Biocatalysts for the Production of Homogeneous NLinked Glycopeptides and Glycoproteins.” Chemical Society Reviews, vol. 46, no. 16, 2017, pp. 5128-46. doi:10.1039/C6CS00897F. https://pubs.rsc.org/en/content/articlepdf/2017/cs/c6cs00897f

${ }^{11}$ Khargonekar, Pramod P. (2020) Kalman Filtering, Sensor Fusion, and Eye Tracking https://faculty.sites.uci.edu/khargonekar/files/2020/08/KFSensorFusion_PPK.pdf ${ }^{12}$ NIST Differential Privacy Engineering (2018) https://www.nist.gov/itl/applied-cybersecurity/privacyengineering/collaboration-space/focus-areas/de-id/tools\#dpchallenge 
${ }^{13}$ Victoria Morgan, Lisseth Casso-Hartman, David Bahamon-Pinzon, Kelli McCourt, Robert G. Hjort, Sahar Bahramzadeh, Irene Velez-Torres, Eric McLamore, Carmen Gomes, Evangelyn C. Alocilja, Shoumen Palit Austin Datta and Diana C. Vanegas (2019) Sensor-as-a-Service: Convergence of Sensor Analytic Point Solutions (SNAPS) and Pay-A-Penny-Per-Use (PAPPU) Paradigm as a Catalyst for Democratization of Healthcare in Underserved Communities. Diagnostics 2020, 10 (1), 22 https://doi.org/10.3390/diagnostics10010022

“SNAPS TRILOGY” MIT Libraries https://dspace.mit.edu/handle/1721.1/123983

${ }^{14}$ Winn, Zach (2020) Real-time data for a better response to disease outbreaks. https://news.mit.edu/2020/kinsa-health-0821

${ }^{15}$ Lamb, James (2020) ADD Appendix - Description of Major Components (personal communication) https://github.com/jameslamb

${ }^{16}$ Zamecnik PC, Stephenson ML.(1978) Inhibition of Rous sarcoma virus replication and cell transformation by a specific oligodeoxynucleotide. Proc Natl Acad Sci (US). 1978 January; 75(1):280-4. doi: 10.1073/pnas.75.1.280 www.ncbi.nlm.nih.gov/pmc/articles/PMC411230/pdf/pnas00013-0285.pdf ${ }^{17}$ Cohn, Danny M., et al. “Antisense Inhibition of Prekallikrein to Control Hereditary Angioedema." New England J of Med. vol. 383, no. 13, September 2020, pp. 1242-1247. doi:10.1056/NEJMoa1915035 ${ }^{18}$ APPENDIX Figure 1: Description of Components https://github.com/shoumendatta/ADD-DIGITAL ${ }^{19}$ McLamore, Eric (2019) Surveillance Smartphone App (personal communication) https://emclamor.wixsite.com/mclamorelab

${ }^{20}$ Shmerling, Robert (2020) Which test is best for COVID-19? Harvard Medical School. 21 Sept 2020. https://www.health.harvard.edu/blog/which-test-is-best-for-covid-19-2020081020734

${ }^{21}$ Classification: True vs. False and Positive vs. Negative https://developers.google.com/machine-learning/crash-course/classification/true-false-positive-negative ${ }^{22}$ Candela M, Luconi V, Vecchio A. Impact of the COVID-19 pandemic on the Internet latency: A largescale study. Computer Networks. 2020 December 9; 182:107495. doi: 10.1016/j.comnet.2020.107495. Epub 2020 August 20. https://www.ncbi.nlm.nih.gov/pmc/articles/PMC7439971/pdf/main.pdf ${ }^{23}$ World Economic Forum (2016) 4 billion people still don't have internet access. https://www.weforum.org/agenda/2016/05/4-billion-people-still-don-t-have-internet-access-here-show-to-connect-them/

${ }^{24}$ Likert Scale https://www.sciencedirect.com/topics/psychology/likert-scale

${ }^{25}$ Roh, Yuji, et al. A Survey on Data Collection for Machine Learning. August 2019. http://arxiv.org/abs/1811.03402 and https://arxiv.org/pdf/1811.03402.pdf ${ }^{26}$ CDC - 2019-nCoV Real-Time RT-PCR Diagnostic Panel. www.fda.gov/media/134920/download ${ }^{27}$ Hutson, Matthew. "Artificial-Intelligence Tools Aim to Tame the Coronavirus Literature.” Nature, June 2020, pp. d41586-020-01733-37. doi:10.1038/d41586-020-01733-7

${ }^{28}$ Kanter, James Max, et al. “Machine Learning 2.0 : Engineering Data Driven AI Products.” July 2018. http://arxiv.org/abs/1807.00401 and https://arxiv.org/pdf/1807.00401.pdf

${ }^{29}$ Collection of papers and books on FEATURES (200MB) http://bit.ly/BOOKS-FEATURES 
${ }^{30}$ Escalante, Hugo Jair. "Automated Machine Learning - Brief Review at the End of the Early Years." August 2020. http://arxiv.org/abs/2008.08516 and https://arxiv.org/pdf/2008.08516.pdf

${ }^{31}$ Kanter, James Max, and Kalyan Veeramachaneni. "Deep Feature Synthesis: Towards Automating Data Science Endeavors.” 2015 IEEE International Conference on Data Science and Advanced Analytics (DSAA), IEEE, 2015, pp. 1-10. doi:10.1109/DSAA.2015.7344858.

http://axperia-ventures.com/wp-content/uploads/2015/10/DSAA_DSM_2015.pdf

${ }^{32}$ Gilad Katz, Eui Chul Richard Shin and Dawn Song (2016) "ExploreKit: Automatic Feature Generation and Selection." 2016 IEEE 16th International Conference on Data Mining, IEEE, 2016, pp. 979-84. doi:10.1109/ICDM.2016.0123 https://people.eecs.berkeley.edu/ dawnsong/papers/icdm-2016.pdf ${ }_{33}$ Data Distribution Service https://www.dds-foundation.org/what-is-dds-3/

${ }^{34}$ Berke EM. Geographic Information Systems: recognizing the importance of place in primary care research \& practice. J Am Board Fam Med. 2010 Jan-Feb; 23(1):9-12. doi: 10.3122/jabfm.2010.01.090119 https://www.ncbi.nlm.nih.gov/pmc/articles/PMC3174470/pdf/nihms-323401.pdf

${ }^{35}$ Tebani, A., Gummesson, A., Zhong, W. et al. Integration of molecular profiles in a longitudinal wellness profiling cohort. Nat Commun 11, 4487 (2020). https://doi.org/10.1038/s41467-020-18148-7 https://www.nature.com/articles/s41467-020-18148-7.pdf

${ }^{36}$ Pennisi, Elizabeth. "Massive Project Reveals Complexity of Gene Regulation.” Science, vol. 369, no. 6509, 10 September 2020, pp. 1286-1287. doi:10.1126/science.369.6509.1286

${ }^{37}$ Zahn, Laura M. “Custom Transcriptome.” Science, vol. 369, no. 6509, 10 September 2020, pp. 1316-17 doi:10.1126/science.abe4492

${ }^{38}$ The GTEx Consortium. "The GTEx Consortium Atlas of Genetic Regulatory Effects across Human Tissues." Science, vol. 369, no. 6509, 10 September 2020, pp. 1318-1330. doi:10.1126/science.aaz1776 https://science.sciencemag.org/content/sci/369/6509/1318.full.pdf

${ }^{39}$ Hutchinson, L., Romero, D. Precision or imprecision medicine?. Nat Rev Clin Oncol 13, 713 (2016) https://doi.org/10.1038/nrclinonc.2016.190 \& https://www.nature.com/articles/nrclinonc.2016.190.pdf ${ }^{40}$ Gold, Larry (2020) Personal Communication https://amzn.to/2QGSz1i

${ }^{41}$ Dodig-Crnković, Tea, et al. "Facets of Individual-Specific Health Signatures Determined from Longitudinal Plasma Proteome Profiling.” EBioMedicine, vol. 57, July 2020, p. 102854. doi:10.1016/j.ebiom.2020.102854 www.thelancet.com/action/showPdf?pii=S2352-3964\%2820\%2930229-2

${ }^{42}$ https://somascandiscovery.com/publications/

${ }^{43}$ APTAMER (Collected Papers) https://bit.ly/APTAMER

${ }^{44}$ She, Richard, et al. "Comprehensive and Quantitative Mapping of RNA-Protein Interactions across a Transcribed Eukaryotic Genome." Proceedings of the National Academy of Sciences, vol. 114, no. 14, April 2017, pp. 3619-3624. doi:10.1073/pnas.1618370114 https://www.pnas.org/content/pnas/114/14/3619.full.pdf 
${ }^{45}$ Pál, Gábor, et al. "Comprehensive and Quantitative Mapping of Energy Landscapes for Protein-

Protein Interactions by Rapid Combinatorial Scanning." Journal of Biological Chemistry, vol. 281, no. 31, August 2006, pp. 22378-22385. doi:10.1074/jbc.M603826200.

https://www.jbc.org/content/281/31/22378.full.pdf

${ }^{46}$ Petricoin, Emanuel F., et al. "Use of Proteomic Patterns in Serum to Identify Ovarian Cancer." The

Lancet, vol. 359, no. 9306, Feb. 2002, pp. 572-77. doi:10.1016/S0140-6736(02)07746-2

http://fenyolab.org/presentations/Proteomics_Informatics_2014/pdf/02_petricoin_lancet.pdf

${ }^{47}$ Canna, Scott W., and Edward M. Behrens. "Making Sense of the Cytokine Storm: A Conceptual

Framework for Understanding, Diagnosing, and Treating Hemophagocytic Syndromes." Pediatric

Clinics of North America, vol. 59, no. 2, April 2012, pp. 329-44. doi:10.1016/j.pcl.2012.03.002

https://www.ncbi.nlm.nih.gov/pmc/articles/PMC3368378/pdf/nihms370318.pdf

${ }^{48}$ Tisoncik, J. R., et al. "Into the Eye of the Cytokine Storm." Microbiology and Molecular Biology

Reviews, vol. 76, no. 1, March 2012, pp. 16-32. doi:10.1128/MMBR.05015-11

https://www.ncbi.nlm.nih.gov/pmc/articles/PMC3294426/pdf/zmr16.pdf

${ }^{49}$ Spit Shines https://science.sciencemag.org/content/369/6507/1041/tab-pdf and

https://www.nejm.org/doi/pdf/10.1056/NEJMc2016359

${ }^{50}$ Gold, Larry. "SELEX: How It Happened and Where It Will Go." Journal of Molecular Evolution, vol.

81, no. 5-6, December 2015, pp. 140-143. doi:10.1007/s00239-015-9705-9

https://www.ncbi.nlm.nih.gov/pmc/articles/PMC4661202/pdf/239_2015_Article_9705.pdf

${ }^{51}$ De La Fuente, Adriana, et al. "Aptamers against Mouse and Human Tumor-Infiltrating Myeloid Cells as Reagents for Targeted Chemotherapy." Science Translational Medicine, vol. 12, no. 548, June 2020, p. eaav9760 doi:10.1126/scitranslmed.aav9760

${ }^{52}$ Hopfield, J. J. "Kinetic Proofreading: A New Mechanism for Reducing Errors in Biosynthetic Processes Requiring High Specificity." Proc National Academy of Sciences, vol. 71, no. 10, Oct. 1974, pp. 4135-4139 doi:10.1073/pnas.71.10.4135 https://www.pnas.org/content/pnas/71/10/4135.full.pdf

${ }^{53}$ Oran DP, Topol EJ. Prevalence of Asymptomatic SARS-CoV-2 Infection : A Narrative Review. Annals of Internal Medicine. 2020 September 1;173(5):362-367. doi: 10.7326/M20-3012. Epub 2020 June 3.

https://www.ncbi.nlm.nih.gov/pmc/articles/PMC7281624/pdf/aim-olf-M203012.pdf

${ }^{54}$ Gheblawi M, Wang K, Viveiros A, Nguyen Q, Zhong JC, Turner AJ, Raizada MK, Grant MB, Oudit GY. Angiotensin-Converting Enzyme 2: SARS-CoV-2 Receptor and Regulator of the Renin-Angiotensin System: Celebrating the 20th Anniversary of the Discovery of ACE2. Circulation Research. 2020 May 8; 126(10):1456-1474. doi: 10.1161/CIRCRESAHA.120.317015. Epub 2020 April 8.

www.ncbi.nlm.nih.gov/pmc/articles/PMC7188049/pdf/res-126-10.1161.circresaha.120.317015.pdf

${ }^{55}$ López-Otín, Carlos, and Judith S. Bond. "Proteases: Multifunctional Enzymes in Life and Disease." Journal of Biological Chemistry, vol. 283, no. 45, November 2008, pp. 30433-30437 doi:10.1074/jbc.R800035200 https://www.ncbi.nlm.nih.gov/pmc/articles/PMC2576539/pdf/30433.pdf 
${ }^{56}$ Hoagland, M. B., Stephenson, M. L., Scott, J. F., Hecht, L. I., and Zamecnik, P. C. (1958) A Soluble Ribonucleic Acid Intermediate in Protein Synthesis. J. Biol. Chem. 231 241-257.

https://pdfs.semanticscholar.org/aad2/985a4bcb40430260e3570683cb2b3b79f7e7.pdf?_ga=2.242690306 $.1804402263 .1599417152-1424810635.1595859001$ https://www.jbc.org/content/280/40/e37

${ }^{57}$ Brenner, S., Jacob, F. \& Meselson, M. (1961). An unstable intermediate carrying information from genes to ribosomes for protein synthesis. Nature 190 576-581

${ }^{58}$ Gros, F., Hiatt, H., Gilbert, W., Kurland, C. G.,Risebrough, R. W. \& Watson, J. D. (1961). Unstable ribonucleic acid revealed by pulse labelling of Escherichia coli. Nature 190 581-585

${ }^{59}$ Jacob, F. and Monod, J. (1961). Genetic regulatory mechanisms in the synthesis of proteins. Journal of Molecular Biology 3 318-356

${ }^{60}$ Monod, J., Changeux, J. P. and Jacob, F. (1963). Allosteric proteins and cellular control systems. Journal of Molecular Biology 6 306-329

${ }^{61}$ Alberts, Bruce and Frey, Linda (1970) T4 Bacteriophage Gene 32: A Structural Protein in the Replication and Recombination of DNA. Nature 227 1313-1318

https://brucealberts.ucsf.edu/wp-content/uploads/2016/07/Alberts-and-Frey-1970-YO.pdf

${ }^{62}$ Tuerk, Craig and Gold, Larry (1990) Systematic evolution ofligands by exponential enrichment: RNA ligands to bacteriophage T4 DNA polymerase. Science 249 505-510

${ }^{63}$ Ellington, Andy D. and Szostak, Jack W. (1990) In vitro selection of RNA molecules that bind specific ligands. Nature $346818-822$

${ }^{64}$ Gold, Larry (2015) “SELEX: How It Happened and Where It Will Go.” Journal of Molecular Evolution, vol. 81, no. 5-6, December 2015, pp. 140-143. doi:10.1007/s00239-015-9705-9

https://www.ncbi.nlm.nih.gov/pmc/articles/PMC4661202/pdf/239_2015_Article_9705.pdf

${ }^{65}$ Lakhin AV, Tarantul VZ, Gening LV. (2013) Aptamers: problems, solutions and prospects. Acta

Naturae. 2013 October, 5(4):34-43.

www.ncbi.nlm.nih.gov/pmc/articles/PMC3890987/pdf/AN20758251-19-034.pdf

${ }^{66} \mathrm{Ku}$ TH, Zhang T, Luo H, Yen TM, Chen PW, Han Y, Lo YH. (2015) Nucleic Acid Aptamers: An

Emerging Tool for Biotechnology and Biomedical Sensing. Sensors (Basel). 2015 July 6; 15(7): 16281-313 doi: 10.3390/s150716281 www.ncbi.nlm.nih.gov/pmc/articles/PMC4541879/pdf/sensors-15-16281.pdf

${ }^{67}$ Kato, Teru, et al (2000) “In Vitro Selection of DNA Aptamers Which Bind to Cholic Acid." Biochimica et Biophysica Acta (BBA) - Gene Structure and Expression, vol. 1493, no. 1-2, September 2000, pp. 12-18 doi:10.1016/S0167-4781(00)00080-4

${ }^{68}$ Kalra, Priya, et al. "Simple Methods and Rational Design for Enhancing Aptamer Sensitivity and Specificity.” Frontiers in Molecular Biosciences, vol. 5, May 2018, p. 41. doi:10.3389/fmolb.2018.00041 https://www.frontiersin.org/articles/10.3389/fmolb.2018.00041/pdf

${ }^{69}$ Strauss S, Nickels PC, Strauss MT, Jimenez Sabinina V, Ellenberg J, Carter JD, Gupta S, Janjic N, Jungmann R. (2018) Modified aptamers enable quantitative sub-10-nm cellular DNA-PAINT imaging. Nature Methods. 2018 September; 15(9):685-688. doi: 10.1038/s41592-018-0105-0 Epub 2018 Aug 20. https://www.ncbi.nlm.nih.gov/pmc/articles/PMC6345375/pdf/emss-78630.pdf 
${ }^{70}$ Kato Teru, Yano K, Ikebukuro K, Karube I. (2000) Interaction of three-way DNA junctions with steroids. Nucleic Acids Res. 2000 May 1; 28(9):1963-1968. doi: 10.1093/nar/28.9.1963

https://www.ncbi.nlm.nih.gov/pmc/articles/PMC103303/pdf/gkd319.pdf

${ }^{71}$ Sun, B.B., Maranville, J.C., Peters, J.E. et al. (2018) Genomic atlas of the human plasma

proteome. Nature 558 73-79 (2018). https://doi.org/10.1038/s41586-018-0175-2

${ }^{72}$ Emilsson, Valur, et al (2018) Co-Regulatory Networks of Human Serum Proteins Link Genetics to

Disease. Science, vol. 361, no. 6404, Aug. 2018, pp. 769-773. doi:10.1126/science.aaq1327

${ }^{73}$ Joshi A and Mayr M. (2018) In Aptamers They Trust: The Caveats of the SOMAscan Biomarker

Discovery Platform from SomaLogic. Circulation. 2018 November 27; 138(22):2482-2485.

doi: 10.1161/CIRCULATIONAHA.118.036823. Epub 2018 November 26.

https://www.ncbi.nlm.nih.gov/pmc/articles/PMC6277005/pdf/emss-80116.pdf

${ }^{74}$ Zhang Y, Lai BS, Juhas M. Recent Advances in Aptamer Discovery and Applications. Molecules. 2019

March 7; 24(5):941. doi: 10.3390/molecules24050941

https://www.ncbi.nlm.nih.gov/pmc/articles/PMC6429292/pdf/molecules-24-00941.pdf

${ }^{75}$ Song, Kyung-Mi; Lee, Seonghwan; Ban, Changill. (2012) Aptamers and Their Biological Applications.

Sensors 12, no. 1: 612-631. https://www.mdpi.com/1424-8220/12/1/612/pdf

${ }^{76} \mathrm{Wu}$, Yao, et al. "Perspective on the Future Role of Aptamers in Analytical Chemistry." Analytical Chemistry, vol. 91, no. 24, December 2019, pp. 15335-15344. doi:10.1021/acs.analchem.9b03853

${ }^{77} \mathrm{De}$ La Fuente, Adriana, et al. "Aptamers against Mouse and Human Tumor-Infiltrating Myeloid Cells as Reagents for Targeted Chemotherapy." Science Translational Medicine, vol. 12, no. 548, June 2020, p. eaav9760. doi:10.1126/scitranslmed.aav9760.

${ }^{78}$ Schmitz, F.R.W., Valério, A., de Oliveira, D. et al. An overview and future prospects on aptamers for food safety. Appl Micro Biotech 104, 6929-6939 (2020) https://doi.org/10.1007/s00253-020-10747-0 https://link.springer.com/content/pdf/10.1007/s00253-020-10747-0.pdf

${ }^{79}$ Sumedha D Jayasena, Aptamers: An Emerging Class of Molecules That Rival Antibodies in Diagnostics, Clinical Chemistry, Volume 45, Issue 9, 1 September 1999, Pages 1628-1650.

https://doi.org/10.1093/clinchem/45.9.1628

${ }^{80}$ Hicke BJ, Stephens AW, Gould T, et al. (2006) Tumor targeting by an aptamer. J Nucl Med. 2006; 47(4):668-678. http://jnm.snmjournals.org/content/47/4/668.full.pdf+html

${ }^{81}$ Trausch, Jeremiah J., et al. "Replacing Antibodies with Modified DNA Aptamers in Vaccine Potency Assays.” Vaccine, vol. 35, no. 41, October 2017, pp. 5495-502. doi:10.1016/j.vaccine.2017.04.003

${ }^{82}$ Javier DJ, Nitin N, Levy M, Ellington A, Richards-Kortum R. Aptamer-targeted gold nanoparticles as molecular-specific contrast agents for reflectance imaging. Bioconjug Chem. 2008 June; 19(6):1309-12. doi: 10.1021/bc8001248. Epub 2008 May 31.

https://www.ncbi.nlm.nih.gov/pmc/articles/PMC2651625/pdf/bc8001248.pdf

${ }^{83}$ Hianik T, Porfireva A, Grman I, Evtugyn G. EQCM biosensors based on DNA aptamers and antibodies for rapid detection of prions. Protein Pept Lett. 2009;16(4):363-367.

doi:10.2174/092986609787848090

40 - ADD is in the MIT Library https://dspace.mit.edu/handle/1721.1/128017 (will be uploaded to ChemRxiv, too). 
${ }^{84}$ Lee, J., So, H., Jeon, E. et al. Aptamers as molecular recognition elements for electrical nanobiosensors. Anal Bioanal Chem 390, 1023-1032 (2008). https://doi.org/10.1007/s00216-007-1643-y https://link.springer.com/content/pdf/10.1007/s00216-007-1643-y.pdf

${ }^{85}$ Arshavsky-Graham, Sofia, et al. "Aptamers vs. Antibodies as Capture Probes in Optical Porous Silicon Biosensors." The Analyst, vol. 145, no. 14, 2020, pp. 4991-5003. doi:10.1039/DoANo0178C

${ }^{86}$ Zou X, Wu J, Gu J, Shen L, Mao L. Application of Aptamers in Virus Detection and Antiviral Therapy. Front Microbiol. 2019 July 3;10:1462. doi: 10.3389/fmicb.2019.01462.

https://www.ncbi.nlm.nih.gov/pmc/articles/PMC6618307/pdf/fmicb-10-01462.pdf

${ }^{87}$ Ahn DG, Jeon IJ, Kim JD, et al. RNA aptamer-based sensitive detection of SARS coronavirus nucleocapsid protein. Analyst. 2009;134(9):1896-1901. doi:10.1039/b906788d https://pubs.rsc.org/en/content/articlepdf/2009/an/b906788d

${ }^{88}$ Wyllie, Anne L., et al. Saliva or Nasopharyngeal Swab Specimens for Detection of SARS-CoV-2. New England J of Medicine, Aug 2020, p. NEJMc2016359 doi:10.1056/NEJMc2016359 https://www.nejm.org/doi/pdf/10.1056/NEJMc2016359 https://science.sciencemag.org/content/369/6507/1041/tab-pdf ${ }^{89}$ Shubham, Shambhavi, "Selection of functional RNA aptamers against Ebola glycoproteins" (2017). Graduate Theses and Dissertations. Iowa State University. https://lib.dr.iastate.edu/etd/16528 ${ }^{90}$ Eichel, H. J., et al. "Acid and Alkaline Ribonucleases of Human Parotid, Submaxillary, and Whole Saliva.” Arch of Biochemistry and Biophysics, vol. 107, no. 2, August. 1964, pp. 197-208 doi:10.1016/0003-9861(64)90322-4

${ }^{91}$ Cho SJ, Woo HM, Kim KS, Oh JW, Jeong YJ. Novel system for detecting SARS coronavirus nucleocapsid protein using an ssDNA aptamer. J Biosci Bioeng. 2011 Dec; 112(6):535-40. doi: 10.1016/j.jbiosc.2011.08.014. www.ncbi.nlm.nih.gov/pmc/articles/PMC7106535/pdf/main.pdf ${ }^{92}$ Chen Z, Wu Q, Chen J, Ni X, Dai J. DNA Aptamer Based Method for Detection of SARS-CoV-2 Nucleocapsid Protein. Virol Sin. 2020 June; 35(3):351-354. doi: 10.1007/s12250-020-00236-z. Epub 2020 May 25. www.ncbi.nlm.nih.gov/pmc/articles/PMC7246297/pdf/12250_2020_Article_236.pdf ${ }_{93}$ Nucleocapsid Phosphoprotein: Severe Acute Respiratory Syndrome Coronav - Protein - NCBI. https://www.ncbi.nlm.nih.gov/protein/YP_009724397.2

${ }^{94}$ Nucleocapsid Protein: Severe Acute Respiratory Syndrome-Related Corona - Protein - NCBI. https://www.ncbi.nlm.nih.gov/protein/NP_828858.1 ${ }^{95}$ Zhang, Liyun, et al. "Discovery of Sandwich Type COVID-19 Nucleocapsid Protein DNA Aptamers.” Chem Communications, vol. 56, no. 70, 2020, pp. 10235-10238. doi:10.1039/DoCC03993D. https://pubs-rsc-org.libproxy.mit.edu/en/content/articlepdf/2020/cc/d0cc03993d

${ }^{96} \mathrm{Li}, \mathrm{Hui}-Y a n$, et al. Advances in Detection of Infectious Agents by Aptamer-Based Technologies. Emerging Microbes \& Infections, vol. 9, no. 1, January 2020, pp. 1671-1681.

doi:10.1080/22221751.2020.1792352. https://www.tandfonline.com/doi/pdf/10.1080/22221751.2020.1792352?needAccess=true ${ }^{97}$ Lucia Wang and Maureen McKeague (2020) Aptamers in the pursuit of COVID-19 management. Aptamers (2020), Vol 4, in press. http://japtamers.co.uk/wp-content/uploads/2020/07/Wang.pdf 
${ }^{98}$ https://www.aptamergroup.co.uk/aptamers-in-the-battle-against-covid19/

${ }^{99}$ Cleri, Fabrizio, Lensink, Marc F., Blossey, Ralf (2020): DNA Aptamers Block the Receptor Binding Domain at the Spike Protein of SARS-CoV-2. ChemRxiv. Preprint.

https://doi.org/10.26434/chemrxiv.12696173.v1 https://chemrxiv.org/ndownloader/files/24042815 ${ }^{100}$ NSF Award Abstract \#2028531(RAPID) Severe Acute Respiratory Syndrome Coronavirus 2 (SARSCoV-2)-Prevention: Multiple-Site Binding with Fusing Aptamers to mitigate Coronavirus Disease 2019. https://www.nsf.gov/awardsearch/showAward?AWD_ID=2028531\&HistoricalAwards=false ${ }^{101}$ Song, Yanling, et al. "Discovery of Aptamers Targeting the Receptor-Binding Domain of the SARSCoV-2 Spike Glycoprotein.” Analytical Chemistry, vol. 92, no. 14, July 2020, pp. 9895-900. doi:10.1021/acs.analchem.0c01394. https://pubs.acs.org/doi/pdf/10.1021/acs.analchem.0c01394 ${ }^{102}$ Bojkova, D., Klann, K., Koch, B. et al. Proteomics of SARS-CoV-2-infected host cells reveals therapy targets. Nature 583, 469-472 (2020). https://doi.org/10.1038/s41586-020-2332-7 https://www.nature.com/articles/s41586-020-2332-7.pdf ${ }^{103} \mathrm{Wu}$, Canrong, et al. "Analysis of Therapeutic Targets for SARS-CoV-2 and Discovery of Potential Drugs by Computational Methods.” Acta Pharmaceutica Sinica B, vol. 10, no. 5, May 2020, pp. 766-788. doi:10.1016/j.apsb.2020.02.008. https://www.sciencedirect.com/science/article/pii/\$2211383520302999 ${ }^{104}$ Thoms, Matthias, et al. "Structural Basis for Translational Shutdown and Immune Evasion by the Nsp1 Protein of SARS-CoV-2." Science, vol. 369, no. 6508, September 2020, pp. 1249-55. doi:10.1126/science.abc8665. https://science.sciencemag.org/content/369/6508/1249.full.pdf ${ }^{105}$ Rong, Y., et al. "Post Hoc Support Vector Machine Learning for Impedimetric Biosensors Based on Weak Protein-Ligand Interactions.” The Analyst, vol. 143, no. 9, 2018, pp. 2066-2075. doi:10.1039/C8AN00065D https://pubs.rsc.org/ko/content/getauthorversionpdf/C8AN00065D ${ }^{106}$ Choi, Jong Hyun, et al. "Aptamer-Capped Nanocrystal Quantum Dots: A New Method for Label-Free Protein Detection." J of the American Chemical Society, vol. 128, no. 49, December 2006, pp. 15584-85. doi:10.1021/ja066506k.

${ }^{107}$ Smith, Andrew M., et al. "Quantum Dot Nanocrystals for In Vivo Molecular and Cellular Imaging." Photochemistry \& Photobiology, vol. 80, no. 3, 2004, p. 377. doi:10.1562/2004-06-21-IR-209.1 ${ }^{108}$ Bagalkot, Vaishali, et al. "Quantum Dot-Aptamer Conjugates for Synchronous Cancer Imaging, Therapy, and Sensing of Drug Delivery Based on Bi-Fluorescence Resonance Energy Transfer." Nano Letters, vol. 7, no. 10, October 2007, pp. 3065-3070. doi:10.1021/nl071546n.

${ }^{109} \mathrm{Li}$, Zhiming, et al. "Aptamer-Conjugated Dendrimer-Modified Quantum Dots for Glioblastoma Cells Imaging.” J of Physics: Conference Series, vol. 188, September 2009, p. 012032. doi:10.1088/1742-6596/188/1/012032.

${ }^{110}$ Roberts, Kenneth and Bumm Lloyd, A. (2010) Quantum Dot Nano-crystals Coupled to DNA Aptamers: Sensors for Biological Weapons Detection https://apps.dtic.mil/dtic/tr/fulltext/u2/a567156.pdf ${ }^{111}$ Zhou, DJ (2012) Quantum dot-nucleic acid/aptamer bioconjugate based fluorimetric biosensors. Biochemical Society Transactions 40635 - 639 ISSN 0300-5127 https://doi.org/10.1042/BST20120059 
${ }^{112}$ https://www.microsoft.com/en-us/hololens/hardware

${ }^{113} \mathrm{https} / / \mathrm{www}$.denso-wave.com/en/technology/vol1.html

${ }^{114}$ https://en.wikipedia.org/wiki/Kinect

${ }^{115}$ Carlo Tomasi and Takeo Kanade (1992) Shape and Motion from Image Streams under Orthography:

Factorization Method. International Journal of Computer Vision 9:2, 137-154

https://people.eecs.berkeley.edu/ yang/courses/cs294-

6/papers/TomasiC_Shape\%20and\%20motion\%20from\%20image\%20streams\%20under\%20orthograph y.pdf

${ }^{116} \mathrm{https} / / /$ www.microsoft.com/en-us/research/blog/in-search-for-future-of-cloud-storage-researcherslook-to-holographic-storage-solutions/

${ }^{117}$ https://emclamor.wixsite.com/mclamorelab

${ }^{118}$ Philip Levis, Sam Madden, David Gay, Joseph Polastre, Robert Szewczyk, Alec Woo, Eric Brewer and David Culler (2003) The Emergence of Networking Abstractions and Techniques in TinyOS www.usenix.org/legacy/events/nsdi04/tech/full_papers/levisEmerge/levisEmerge_html/tinyosnsdi03.html

${ }^{119}$ McLamore, E.S., S.P.A. Datta, V. Morgan, N. Cavallaro, G. Kiker, D.M. Jenkins, Y. Rong, C. Gomes, J. Claussen, D. Vanegas, E.C. Alocilja (2019) SNAPS: Sensor Analytics Point Solutions for Detection and Decision Support. Sensors, vol. 19, no. 22, November 2019, p. 4935 www.mdpi.com/1424-8220/19/22/4935/pdf and https://dspace.mit.edu/handle/1721.1/123983 ${ }^{120}$ Walker, Bruce (2020) MIT Biology course number 7.00 (COVID-19, SARS-CoV-2 and the Pandemic) https://biology.mit.edu/undergraduate/current-students/subject-offerings/covid-19-sars-cov-2-and-thepandemic/ and https://biology.mit.edu/wp-content/uploads/2020/09/7.00_Syllabus_9.8.20.pdf ${ }^{121}$ Jack-in-the-Box https://en.wikipedia.org/wiki/Jack-in-the-box ${ }^{122}$ Walls, Alexandra C., et al. "Structure, Function, and Antigenicity of the SARS-CoV-2 Spike Glycoprotein.” Cell, vol. 181, no. 2, April 2020, pp. 281-292.e6. doi:10.1016/j.cell.2020.02.058 https://www.cell.com/cell/pdf/S0092-8674(20)30262-2.pdf

${ }^{123}$ Ellen Shrock, Eric Fujimura, Tomasz Kula, Richard T. Timms, I-Hsiu Lee, Yumei Leng, Matthew L. Robinson, Brandon M. Sie, Mamie Z. Li, Yuezhou Chen, Jennifer Logue, Adam Zuiani, Denise Mcculloch, Felipe J. N. Lelis, Stephanie Henson, Daniel E. Monaco, Meghan Travers, Shaghayegh Habibi, William A. Clarke, Patrizio Caturegli, Oliver Laeyendecker, Alicja Piechocka-Trocha, Jon Li, Ashok Khatri, Helen Y. Chu, MGH COVID-19 Collection \& Processing Team, Alexandra-Chloé Villani, Kyle Kays, Marcia B. Goldberg, Nir Hacohen, Michael R. Filbin, Xu G. Yu, Bruce D. Walker, Duane R. Wesemann, H. Benjamin Larman, James A. Lederer, and Stephen J. Elledge (2020) Viral epitope profiling of covid-19 patients reveals cross-reactivity and correlates of severity. Published online 29 sep 2020. Science doi: 10.1126/science.abd4250 https://science.sciencemag.org/content/early/2020/09/28/science.abd4250/tab-pdf ${ }^{124}$ McKee DL, Sternberg A, Stange U, Laufer S, Naujokat C. Candidate drugs against SARS-CoV-2 and COVID-19. Pharmacol Res. 2020 July; 157:104859. doi: 10.1016/j.phrs.2020.104859. Epub 2020 April 29. https://www.ncbi.nlm.nih.gov/pmc/articles/PMC7189851/pdf/main.pdf 
${ }^{125}$ Mark Fischetti, Veronica Falconieri Hays, Britt Glaunsinger and Jen Christiansen (2020) Inside the Coronavirus. Scientific American 323, 1, 32-37 (July 1, 2020) doi:10.1038/scientificamerican0720-32 A Visual Guide to the SARS-CoV-2 Coronavirus: What scientists know about the inner workings of the pathogen that has infected the world. July 1, 2020. Scientific American.

https://www.scientificamerican.com/article/a-visual-guide-to-the-sars-cov-2-coronavirus/ \& https://www.scientificamerican.com/interactive/inside-the-coronavirus/ ${ }^{126}$ Glaunsinger, Britt (2020) MIT Biology course 7.00 (COVID-19, SARS-CoV-2 and the Pandemic) https://biology.mit.edu/undergraduate/current-students/subject-offerings/covid-19-sars-cov-2-and-thepandemic/ and https://biology.mit.edu/wp-content/uploads/2020/09/7.00_Syllabus_9.8.20.pdf ${ }^{127}$ Jia HP, Look DC, Shi L, Hickey M, Pewe L, Netland J, Farzan M, Wohlford-Lenane C, Perlman S, McCray PB Jr. ACE2 receptor expression and severe acute respiratory syndrome coronavirus infection depend on differentiation of human airway epithelia. J Virol. 2005 December; 79(23):14614-14621. doi: 10.1128/JVI.79.23.14614-14621.2005 www.ncbi.nlm.nih.gov/pmc/articles/PMC1287568/pdf/1240-05.pdf ${ }^{128}$ Saheb Sharif-Askari, Narjes, et al. "Airways Expression of SARS-CoV-2 Receptor, ACE2, and TMPRSS2 Is Lower in Children Than Adults and Increases with Smoking and COPD." Molecular Therapy - Methods \& Clin Development, vol. 18, Sept. 2020, pp. 1-6. doi:10.1016/j.omtm.2020.05.013 https://www.cell.com/molecular-therapy-family/methods/pdf/S2329-0501(20)30100-5.pdf ${ }^{129}$ Hilgenfeld R. From SARS to MERS: crystallographic studies on coronaviral proteases enable antiviral drug design. FEBS J. 2014; 281(18):4085-4096. doi:10.1111/febs.12936 https://www.ncbi.nlm.nih.gov/pmc/articles/PMC7163996/pdf/FEBS-281-4085.pdf ${ }^{130}$ Goodsell, D. S. “Coronavirus Proteases.” RCSB Protein Data Bank, February 2020. doi:10.2210/rcsb_pdb/mom_2020_2 https://pdb101.rcsb.org/motm/242 ${ }^{131}$ Barretto, Naina, et al. “The Papain-Like Protease of Severe Acute Respiratory Syndrome Coronavirus Has Deubiquitinating Activity.” Journal of Virology, vol. 79, no. 24, December 2005, pp. 15189-15198. doi:10.1128/JVI.79.24.15189-15198.2005 https://jvi.asm.org/content/jvi/79/24/15189.full.pdf ${ }^{132}$ Boras, Britton, et al. Discovery of a Novel Inhibitor of Coronavirus 3CL Protease as a Clinical Candidate for the Potential Treatment of COVID-19. preprint, Pharmacology and Toxicology, 13 September 2020. doi:10.1101/2020.09.12.293498 https://www.biorxiv.org/content/10.1101/2020.09.12.293498v2.full.pdf ${ }^{133}$ Xue, Xiaoyu, et al. "Structures of Two Coronavirus Main Proteases: Implications for Substrate Binding and Antiviral Drug Design." Journal of Virology, vol. 82, no. 5, March 2008, pp. 2515-2527. doi:10.1128/JVI.02114-07 https://jvi.asm.org/content/jvi/82/5/2515.full.pdf ${ }^{134}$ Tahir ul Qamar, Muhammad, et al. "Structural Basis of SARS-CoV-2 3CLpro and Anti-COVID-19 Drug Discovery from Medicinal Plants." Journal of Pharmaceutical Analysis, vol. 10, no. 4, Aug. 2020, pp. 313-319. doi:10.1016/j.jpha.2020.03.009 https://www.sciencedirect.com/science/article/pii/S2095177920301271 
${ }^{135}$ Rathnayake, Athri D., et al. “3C-like Protease Inhibitors Block Coronavirus Replication in Vitro and Improve Survival in MERS-CoV Infected Mice." Sci Trans Med, vol. 12, no. 557, Aug. 2020, p. eabc5332. doi:10.1126/scitranslmed.abc5332 https://stm.sciencemag.org/content/12/557/eabc5332/tab-pdf ${ }^{136}$ Zhang, Linlin, et al. "Crystal Structure of SARS-CoV-2 Main Protease Provides a Basis for Design of Improved $\alpha$-Ketoamide Inhibitors.” Science, March 2020, p. eabb3405. doi:10.1126/science.abb3405 https://science.sciencemag.org/content/368/6489/409/tab-pdf

${ }^{137}$ Báez-Santos YM, Barraza SJ, Wilson MW, Agius MP, Mielech AM, Davis NM, Baker SC, Larsen SD, Mesecar AD. (2014) X-ray structural and biological evaluation of a series of potent and highly selective inhibitors of human coronavirus papain-like proteases. J Med Chem. 2014 March 27; 57(6):2393-412. doi: 10.1021/jm401712t. Epub 2014 March 14. https://www.ncbi.nlm.nih.gov/pmc/articles/PMC3983375/pdf/jm401712t.pdf ${ }^{138}$ Rut, Wioletta, et al. Activity Profiling and Structures of Inhibitor-Bound SARS-CoV-2-PLpro Protease Provides a Framework for Anti-COVID-19 Drug Design. preprint, Biochemistry, 29 April 2020. doi:10.1101/2020.04.29.068890 https://www.biorxiv.org/content/biorxiv/early/2020/04/29/2020.04.29.068890.full.pdf ${ }^{139}$ Shin, D., Mukherjee, R., Grewe, D. et al. Papain-like protease regulates SARS-CoV-2 viral spread and innate immunity. Nature (2020). https://doi.org/10.1038/s41586-020-2601-5 https://www.nature.com/articles/s41586-020-2601-5_reference.pdf ${ }^{140}$ Thoms, Matthias, et al. "Structural Basis for Translational Shutdown and Immune Evasion by the Nsp1 Protein of SARS-CoV-2.” Science, vol. 369, no. 6508, September 2020, pp. 1249-55. doi:10.1126/science.abc8665 https://science.sciencemag.org/content/369/6508/1249.full.pdf ${ }^{141}$ Kamitani W, Huang C, Narayanan K, Lokugamage KG, Makino S. (2009) A two-pronged strategy to suppress host protein synthesis by SARS coronavirus Nsp1 protein. Nat Struct Mol Biol. 2009 November; 16(11):1134-40. doi: 10.1038/nsmb.1680. Epub 2009 October 18.

https://www.ncbi.nlm.nih.gov/pmc/articles/PMC2784181/pdf/41594_2009_Article_BFnsmb1680.pdf ${ }^{142}$ Lapointe, Christopher P., et al. Dynamic Competition between SARS-CoV-2 NSP1 and MRNA on the Human Ribosome Inhibits Translation Initiation. preprint, Biophysics, 21 August 2020.

doi:10.1101/2020.08.20.259770 https://www.biorxiv.org/content/10.1101/2020.08.20.259770v1.full.pdf ${ }^{143}$ Schubert, K., Karousis, E.D., Jomaa, A. et al. SARS-CoV-2 Nsp1 binds the ribosomal mRNA channel to inhibit translation. Nat Struct Mol Biol (2020). https://doi.org/10.1038/s41594-020-0511-8 https://www.nature.com/articles/s41594-020-0511-8.pdf ${ }^{144}$ Lee, J.S., Shin, E. The type I interferon response in COVID-19: implications for treatment. Nature Review of Immunology 20, 585-586 (2020). https://doi.org/10.1038/s41577-020-00429-3 https://www.nature.com/articles/s41577-020-00429-3.pdf ${ }^{145}$ Zhang, Qian, et al. “Inborn Errors of Type I IFN Immunity in Patients with Life-Threatening COVID-19.” Science, September 24, 2020, p. eabd4570. doi:10.1126/science.abd4570 https://science.sciencemag.org/content/early/2020/09/23/science.abd4570/tab-pdf 
${ }^{146}$ Hadjadj, Jérôme, et al. "Impaired Type I Interferon Activity and Inflammatory Responses in Severe COVID-19 Patients.” Science, vol. 369, no. 6504, August 7, 2020, pp. 718-724.

doi:10.1126/science.abc6027 https://science.sciencemag.org/content/369/6504/718/tab-pdf

${ }^{147}$ Xia, H., Cao, Z., Xie, X., Zhang, X., Yun-Chung Chen, J., Wang, H., Menachery, V.D., Rajsbaum, R., Shi, P.-Y. (2020) Evasion of type-I interferon by SARS-CoV-2. Cell Reports (2020).

https://doi.org/10.1016/j.celrep.2020.108234

https://www.cell.com/action/showPdf?pii=S2211-1247\%2820\%2931223-7

${ }^{148}$ Ella Hartenian, Divya Nandakumar, Azra Lari, Michael Ly, Jessica M Tucker and Britt A Glaunsinger.

“The Molecular Virology of Coronaviruses.” J of Biol Chem, vol. 295, no. 37, September 2020, pp.

12910-12934. https://www.jbc.org/cgi/doi/10.1074/jbc.REV120.013930

https://www.jbc.org/content/early/2020/07/13/jbc.REV120.013930.full.pdf

${ }^{149}$ Eckerle LD, Becker MM, Halpin RA, Li K, Venter E, Lu X, Scherbakova S, Graham RL, Baric RS, Stockwell TB, Spiro DJ, Denison MR. (2010) Infidelity of SARS-CoV Nsp14-exonuclease mutant virus replication is revealed by complete genome sequencing. PLoS Pathog. 2010 May 6; 6(5):e1000896. doi: 10.1371/journal.ppat.1000896 www.ncbi.nlm.nih.gov/pmc/articles/PMC2865531/pdf/ppat.1000896.pdf ${ }^{150}$ Streisinger G, Okada Y, Emrich J, et al. (1966) Frameshift mutations and the genetic code. This paper is dedicated to Professor Theodosius Dobzhansky on the occasion of his 66th birthday. Cold Spring Harb Symp Quant Biol. 1966; 31:77-84. doi:10.1101/sqb.1966.031.01.014

http://symposium.cshlp.org/content/31/77.long

${ }^{151}$ Reddy, E. P., et al. A point mutation is responsible for the acquisition of transforming properties by the T24 human bladder carcinoma oncogene. Nature 300, 149-152 (1982)

${ }^{152}$ Ou X, Zheng W, Shan Y, Mu Z, Dominguez SR, Holmes KV, Qian Z. (2016) Identification of the Fusion Peptide-Containing Region in Betacoronavirus Spike Glycoproteins. J Virol. 2016 May 27; 90(12):5586-5600. doi: 10.1128/JVI.00015-16 https://www.ncbi.nlm.nih.gov/pmc/articles/PMC4886789/pdf/zjv5586.pdf

${ }^{153} \mathrm{Xu}$, Yanhui, et al. "Crystal Structure of Severe Acute Respiratory Syndrome Coronavirus Spike Protein Fusion Core.” Journal of Biological Chemistry, vol. 279, no. 47, November 2004, pp. 49414-419. doi:10.1074/jbc.M408782200 https://www.jbc.org/content/279/47/49414.full.pdf

${ }^{154}$ Madu IG, Roth SL, Belouzard S, Whittaker GR. (2009) Characterization of a highly conserved domain within the severe acute respiratory syndrome coronavirus spike protein S2 domain with characteristics of a viral fusion peptide. J Virol. 2009 August; 83(15):7411-21. doi: 10.1128/JVI.00079-09. Epub 2009 May 13 https://www.ncbi.nlm.nih.gov/pmc/articles/PMC2708636/pdf/0079-09.pdf

${ }^{155}$ Tang T, Bidon M, Jaimes JA, Whittaker GR, Daniel S. (2020) Coronavirus membrane fusion mechanism offers a potential target for antiviral development. Antiviral Res. 2020 June; 178:104792.

doi: 10.1016/j.antiviral.2020.104792. Epub 2020 April 6.

https://www.ncbi.nlm.nih.gov/pmc/articles/PMC7194977/pdf/main.pdf

${ }^{156}$ Pattnaik GP, Chakraborty H. Entry Inhibitors: Efficient Means to Block Viral Infection. J Membrane Biology. 2020 August 30: 1-20. doi: 10.1007/s00232-020-00136-Z https://www.ncbi.nlm.nih.gov/pmc/articles/PMC7456447/pdf/232_2020_Article_136.pdf 
${ }^{157}$ Bosch BJ, Martina BE, Van Der Zee R, Lepault J, Haijema BJ, Versluis C, Heck AJ, De Groot R, Osterhaus AD, Rottier PJ. (2004) Severe acute respiratory syndrome coronavirus (SARS-CoV) infection inhibition using spike protein heptad repeat-derived peptides. Proc Natl Acad Sci U S A. 2004 June 1; 101(22):8455-60. doi: 10.1073/pnas.0400576101. Epub 2004 May 18. https://www.ncbi.nlm.nih.gov/pmc/articles/PMC420415/pdf/1018455.pdf ${ }^{158}$ Leila Kashefi-Kheyrabadi, Junmoo Kim, Sudesna Chakravarty, Sunyoung Park, Hogyeong Gwak, Seung-Il Kim, Mohsen Mohammadniaei, Min-Ho Lee, Kyung-A Hyun and Hyo-Il Jung (2020) Detachable microfluidic device implemented with electrochemical aptasensor (DeMEA) for sequential analysis of cancerous exosomes. Biosensors \& Bioelectronics ( IF 10.257 ) Published September 17, 2020. DOI: $10.1016 /$ j.bios.2020.112622

${ }^{159}$ Contreras-Naranjo JC, Wu HJ, Ugaz VM. (2017) Microfluidics for exosome isolation and analysis: enabling liquid biopsy for personalized medicine. Lab Chip. 2017 October 25; 17(21):3558-3577. doi: 10.1039/c7lc00592j www.ncbi.nlm.nih.gov/pmc/articles/PMC5656537/pdf/nihms903616.pdf ${ }^{160}$ Economics of Technology (Collected Papers) http://bit.ly/Economics-of-Technology ${ }^{161}$ Brat, Gabriel A., et al. "International Electronic Health Record-Derived COVID-19 Clinical Course Profiles: The 4CE Consortium.” Npj Digital Medicine, vol. 3, no. 1, December. 2020, p. 109. doi:10.1038/s41746-020-00308-0 https://www.nature.com/articles/s41746-020-00308-0.pdf ${ }^{162}$ Tromberg BJ, Schwetz TA, Pérez-Stable EJ, et al. Rapid Scaling Up of Covid-19 Diagnostic Testing in the United States - The NIH RADx Initiative. N Engl J Med. September 10, 2020; 383(11):1071-1077. doi:10.1056/NEJMsr2022263 www.nejm.org/doi/pdf/10.1056/NEJMsr2022263?articleTools=true ${ }^{163}$ Yan, Li-Meng, et al. Unusual Features of the SARS-CoV-2 Genome Suggesting Sophisticated Laboratory Modification Rather Than Natural Evolution and Delineation of Its Probable Synthetic Route. Sept. 2020. doi:10.5281/ZENODO.4028830 https://zenodo.org/record/4028830/files/The_Yan_Report.pdf?download=1 ${ }^{164}$ Mariana Guadalupe Matus García (2018) Analysis of fecal biomarkers to impact clinical care and public health. Thesis: Ph. D., Massachusetts Institute of Technology, Computational and Systems Biology Program, 2018. MIT Library https://dspace.mit.edu/handle/1721.1/119603 ${ }^{165}$ Polo, David, et al. "Making Waves: Wastewater-Based Epidemiology for COVID-19 - Approaches and Challenges for Surveillance and Prediction." Water Research, vol. 186, November 2020, p. 116404. doi:10.1016/j.watres.2020.116404 www.ncbi.nlm.nih.gov/pmc/articles/PMC7480445/pdf/main.pdf ${ }^{166}$ Duvallet C, Hayes BD, Erickson TB, Chai PR, Matus M. (2020) Mapping Community Opioid Exposure Through Wastewater-Based Epidemiology as a Means to Engage Pharmacies in Harm Reduction Efforts. Prevention of Chronic Diseases 2020; 17:200053. DOI: http://dx.doi.org/10.5888/pcd17.200053 ${ }^{167}$ Leonard, Maureen, et al. (2020) "Multi-Omics Analysis Reveals the Influence of Genetic and Environmental Risk Factors on Developing Gut Microbiota in Infants at Risk of Celiac Disease.” Microbiome, vol. 8, no. 1, December 2020, p. 130. doi:10.1186/s40168-020-00906-w ${ }^{168}$ Lee, J., Hyeon, D.Y. and Hwang, D. (2020) Single-cell multiomics: technologies and data analysis methods. Exp Mol Med (2020). https://doi.org/10.1038/s12276-020-0420-2 \& www.nature.com/articles/s12276-020-0420-2.pdf 
${ }^{169}$ Foy BH, Carlson JCT, Reinertsen E, et al. Association of Red Blood Cell Distribution Width (RDW) With Mortality Risk in Hospitalized Adults With SARS-CoV-2 Infection. JAMA Network Open 2020; 3(9):e2022058. doi:10.1001/jamanetworkopen.2020.22058

https://jamanetwork.com/journals/jamanetworkopen/fullarticle/2770945

${ }^{170}$ Mackul'ak, Tomáš, et al. "Music Festivals and Drugs: Wastewater Analysis." Science of The Total Environment, vol. 659, April 2019, pp. 326-334. doi:10.1016/j.scitotenv.2018.12.275

${ }^{171}$ Castiglioni, S. and Vandam, L. (2016) A global overview of wastewater-based epidemiology. pp. 45-54 in "Assessing illicit drugs in wastewater: advances in wastewater-based drug epidemiology" EMCDDA Insights 22 (EU). www.emcdda.europa.eu/system/files/publications/2273/TDXD16022ENC_4.pdf ${ }^{172}$ EMCDDA (European Monitoring Centre for Drugs and Drug Addiction) (2020) PERSPECTIVES ON DRUGS: Wastewater analysis and drugs: results from a European multi-city study. EU Publications Office www.emcdda.europa.eu/system/files/publications/2757/POD_Wastewater\%20analysis_update2020.pdf ${ }^{173}$ Gina Pocock, Leanne Coetzee, Janet Mans, Maureen Taylor and Bettina Genthe (2020) PROOF OF CONCEPT STUDY: Application of wastewater-based surveillance to monitor SARS-CoV-2 prevalence in South African communities. Report to the Water Research Commission WRC Report no. TT 832/20 ISBN 978-0-6392-0187-0 (September 2020) Water Research Commission, South Africa www.wrc.org.za http://wrcwebsite.azurewebsites.net/wp-content/uploads/mdocs/TT\%20832-20\%20final\%20web.pdf ${ }^{174}$ Delaney SK, Hultner ML, Jacob HJ, Ledbetter DH, McCarthy JJ, Ball M, Beckman KB, Belmont JW, Bloss CS, Christman MF, Cosgrove A, Damiani SA, Danis T, Delledonne M, Dougherty MJ, Dudley JT, Faucett WA, Friedman JR, Haase DH, Hays TS, Heilsberg S, Huber J, Kaminsky L, Ledbetter N, Lee WH, Levin E, Libiger O, Linderman M, Love RL, Magnus DC, Martland A, McClure SL, Megill SE, Messier H, Nussbaum RL, Palaniappan L, Patay BA, Popovich BW, Quackenbush J, Savant MJ, Su MM, Terry SF, Tucker S, Wong WT, Green RC. (2016) Toward clinical genomics in everyday medicine: perspectives and recommendations. Expert Rev Mol Diagn. 2016; 16(5):521-532. doi: 10.1586/14737159.2016.1146593.

Epub 2016 February 24. https://www.ncbi.nlm.nih.gov/pmc/articles/PMC4841021/pdf/iero-16-521.pdf ${ }^{175}$ http://www.opengroup.org/iot/odf/

${ }^{176}$ Perron, Paul. “Relire Le Fou d'Elsa de Louis Aragon.” Études Littéraires, vol. 28, no. 1, April 2005, pp. 69-82. doi:10.7202/501111ar.

${ }^{177}$ Stephens DS, McElrath MJ. COVID-19 and the Path to Immunity. JAMA. Published online September 11, 2020. doi:10.1001/jama.2020.16656

${ }^{178}$ Korber, B., et al. Spike Mutation Pipeline Reveals the Emergence of a More Transmissible Form of SARS-CoV-2. preprint, Evolutionary Biology, 30 April 2020. doi:10.1101/2020.04.29.069054 https://www.biorxiv.org/content/10.1101/2020.04.29.069054v2.full.pdf 
${ }^{179}$ Jerald Sadoff, Mathieu Le Gars, Georgi Shukarev, Dirk Heerwegh, Carla Truyers, Anne Marit de Groot, Jeroen Stoop, Sarah Tete, Wim Van Damme, Isabel Leroux-Roels, Pieter-Jan Berghmans, Murray Kimmel, Pierre Van Damme, Jan de Hoon, Williams Smith, Kathryn E. Stephenson, Dan H. Barouch, Stephen C. De Rosa, Kristen W. Cohen, M. Juliana McElrath, Emmanuel Cormier, Gert Scheper, Jenny Hendriks, Frank Struyf, Macaya Douoguih, Johan Van Hoof, and Hanneke Schuitemaker (2020) Safety and Immunogenicity of the Ad26.COV2.S COVID-19 Vaccine Candidate: Interim Results of a Phase 1/2a, Double-Blind, Randomized, Placebo-Controlled Trial. preprint, Infectious Diseases (except HIV/AIDS), 25 September 2020. doi:10.1101/2020.09.23.20199604

https://www.medrxiv.org/content/10.1101/2020.09.23.20199604v1.full.pdf

${ }^{180}$ Logunov, D. Y. et al (2020) Safety and immunogenicity of an rAd26 and rAd5 vector-based heterologous prime-boost COVID-19 vaccine in two formulations: two open, non-randomised phase 1/2 studies from Russia. Lancet 2020; 396: 887-897. Published Online September 4, 2020. https://www.thelancet.com/action/showPdf?pii=S0140-6736\%2820\%2931866-3 ${ }^{181}$ Chadi M. Saad-Roy, Caroline E. Wagner, Rachel E. Baker, Sinead E. Morris, Jeremy Farrar, Andrea 1. Graham, Simon A. Levin, Michael J. Mina, C. Jessica E. Metcalf, and Bryan T. Grenfell (2020) Immune life history, vaccination, and the dynamics of SARS-CoV-2 over the next 5 years. Published 21 Sep 2020 doi:10.1126/science.abd7343 https://science.sciencemag.org/content/early/2020/09/18/science.abd7343 https://science.sciencemag.org/content/early/2020/09/18/science.abd7343/tab-pdf ${ }^{182}$ Neilan, A. M. et al (2020) Clinical Impact, Costs, and Cost-Effectiveness of Expanded SARS-CoV-2 Testing in Massachusetts. Clinical Infectious Diseases https://doi.org/10.1093/cid/ciaa1418 ${ }^{183}$ The Global HIV/AIDS Epidemic https://www.kff.org/global-health-policy/fact-sheet/the-global-hivaids-epidemic/\#footnote-475993-1 ${ }^{184}$ Corey L, Mascola JR, Fauci AS, Collins FS. A strategic approach to COVID-19 vaccine R\&D. Science. 2020 May 29; 368(6494):948-950. doi: 10.1126/science.abc5312. Epub 2020 May 11.

https://science.sciencemag.org/content/368/6494/948/tab-pdf

${ }^{185}$ Anderson E. J. et al and the mRNA-1273 Study Group*(2020) Safety and immunogenicity of SARSCoV-2 mRNA1273 vaccine in older adults. Published 29 Sep 2020 NEJM DOI: 10.1056/NEJMoa2028436 https://www.nejm.org/doi/pdf/10.1056/NEJMoa2028436?articleTools=true ${ }^{186}$ McLellan JS, Chen M, Joyce MG, Sastry M, Stewart-Jones GB, Yang Y, Zhang B, Chen L, Srivatsan S, Zheng A, Zhou T, Graepel KW, Kumar A, Moin S, Boyington JC, Chuang GY, Soto C, Baxa U, Bakker AQ, Spits H, Beaumont T, Zheng Z, Xia N, Ko SY, Todd JP, Rao S, Graham BS, Kwong PD. Structurebased design of a fusion glycoprotein vaccine for respiratory syncytial virus. Science. 2013 November 1; 342(6158):592-8. doi: 10.1126/science.1243283. Erratum in: Science. 2013 November 22;342(6161):931 ${ }^{187}$ Hsieh CL, Goldsmith JA, Schaub JM, DiVenere AM, Kuo HC, Javanmardi K, Le KC, Wrapp D, Lee AG, Liu Y, Chou CW, Byrne PO, Hjorth CK, Johnson NV, Ludes-Meyers J, Nguyen AW, Park J, Wang N, Amengor D, Maynard JA, Finkelstein IJ, McLellan JS. Structure-based Design of Prefusion-stabilized SARS-CoV-2 Spikes. bioRxiv. 2020 May 30:2020.05.30.125484. doi: 10.1101/2020.05.30.125484. Update: Science. 2020 July 23. 
${ }^{188}$ Anderson EJ, Rouphael NG, Widge AT, et al. Safety and immunogenicity of SARS-CoV-2 mRNA1273 vaccine in older adults. N Engl J Med. DOI: 10.1056/NEJMoa2028436 https://www.nejm.org/doi/suppl/10.1056/NEJMoa2028436/suppl_file/nejmoa2028436_protocol.pdf ${ }^{189}$ Our World in Data https://ourworldindata.org/grapher/daily-covid-cases-7-day?time $=2020-03-31$..latest ${ }^{190}$ Endalew AD, Faburay B, Wilson WC, Richt JA. Schmallenberg Disease-A Newly Emerged Culicoidesborne Viral Disease of Ruminants. Viruses. 2019 November 15; 11(11):1065. doi: 10.3390/v11111065 https://www.ncbi.nlm.nih.gov/pmc/articles/PMC6893508/pdf/viruses-11-01065.pdf ${ }^{191}$ Collins ÁB, Doherty ML, Barrett DJ, Mee JF. Schmallenberg virus: a systematic international literature review (2011-19) from an Irish perspective. Irish Vet J. 2019 Oct 9; 72:9. doi: 10.1186/s13620-019-0147-3. https://www.ncbi.nlm.nih.gov/pmc/articles/PMC6785879/pdf/13620_2019_Article_147.pdf

${ }^{192}$ Lechevalier H. Dmitri Iosifovich Ivanovski (1864-1920). Bacteriol Rev. 1972 June; 36(2):135-45. https://www.ncbi.nlm.nih.gov/pmc/articles/PMC408320/pdf/bactrev00200-0002.pdf ${ }^{193}$ Lustig, Alice and Levine, Arnold J. (1992) One hundred years of virology. J Virol. 1992 August; 66(8):4629-4631. doi: 10.1128/JVI.66.8.4629-4631.1992.

https://www.ncbi.nlm.nih.gov/pmc/articles/PMC241285/pdf/jvirolo0040-0015.pdf

${ }^{194}$ Fauci, Anthony (2020) MIT Biology course number 7.00 (COVID-19, SARS-CoV-2 and the Pandemic) https://biology.mit.edu/wp-content/uploads/2020/09/7.00_Syllabus_9.8.20.pdf and https://biology.mit.edu/undergraduate/current-students/subject-offerings/covid-19-sars-cov-2-and-thepandemicl

${ }^{195}$ Baltimore, David (2020) MIT Biology course number 7.00 (COVID-19, SARS-CoV-2 and the Pandemic) https://biology.mit.edu/undergraduate/current-students/subject-offerings/covid-19-sarscov-2-and-the-pandemicl and https://biology.mit.edu/wp-content/uploads/2020/09/7.00_Syllabus_9.8.20.pdf

${ }^{196}$ Baltimore, David. https://www.nobelprize.org/prizes/medicine/1975/baltimore/facts/

${ }^{197}$ Daly, James L., et al. "Neuropilin-1 Is a Host Factor for SARS-CoV-2 Infection.” Science, Oct 20, 2020. p. eabd3072. doi:10.1126/science.abd3072.

${ }^{198}$ Cantuti-Castelvetri, Ludovico, et al. "Neuropilin-1 Facilitates SARS-CoV-2 Cell Entry and Infectivity.” Science, October 20, 2020, p. eabd2985. doi:10.1126/science.abd2985.

199 Tufekci, Zeynep. “This Overlooked Variable Is the Key to the Pandemic.” The Atlantic, 30 Sept. 2020. https://www.theatlantic.com/health/archive/2020/09/k-overlooked-variable-driving-pandemic/616548/ ${ }^{200}$ Kai Kupferschmidt (2020) Why do some COVID-19 patients infect many others, whereas most don't spread the virus at all? Science. May 19, 2020. doi:10.1126/science.abc8931

${ }^{201}$ Thurner, Stefan, et al. Why Are Most COVID-19 Infection Curves Linear? preprint, Epidemiology, 24 May 2020. doi:10.1101/2020.05.22.20110403.

https://www.medrxiv.org/content/10.1101/2020.05.22.20110403v1.full.pdf ${ }^{202}$ Vilfredo Pareto, Cours d'conomie Politique Profess a l'Universit de Lausanne, Vol. I, 1896; Vol. II, 1897. https://pdfs.semanticscholar.org/ef82/dfe7boef7a88727636f5ad680a464e33e345.pdf 
${ }^{203}$ Zhang, Qian, et al. Inborn Errors of Type I IFN Immunity in Patients with Life-Threatening COVID19. Science, vol. 370, no. 6515, October 23, 2020, p. eabd4570. doi:10.1126/science.abd4570.

${ }^{204}$ Noah G. Schwartz, Anne C. Moorman, Anna Makaretz, Karen T. Chang, Victoria T. Chu, Christine M. Szablewski, Anna R. Yousaf, Marie M. Brown, Ailis Clyne, Amanda DellaGrotta, Jan Drobeniuc, Jacqueline Korpics, Adam Muir, Cherie Drenzek, Utpala Bandy, Hannah L. Kirking, Jacqueline E. Tate, Aron J. Hall, Tatiana M. Lanzieri and Rebekah J. Stewart (2020) Adolescent with COVID-19 as the Source of an Outbreak at a 3-Week Family Gathering — Four States, June-July 2020. CDC MMWR vol. 69, October 5, 2020. https://www.cdc.gov/mmwr/volumes/69/wr/pdfs/mm6940e2-H.pdf ${ }^{205}$ Peccia, J., Zulli, A., Brackney, D.E. et al. Measurement of SARS-CoV-2 RNA in wastewater tracks community infection dynamics. Nature Biotechnology 38, 1164-1167 (2020). https://doi.org/10.1038/s41587-020-0684-z and https://www.nature.com/articles/s41587-020-0684-z.pdf ${ }^{206}$ MIT begins testing wastewater to help detect Covid-19 on campus.

https://news.mit.edu/2020/testing-wastewater-covid-19-1002

${ }^{207}$ Gusella JF, Wexler NS, Conneally PM, Naylor SL, Anderson MA, Tanzi RE, Watkins PC, Ottina K, Wallace MR, Sakaguchi AY, et al. (1983) A polymorphic DNA marker genetically linked to Huntington's disease. Nature. 1983 November 17-23; 306(5940): 234-8. doi: 10.1038/306234a0

https://www.nature.com/articles/306234a0

${ }^{208}$ Mazini PS, Alves HV, Reis PG, Lopes AP, Sell AM, Santos-Rosa M, Visentainer JE, Rodrigues-Santos P. (2016) Gene Association with Leprosy: A Review of Published Data. Frontiers in Immunology. 2016 January 12; 6:658. doi: 10.3389/fimmu.2015.00658 www.ncbi.nlm.nih.gov/pmc/articles/PMC4709443/pdf/fimmu-06-00658.pdf ${ }^{209}$ Dallmann-Sauer M, Fava VM, Gzara C, Orlova M, Van Thuc N, Thai VH, et al. (2020) The complex pattern of genetic associations of leprosy with HLA class I and class II alleles can be reduced to four amino acid positions. PLoS Pathog 16(8): e1008818. https://doi.org/10.1371/journal.ppat.1008818 https://journals.plos.org/plospathogens/article/file?id=10.1371/journal.ppat.1008818\&type=printable ${ }^{210}$ Zeberg, H. and Pääbo, S. (2020) The major genetic risk factor for severe COVID-19 is inherited from Neanderthals. Nature (30 September 2020). https://doi.org/10.1038/s41586-020-2818-3 https://www.nature.com/articles/s41586-020-2818-3_reference.pdf ${ }^{211}$ Kenney AD, Dowdle JA, Bozzacco L, McMichael TM, St Gelais C, Panfil AR, Sun Y, Schlesinger LS, Anderson MZ, Green PL, López CB, Rosenberg BR, Wu L, Yount JS. Human Genetic Determinants of Viral Diseases. Annu Rev Genet. 2017 Nov 27; 51:241-263. doi: 10.1146/annurev-genet-120116-023425. Epub 2017 August 30. https://www.ncbi.nlm.nih.gov/pmc/articles/PMC6038703/pdf/nihms-978947.pdf ${ }^{212}$ Rubin R. Investigating Whether Blood Type Is Linked to COVID-19 Risk. JAMA. 2020 September 16. doi: 10.1001/jama.2020.16516. https://jamanetwork.com/journals/jama/fullarticle/2770889 ${ }^{213}$ Kaiser, Jocelyn. "How Sick Will the Coronavirus Make You? The Answer May Be in Your Genes." Science, March 27, 2020. doi:10.1126/science.abb9192 
${ }^{214}$ Liu, Y.-M., Xie, J., Chen, M.-M., Zhang, X., Cheng, X., Li, H., Zhou, F., Qin, J.- J., Lei, F., Chen, Z., Lin, L., Yang, C., Mao, W., Chen, G., Lu, H., Xia, X., Wang, D., Liao, X., Yang, J., Huang, X., Zhang, B.H., Yuan, Y., Cai, J., Zhang, X.-J., Wang, Y., Zhang, X., She, Z.-G., Li, H., Kidney function indicators predict adverse outcomes of COVID-19. Med (2020). https://www.cell.com/med/pdf/S2666-6340(20)30017-9.pdf ${ }^{215}$ Janardhan, Vallabh, et al. "COVID-19 as a Blood Clotting Disorder Masquerading as a Respiratory Illness: A Cerebrovascular Perspective and Therapeutic Implications for Stroke Thrombectomy.” J of Neuroimaging, vol. 30, no. 5, September 2020, pp. 555-561.

https://onlinelibrary.wiley.com/doi/epdf/10.1111/jon.12770

${ }^{216}$ Bastard, Paul, et al. Autoantibodies against Type I IFNs in Patients with Life-Threatening COVID-19. Science, vol. 370, no. 6515, October 23, 2020, p. eabd4585. doi:10.1126/science.abd4585.

${ }^{217}$ Torrente-Rodriguez, Rebeca et al., SARS-CoV-2 RapidPlex: A Graphene-Based Multiplexed Telemedicine Platform for Rapid and Low-Cost COVID-19 Diagnosis and Monitoring. Matter (Oct 1, 20) https://doi.org/10.1016/j.matt.2020.09.027; www.cell.com/matter/pdfExtended/S2590-2385(20)30553-1 ${ }^{218}$ Sanjay E. Sarma, Stephen A. Weis, Daniel W. Engels (2002) RFID Systems, Security and Privacy Implications. White Paper. MIT Auto ID Center. Published November 1, 2002. https://cocoa.ethz.ch/downloads/2014/06/None_MIT-AUTOID-WH-014.pdf ${ }^{219}$ Mark Roberti (2004) The 5-cent Challenge. RFID Journal. Published August 30, 2004. https://www.rfidjournal.com/the-5-cent-challenge ${ }^{220}$ Zhou, Lian, et al. Detection of SARS-CoV-2 in Exhaled Breath from COVID-19 Patients Ready for Hospital Discharge. preprint, Public and Global Health, 2 June 2020. doi:10.1101/2020.05.31.20115196. https://www.medrxiv.org/content/10.1101/2020.05.31.20115196v1.full.pdf ${ }^{221} \mathrm{Ma}$, Jianxin, et al. Exhaled Breath Is a Significant Source of SARS-CoV-2 Emission. preprint, Public and Global Health, 2 June 2020. doi:10.1101/2020.05.31.20115154.

https://www.medrxiv.org/content/10.1101/2020.05.31.20115154v1.full.pdf

${ }^{222}$ Emam, Shadi, et al. Verification of Gas Sensors to Detect Alzheimer's Disease Biomarkers with Diabetic Rats. ALZ, 2020. alz.confex.com, https://alz.confex.com/alz/20amsterdam/meetingapp.cgi/Paper/43611 https://www.wired.com/story/could-breathalyzers-make-covid-testing-quicker-and-easier ${ }^{223}$ Kybert, Nicholas, et al. "Exploring Ovarian Cancer Screening Using a Combined Sensor Approach: A Pilot Study.” AIP Advances, vol. 10, no. 3, March 2020, p. 035213. doi:10.1063/1.5144532 https://aip.scitation.org/doi/pdf/10.1063/1.5144532 ${ }^{224}$ Shan, Benjie, et al. "Multiplexed Nanomaterial-Based Sensor Array for Detection of COVID-19 in Exhaled Breath.” ACS Nano, vol. 14, no. 9, Sept. 2020, pp. 12125-32. ACS Publications, doi:10.1021/acsnano.0c05657. https://pubs.acs.org/doi/pdf/10.1021/acsnano.0c05657 ${ }^{225}$ Kahn N, Lavie O, Paz M, Segev Y, Haick H. (2015) Dynamic Nanoparticle-Based Flexible Sensors: Diagnosis of Ovarian Carcinoma from Exhaled Breath. Nano Lett. 2015 October14;15(10):7023-8. doi: 10.1021/acs.nanolett.5b03052. Epub 2015 Sep 11. https://pubs.acs.org/doi/pdf/10.1021/acs.nanolett.5b03052 
${ }^{226}$ Chandrapalan, S. et al (2020) Breath diagnostics in the era of SARS-CoV-2 - clinical and research arena. Journal of Breath Research 14042002 https://iopscience.iop.org/article/10.1088/1752-7163/ab924a/pdf ${ }^{227}$ Oliveira AD, Prats C, Espasa M, Zarzuela Serrat F, Montañola Sales C, Silgado A, Codina DL, Arruda ME, I Prat JG, Albuquerque J. (2017) The Malaria System MicroApp: A New, Mobile Device-Based Tool for Malaria Diagnosis. JMIR Research Protocols. 2017 April 25; 6(4):e70. doi: 10.2196/resprot.6758.

${ }^{228}$ Pirnstill CW, Coté GL. Malaria Diagnosis Using a Mobile Phone Polarized Microscope. Nature Science Reports 2015 Aug 25; 5:13368. doi: 10.1038/srep13368.

https://www.ncbi.nlm.nih.gov/pmc/articles/PMC4548194/pdf/srep13368.pdf

${ }^{229}$ SARS-CoV-2 (COVID-19) Detection Using the Breath Analizer TeraSystem https://clinicaltrials.gov/ct2/show/NCT04497610

${ }^{230}$ Parinaz Fozouni, Sungmin Son, María Díaz de León Derby, Gavin J. Knott, Carley N. Gray, Michael V. D’Ambrosio, Chunyu Zhao, Neil A. Switz, G. Renuka Kumar, Stephanie I. Stephens, Daniela Boehm, Chia-Lin Tsou, Jeffrey Shu, Abdul Bhuiya, Max Armstrong, Andrew Harris, Jeannette M. Osterloh, Anke Meyer-Franke, Charles Langelier, Katherine S. Pollard, Emily D. Crawford, Andreas S. Puschnik, Maira Phelps, Amy Kistler, Joseph L. DeRisi, Jennifer A. Doudna, Daniel A. Fletcher and Melanie Ott (2020) Direct detection of SARS-CoV-2 using CRISPR-Cas13a and a mobile phone. Published 30 Sep 2020 https://doi.org/10.1101/2020.09.28.20201947 https://www.medrxiv.org/content/10.1101/2020.09.28.20201947v1.full.pdf

${ }^{231}$ Rockefeller Foundation. National Covid-19 testing and tracing action plan. July 16, 2020. https://www-rockefellerfoundation-org.libproxy.mit.edu/wpcontent/uploads/2020/07/TheRockefellerFoundation_ExecutiveSummary_7_20.pdf 232 “The Nobel Prize in Chemistry 2020." https://www.nobelprize.org/uploads/2020/10/presschemistryprize2020.pdf \& https://www.nobelprize.org/prizes/chemistry/2020/press-release/ (10-7-2020) ${ }^{233}$ Service, R. New Test Detects Coronavirus in 5 Minutes. Science, 10-8-20. doi:10.1126/science.abf1752 https://www.sciencemag.org/news/2020/10/new-test-detects-coronavirus-just-5-minutes ${ }^{234}$ Service, Robert. In 'Milestone,' FDA OKs Simple, Accurate Coronavirus Test That Could Cost \$5. Science, August 27-28, 2020. doi:10.1126/science.abe5319 235 The Nobel Prize in Physiology or Medicine 2020. October 5, 2020.

https://www.nobelprize.org/prizes/medicine/2020/press-release/ ${ }^{236}$ Schweitzer, Albert (1922) The Decay and the Restoration of Civilization (Translated by C. T. Campion. Published by A. C. Black, London, 1923) https://ia800904.us.archive.org/9/items/p1decayrestorati00schwuoft/p1decayrestoratio0schwuoft.pdf ${ }^{237}$ David M Cutler and Larry H Summers. COVID-19 Pandemic and the \$16 Trillion Virus. JAMA. Pub Oct 12, 2020. doi:10.1001/jama.2020.19759 https://jamanetwork.com/journals/jama/fullarticle/2771764 238 “The World's $\$ 80$ Trillion Economy - in One Chart.” World Economic Forum, https://www.weforum.org/agenda/2018/10/the-80-trillion-world-economy-in-one-chart/ ${ }^{239} \mathrm{https://www.worldometers.info/gdp/gdp-by-country}$ 
${ }^{240}$ Lulla, Valeria, et al. Antisense Oligonucleotides Target a Nearly Invariant Structural Element from the SARS-CoV-2 Genome and Drive RNA Degradation. preprint, Molecular Biology, 19 September 2020. doi:10.1101/2020.09.18.304139 https://www.biorxiv.org/content/10.1101/2020.09.18.304139v1.full.pdf ${ }^{241}$ David Chiriboga, Juan Garay, Paulo Buss, Rocío Sáenz Madrigal, Laetitia Charmaine Rispel (2020) "Health Inequity during the COVID-19 Pandemic: A Cry for Ethical Global Leadership." The Lancet, vol. 395, no. 10238, May 2020, pp. 1690-1691. doi:10.1016/S0140-6736(20)31145-4 https://www.thelancet.com/action/showPdf?pii=S0140-6736\%2820\%2931145-4 ${ }^{242}$ Lorenzo Casalino, Zied Gaieb, Jory A. Goldsmith, Christy K. Hjorth, Abigail C. Dommer, Aoife M. Harbison, Carl A. Fogarty, Emilia P. Barros, Bryn C. Taylor, Jason S. McLellan, Elisa Fadda, and Rommie E. Amaro (2020) "Beyond Shielding: The Roles of Glycans in the SARS-CoV-2 Spike Protein." ACS Central Science, September 2020, p. acscentsci.0c01056. doi:10.1021/acscentsci.0c01056.

https://pubs.acs.org/doi/pdf/10.1021/acscentsci.0c01056

${ }^{243}$ Hodcroft, Emma B., et al. Emergence and Spread of a SARS-CoV-2 Variant through Europe in the Summer of 2020. preprint, Epidemiology, 28 October 2020. doi:10.1101/2020.10.25.20219063.

${ }^{244}$ Shaman, J. and Galanti, Marta (2020) Will SARS-CoV-2 become endemic? Science 14 Oct 2020. DOI: $10.1126 /$ science.abe5960 https://science.sciencemag.org/content/early/2020/10/13/science.abe5960/tab-pdf ${ }^{245}$ Cao L, Goreshnik I, Coventry B, Case JB, Miller L, Kozodoy L, Chen RE, Carter L, Walls L, Park YJ, Stewart L, Diamond M, Veesler D, Baker D. De novo design of picomolar SARS-CoV-2 miniprotein inhibitors. bioRxiv [Preprint]. 2020 Aug 3. DOI: 10.1101/2020.08.03.234914. Science 23 October 2020: Vol. 370, Issue 6515, pp. 426-431 DOI: 10.1126/science.abd9909.

https://www.biorxiv.org/content/10.1101/2020.08.03.234914v1.full.pdf ${ }^{246}$ Coase, R. H. (1937) “The Nature of the Firm.” Economica, vol. 4, no. 16, Nov. 1937, pp. 386-405. doi:10.1111/j.1468-0335.1937.tb00002.x https://www.law.uchicago.edu/files/file/coase-nature.pdf http://bit.ly/COASE5PAPERS ${ }^{247}$ Stephanie K. Pell and Christopher Soghoian (2014) Your Secret Stingray's No Secret Anymore: The Vanishing Government Monopoly Over Cell Phone Surveillance and Its Impact On National Security and Consumer Privacy. Harvard Journal of Law and Technology Volume 28, Number 1 Fall 2014 ${ }^{248}$ Kevin S. Bankston and Ashkan Soltani (2014) Tiny Constables and the Cost of Surveillance: Making Cents Out of United States v. Jones, 123 Yale Law Journal OnLIne 335 (2014)

http://yalelawjournal.org/forum/tiny-constables-and-the-cost-of-surveillance-making-cents-out-ofunited-states-v-jones

${ }^{249}$ Roosa Tikkanen and Melinda K. Abrams (2020) U.S. Health Care from a Global Perspective, 2019: Higher Spending, Worse Outcomes? January 30, 2020

https://www.commonwealthfund.org/publications/issue-briefs/2020/jan/us-health-care-globalperspective-2019

${ }^{250}$ Landgrebe, D. (1998) Information Extraction Principals and Methods for Multispectral and Hyperspectral Image Data, Information processing for Remote Sensing. World Scientific Publishing Co. https://engineering.purdue.edu/ landgreb/whitepaper.pdf 
${ }^{251}$ Moghimi, Ali, et al. "A Novel Machine Learning Approach to Estimate Grapevine Leaf Nitrogen Concentration Using Aerial Multispectral Imagery.” Remote Sensing, vol. 12, no. 21, October 2020, p. 3515. doi:10.3390/rs12213515. https://www.mdpi.com/2072-4292/12/21/3515/pdf

${ }^{252}$ Huang, Y., Ren, Z., Li, D. et al. Phenotypic techniques and applications in fruit trees: a review. Plant Methods 16, 107 (2020). https://doi.org/10.1186/s13007-020-00649-7

${ }^{253}$ Lorenzen, Bent \& Arne, Jensen (1988) "Reflectance of Blue, Green, Red and near Infrared Radiation from Wetland Vegetation Used in a Model Discriminating Live and Dead above Ground Biomass." New Phytologist, vol. 108, no. 3, March 1988, pp. 345-55. doi:10.1111/j.1469-8137.1988.tb04173.x.

${ }^{254}$ Soo Chung, Lane E. Breshears and Jeong-Yeol Yoon, "Smartphone Near Infrared Monitoring of Plant Stress," Computers and Electronics in Ag, 2018, 154: 93-98. https://doi.org/10.1016/j.compag.2018.08.046 ${ }^{255}$ Marturano F, Ciparisse JF, Chierici A, d'Errico F, Di Giovanni D, Fumian F, Rossi R, Martellucci L, Gaudio P, Malizia A. Enhancing Radiation Detection by Drones through Numerical Fluid Dynamics Simulations. Sensors (Basel). 2020 March 23; 20(6):1770. doi: 10.3390/s20061770. https://www.ncbi.nlm.nih.gov/pmc/articles/PMC7147154/pdf/sensors-20-01770.pdf ${ }^{256}$ William Joseph Butera (2002) Programming a Paintable Computer. Submitted to the Program in Media Arts \& Sciences, School of Architecture and Planning, in partial fulfillment of the requirements for the degree of Doctor of Philosophy in Media Arts \& Sciences, Massachusetts Institute of Technology February 2002 http://cba.mit.edu/docs/theses/02.02.butera.pdf http://cba.mit.edu/events/01.11.retreat/Butera/Butera_files/v3_document.htm ${ }^{257}$ Wicaksono, I., Tucker, C.I., Sun, T. et al. A tailored, electronic textile conformable suit for large-scale spatiotemporal physiological sensing in vivo. npj Flex Electron 4, 5 (2020).

https://doi.org/10.1038/s41528-020-0068-y

${ }^{258}$ Mark Weiser, Rich Gold and John Seeley Brown (1999) The origins of ubiquitous computing research at PARC in the late 1980s. IBM Systems Journal, vol 38, no. 4, pp. 693-696, 1999.

http://www.cs.cmu.edu/ jasonh/courses/ubicomp-sp2007/papers/03-weiser-origins.pdf ${ }^{259}$ Mark Weiser (1991) The Computer for the 21st Century. Scientific American 265, No. 3, pp. $94-104$ (September 1991). https://www.lri.fr/ mbl/Stanford/CS477/papers/Weiser-SciAm.pdf ${ }^{260}$ William D. Nordhaus (2001) Progress of Computing. Cowles Foundation Discussion Paper No. 1324. Cowles Foundation For Research in Economics, Yale University, New Haven, Connecticut, USA. http://cowles.econ.yale.edu/https://cowles.yale.edu/sites/default/files/files/pub/d13/d1324.pdf and https://aiimpacts.org/trends-in-the-cost-of-computing/

${ }^{261}$ David H Wolpert. (2019) The stochastic thermodynamics of computation, Journal of Physics A: Mathematical and Theoretical (2019). DOI: 10.1088/1751-8121/ab0850

${ }^{262}$ Charles, J. (2012) https://jcharles00.wordpress.com/2012/05/

${ }^{263}$ What is IPv6? https://www.internetsociety.org/deploy360/ipv6/

${ }^{264}$ Hinden, Bob and Krishnan, Suresh (2018) IPv6 is an Internet Standard. https://www.ietf.org/blog/ipv6-internet-standard/ 
${ }^{265}$ Raffi C. Krikorian (2004) Internet 0. Submitted to the Program in Media Arts \& Sciences, School of Architecture and Planning in partial fulfillment of the requirements for the degree of Master of Science in Media Arts \& Sciences at the Massachusetts Institute Of Technology, August 2004 https://dspace.mit.edu/bitstream/handle/1721.1/28866/60412683-MIT.pdf?sequence=2\&isAllowed=y ${ }^{266}$ Ishii, H. and Ullmer, B. (1997) Tangible Bits: Towards Seamless Interfaces between People, Bits, and Atoms. Proceedings of CHI'97 (ACM, March 1997) http://tangible.media.mit.edu/person/hiroshi-ishii/ ${ }^{267}$ Hiroshi Ishi https://tangible.media.mit.edu/person/hiroshi-ishii/ ${ }^{268}$ Gershenfeld, Neil A. When Things Start to Think. 1st ed, Henry Holt, 1999.

${ }^{269}$ Nelson Minar, Matthew Gray, Oliver Roup, Raffi Krikorian and Patti Maes "Hive: Distributed Agents for Networking Things.” IEEE Concurrency, vol. 8, no. 2, Apr. 2000, pp. 24-33. doi:10.1109/4434.846191 ${ }^{270}$ Gershenfeld, Neil. http://ng.cba.mit.edu/

${ }^{271}$ Origins of IoT https://autoid.mit.edu/

${ }^{272}$ Greengard, Samuel. The Internet of Things. MIT Press, 2015.

${ }^{273}$ https://autoid.mit.edu/people-2

${ }^{274}$ https://openlearning.mit.edu/about/our-team/sanjay-sarma

${ }^{275}$ Simon, Herbert, A. The Steam Engine and the Computer: What Makes Technology Revolutionary. EDUCOM Bulletin, vol. 22, no.1, pp. 2-5 Spring 1987

https://er.educause.edu/-/media/files/article-downloads/erm0132.pdf http://digitalcollections.library.cmu.edu/awweb/awarchive?type=file\&item $=34057$

${ }^{276}$ Sarma, S., Brock, D. and Engels, D. (2001) "Radio Frequency Identification and the Electronic Product Code," IEEE Micro, vol. 21, no. 6, December 2001, pp. 50-54. doi:10.1109/40.977758.

${ }^{277}$ MIT Project Oxygen (2001) Computer Science and Artificial Intelligence Laboratory, MIT. http://www.ai.mit.edu/projects/oxygen/oxygen-book2001/oxygenbook2001.pdf ${ }^{278}$ Katz, Randall (2002) Sketch - http://oxygen.csail.mit.edu/videosketching.html and Sketch Video Demonstration http://oxygen.csail.mit.edu/videos/sketching.mpeg

${ }^{279}$ Project Oxygen. Massachusetts Institute of Technology http://oxygen.csail.mit.edu/Overview.html

${ }^{280}$ Jorgenson, Dale Weldeau, et al., editors. Measuring and Sustaining the New Economy: Report of a Workshop. National Academy Press, 2002. https://www.nap.edu/download/10282

${ }^{281} \mathrm{https}$ ://www.pcgamesn.com/intel/memory-nand-ssd-price-drop-2019-oversupply

${ }^{282}$ https://www.iotone.com/term/decreasing-cost-of-storage/t172

${ }^{283}$ Golubchik, Leana, Khuller, Samir, Mukherjee, Koyel andYao, Yuan. (2013). To send or not to send: Reducing the cost of data transmission. IEEE Infocom. 2472-2478. Doi: 10.1109/INFCOM.2013.6567053 ${ }^{284}$ Asimov, Isaac (1953) http://www.self.gutenberg.org/articles/Sally_(short_story)

${ }^{285}$ Asimov, Isaac. The Complete Robot. HarperCollins, 1995.

https://en.wikipedia.org/wiki/Sally_(short_story)

${ }^{286}$ Sanjay Sarma, David Brock and Kevin Ashton (1999) "The Networked Physical World - Proposals for Engineering the Next Generation of Computing, Commerce, and Automatic-Identification, " MIT Auto-ID Center White Paper. MIT-AUTOID-WH001, 1999. https://autoid.mit.edu/publications-0 https://pdfs.semanticscholar.org/88b4/a255082d91b3c88261976c85a24f2f92c5c3.pdf 
${ }^{287}$ Ghasempour, Alireza. Internet of Things in Smart Grid: Architecture, Applications, Services, Key Technologies, and Challenges. Inventions, vol. 4, no. 1, Mar 2019, p. 22. doi:10.3390/inventions4010022 ${ }^{288}$ Christopher Greer, Martin Burns, David Wollman and Edward Griffor (2019) Cyber-Physical Systems and Internet of Things. https://doi.org/10.6028/NIST.SP.1900-202 https://nvlpubs.nist.gov/nistpubs/SpecialPublications/NIST.SP.1900-202.pdf ${ }^{289}$ Edward A. Lee and Sanjit A. Seshia. Introduction to Embedded Systems, A Cyber-Physical Systems Approach, Second Edition, MIT Press, 2017. ISBN 978-0-262-53381-2 https://ptolemy.berkeley.edu/books/leeseshia/releases/LeeSeshia_DigitalV2_2.pdf ${ }^{290}$ Rajkumar R, Lee I, Sha L, Stankovic J (2010) Cyber-Physical Systems: The Next Computing Revolution. Proceedings of the 47th Design Automation Conference (IEE, Anaheim, CA), pp 731- 736. https://ieeexplore.ieee.org/document/5523280 https://www.cs.virginia.edu/ stankovic/psfiles/Rajkumar-DAC2010-Final.pdf ${ }^{291}$ Robert E. Horn (2015) Information Design: Emergence of a New Profession https://steinhardtapps.es.its.nyu.edu/create/courses/2015/reading/Horn.pdf ${ }^{292}$ Jacobson, Robert E., editor. Information Design. MIT Press, 1999.

https://epdf.pub/queue/information-design.html ${ }^{293}$ Jimmy Soni and Rob Goodman (2018) A Mind at Play: How Claude Shannon Invented the Information Age. Simon \& Schuster (July 17, 2018) ISBN13: 9781476766690 https://spectrum.ieee.org/geek-life/history/a-man-in-a-hurry-claude-shannons-new-york-years ${ }^{294}$ Pham NM, Karlen W, Beck HP, Delamarche E. Malaria and the 'last' parasite: how can technology help? Malaria Journal 2018 July 11; 17(1):260. doi: 10.1186/s12936-018-2408-0 https://www.ncbi.nlm.nih.gov/pmc/articles/PMC6042346/pdf/12936_2018_Article_2408.pdf ${ }^{295}$ Pierce, David (2016) Project Ara Lives: Google's Modular Phone Is Ready for You Now. https://www.wired.com/2016/05/project-ara-lives-googles-modular-phone-is-ready/ ${ }^{296}$ NK Labs, Cambridge, Massachusetts https://www.nklabs.com/ara-knaian ${ }^{297}$ Bhardwaj, Vinay, and Vinod Gaur. "Raman Spectroscopy as a Blood Glucose Monitoring Tool.” European Pharmaceutical Review, vol. 22, no. 3, 2017, pp. 26-29.

${ }^{298}$ Pandey R, Paidi SK, Valdez TA, Zhang C, Spegazzini N, Dasari RR, Barman I. Noninvasive Monitoring of Blood Glucose with Raman Spectroscopy. Acc Chem Res. 2017 February 21; 50(2):264-272.

doi: 10.1021/acs.accounts.6b00472. Epub 2017 January 10. https://www.ncbi.nlm.nih.gov/pmc/articles/PMC5896772/pdf/nihms955832.pdf ${ }^{299}$ Kakkar, T., Richards, B., Jha, A., Saha, S., Ajjan, R., Grant, P. and Jose, G. (2015) Glucosense: Photonic Chip Based Non-Invasive Glucose Monitor. Diabetes Technology Therapeutics, vol. 17, pp. A82-A83 ${ }^{300}$ Jose, Gin. GLUCOSENSE. University of Leeds, UK. www.leeds.ac.uk/site/custom_scripts/profilesingle.php? profileTypeID $=3 \&$ category $I D=2000$ \&profile $I D=116$ ${ }^{301}$ Jung, D.G.; Jung, D.; Kong, S.H. (2017) A Lab-on-a-Chip-Based Non-Invasive Optical Sensor for Measuring Glucose in Saliva. Sensors 2017, 17, 2607. https://www.mdpi.com/1424-8220/17/11/2607/pdf 
302 Zhang R, Liu S, Jin H, Luo Y, Zheng Z, Gao F, Zheng Y. (2019) Noninvasive Electromagnetic Wave Sensing of Glucose. Sensors (Basel). 2019 March 7; 19(5):1151. doi: 10.3390/s19051151 https://www.ncbi.nlm.nih.gov/pmc/articles/PMC6427587/pdf/sensors-19-01151.pdf ${ }^{303}$ Narayan KMV, Zhang P, Kanaya AM, et al. Diabetes: The Pandemic and Potential Solutions. In: Jamison DT, Breman JG, Measham AR, et al., editors. Disease Control Priorities in Developing Countries. 2nd ed. Washington (DC): International Bank for Reconstruction and Development, The World Bank. 2006. Chapter 30. Oxford University Press, NY. https://www.ncbi.nlm.nih.gov/books/NBK11777/ https://www.ncbi.nlm.nih.gov/books/NBK11777/pdf/Bookshelf_NBK11777.pdf ${ }^{304}$ Villena Gonzales W, Mobashsher AT, Abbosh A. The Progress of Glucose Monitoring-A Review of Invasive to Minimally and Non-Invasive Techniques, Devices and Sensors. Sensors (Basel). 2019 Feb 15; 19(4):800. doi: 10.3390/s19040800 https://www.ncbi.nlm.nih.gov/pmc/articles/PMC6412701/pdf/sensors-19-00800.pdf ${ }^{305}$ Kang, Jeon Woong, et al. (2020) "Direct Observation of Glucose Fingerprint Using in Vivo Raman Spectroscopy.” Science Advances, vol. 6, no. 4, Jan. 2020, p. eaay5206. doi:10.1126/sciadv.aay5206 ${ }^{306} \mathrm{Zhu}$, Lian, et al. (2013) "Direct Electrochemistry of Cholesterol Oxidase Immobilized on Gold Nanoparticles-Decorated Multiwalled Carbon Nanotubes and Cholesterol Sensing." Talanta, vol. 106, March 2013, pp. 192-99. doi:10.1016/j.talanta.2012.12.036

${ }^{307}$ N. Agrawal, B. Zhang, C. Saha, C. Kumar, X. Pu and S. Kumar. Ultra-Sensitive Cholesterol Sensor Using Gold and Zinc-Oxide Nanoparticles Immobilized Core Mismatch MPM/SPS Probe. Journal of Lightwave Technology, vol. 38, no. 8, pp. 2523-2529, 15 April 2020. doi: 10.1109/JLT.2020.2974818 ${ }^{308}$ Oncescu V, Mancuso M, Erickson D. Cholesterol testing on a smartphone. Lab Chip. 2014 Feb 21; 14(4):759-63. doi: 10.1039/c3lc51194d. Epub 2013 December 13.

${ }^{309}$ de Bold AJ, Borenstein HB, Veress AT, Sonnenberg H. (1981) A rapid and potent natriuretic response to intravenous injection of atrial myocardial extract in rats. Life Sci 1981; vol. 28: pp. 89-94

${ }^{310}$ Sudoh, T., Kangawa, K., Minamino, N. et al. (1988) A new natriuretic peptide in porcine brain. Nature 332, 78-81 (1988). https://doi.org/10.1038/332078a0

${ }^{311}$ Sudoh T, Minamino N, Kangawa K, Matsuo H. C-type natriuretic peptide (CNP): A new member of natriuretic peptide family identified in porcine brain. Biochem Biophys Res Commun 1990; 168: 863-870 ${ }^{312}$ Pollok, Nicole E., et al. Electrochemical Detection of NT-ProBNP Using a Metalloimmunoassay on a Paper Electrode Platform. ACS Sensors, vol. 5, n. 3, Mar 2020, p 853-60. doi: 10.1021/acssensors.0c00167 ${ }^{313}$ Grabowska I, Sharma N, Vasilescu A, Iancu M, Badea G, Boukherroub R, Ogale S, Szunerits S. Electrochemical Aptamer-Based Biosensors for the Detection of Cardiac Biomarkers. ACS Omega. 2018 September 30; 3(9): pp. 12010-12018. doi: 10.1021/acsomega.8b01558. Epub 2018 September 26. ${ }^{314}$ Gaetano Ruocco, Marco Pellegrini, Carmelo De Gori, Beatrice Franci, Ranuccio Nuti, Alberto Palazzuoli. (2016) The prognostic combined role of B-type natriuretic peptide, blood urea nitrogen and congestion signs persistence in patients with acute heart failure. Journal of Cardiovascular Medicine, vol. 17, no. 11, pp. 818-827 (2016) doi: 10.2459/JCM.0000000000000350 
${ }^{315}$ Fonarow GC, Peacock WF, Phillips CO, Givertz MM, Lopatin M; ADHERE Scientific Advisory Committee and Investigators. Admission B-type natriuretic peptide levels and in-hospital mortality in acute decompensated heart failure. Journal of the American College of Cardiology. 2007 May 15; 49(19): pp. 1943-50. doi: 10.1016/j.jacc.2007.02.037. Epub 2007 April 30.

${ }^{316}$ Lin, Chung-Yin, et al. "Detection of Oxytocin, Atrial Natriuretic Peptide, and Brain Natriuretic Peptide Using Novel Imprinted Polymers Produced with Amphiphilic Monomers." Journal of Peptide Science, vol. 25, no. 3, March 2019. doi:10.1002/psc.3150

${ }^{317}$ Ven Manda, Tommy D. Bennett and Zhongping Yang (2003) Implantable biosensor devices for monitoring cardiac marker molecules https://patents.google.com/patent/US7632234B2/en https://patentimages.storage.googleapis.com/20/27/7b/4ba70677881f9c/US7632234.pdf ${ }^{318}$ Gutterman, David (2013) Silent Myocardial Ischemia https://www.escardio.org/staticfile/Escardio/education/live-events/courses/education-resource/Fri-11-SMI-Gutterman.pdf ${ }^{319}$ Deanfield JE, Maseri A, Selwyn AP, Ribeiro P, Chierchia S, Krikler S, Morgan M. (1983) Myocardial ischaemia during daily life in patients with stable angina: its relation to symptoms and heart rate changes. Lancet. 1983 Oct 1; 2(8353): pp. 753-758. doi: 10.1016/s0140-6736(83)92295-x.

${ }^{320}$ Eric S. McLamore, Evanglyn Alocilja, Carmen Gomes, Sundaram Gunasekaran, Daniel Jenkins, Yanbin Li, Yu (Jessie) Mao, Sam R. Nugen, Jose Reyes De Corcuera, Paul Takhistov, Olga Tsyusko, Jarad P. Cochran, Tzuen-Rong (Jeremy) Tzeng, Jeong-Yeol Yoon, Chenxu Yu, and Anhong Zhou (2020). A FEAST of Biosensors: Food, Environment, Agriculture, Science, Technology (FEAST) for Biosensing in North America (in preparation)

${ }^{321}$ Schoettker P, Degott J, Hofmann G, Proença M, Bonnier G, Lemkaddem A, Lemay M, Schorer R, Christen U, Knebel JF, Wuerzner A, Burnier M, Wuerzner G. Blood pressure measurements with the OptiBP smartphone app validated against reference auscultatory measurements. Nature Science Reports 2020 October 20; 10(1):17827. doi: 10.1038/s41598-020-74955-4

https://www.ncbi.nlm.nih.gov/pmc/articles/PMC7576142/pdf/41598_2020_Article_74955.pdf ${ }^{322}$ Noninvasive Device Could End Daily Finger Pricking for People with Diabetes.

https://medicalxpress.com/news/2015-07-noninvasive-device-daily-finger-people.html ${ }^{323}$ Glucosense Monitoring. University of Leeds, UK https://www.youtube.com/watch?v=j--utQE9Pz8 ${ }^{324}$ Sato H, Chiba H, Tashiro H, Ozaki Y.(2001) Excitation wavelength-dependent changes in Raman spectra of whole blood and hemoglobin: comparison of the spectra with 514.5-, 720-, and 1064-nm excitation. J Biomed Opt. 2001 July; 6(3): pp. 366-370. doi: 10.1117/1.1380668

https://www.spiedigitallibrary.org/journalArticle/Download?fullDOI=10.1117\%2F1.1380668 ${ }^{325}$ Hasan MK, Haque MM, Adib R, Tumpa JF, Begum A, Love RR, Kim YL, Sheikh IA. (2018) SmartHeLP: Smartphone-based Hemoglobin Level Prediction Using an Artificial Neural Network. AMIA Annual Symposium Proceedings. 2018 December 5 : pp. 535-544.

https://www.ncbi.nlm.nih.gov/pmc/articles/PMC6371334/pdf/2976625.pdf ${ }^{326}$ Mannino, R.G., Myers, D.R., Tyburski, E.A. et al. (2018) Smartphone app for non-invasive detection of anemia using only patient-sourced photos. Nature Communications 9, 4924 (2018).

https://doi.org/10.1038/s41467-018-07262-2

59 - ADD is in the MIT Library https://dspace.mit.edu/handle/1721.1/128017 (will be uploaded to ChemRxiv, too). 
${ }^{327}$ Yan, Q., Zhi, N., Yang, L. et al. A highly sensitive uric acid electrochemical biosensor based on a nano-cube cuprous oxide/ferrocene/uricase modified glassy carbon electrode. Sci Rep 10, 10607 (2020). https://doi.org/10.1038/s41598-020-67394-8

${ }^{328}$ Yang, Y., Song, Y., Bo, X. et al. A laser-engraved wearable sensor for sensitive detection of uric acid and tyrosine in sweat. Nat Biotechnol 38, 217-224 (2020). https://doi.org/10.1038/s41587-019-0321-X ${ }^{329}$ Bastawrous A, Giardini ME, Bolster NM, Peto T, Shah N, Livingstone IA, Weiss HA, Hu S, Rono H, Kuper H, Burton M. (2016) Clinical Validation of a Smartphone-Based Adapter for Optic Disc Imaging in Kenya. JAMA Ophthalmology 2016 Feb; 134(2): pp.151-158. doi: 10.1001/jamaophthalmol.2015.4625 https://www.ncbi.nlm.nih.gov/pmc/articles/PMC5321504/pdf/emss-71475.pdf ${ }^{330}$ Di Santo P, Harnett DT, Simard T, Ramirez FD, Pourdjabbar A, Yousef A, Moreland R, Bernick J, Wells G, Dick A, Le May M, Labinaz M, So D, Motazedian P, Jung RG, Chandrasekhar J, Mehran R, Chong AY, Hibbert B. Photoplethysmography using a smartphone application for assessment of ulnar artery patency: a randomized clinical trial. CMAJ. 2018 April 3; 190(13): E380-E388. doi: 10.1503/cmaj.170432 https://www.ncbi.nlm.nih.gov/pmc/articles/PMC5880645/pdf/190e380.pdf ${ }^{331}$ Malamas, Peter (2011) A 3-D Heart Model for Arrhythmia Simulation and Visualization https://sunfest.seas.upenn.edu/wp-content/uploads/2018/07/MALAMASPETER.pdf ${ }^{332}$ Saxon Leslie A. Ubiquitous wireless ECG recording: a powerful tool physicians should embrace. J Cardiovasc Electrophysiol. 2013 April; 24(4): pp. 480-483. doi: 10.1111/jce.12097. Epub 2013 Feb 19. ${ }^{333}$ Fadel Adib, Hongzi Mao, Zachary Kabelac, Dina Katabi and Robert C. Miller. "Smart Homes That Monitor Breathing and Heart Rate." Proceedings of the 33rd Annual ACM Conference on Human Factors in Computing Systems, Association for Computing Machinery, 2015, pp. 837-846. ACM Digital Library, doi:10.1145/2702123.2702200. http://www.mit.edu/ fadel/papers/vitalradio-paper.pdf http://witrack.csail.mit.edu/vitalradio/ ${ }^{334}$ Fadel Adib and Dina Katabi (2013) See Through Walls with Wi-Fi. SIGCOMM'13, August 12-16, 2013. Hong Kong, China. https://people.csail.mit.edu/fadel/papers/wivi-paper.pdf 335 Tomlinson S, Behrmann S, Cranford J, Louie M, Hashikawa A. (2018) Accuracy of Smartphone-Based Pulse Oximetry Compared with Hospital-Grade Pulse Oximetry in Healthy Children. Telemed J E Health. 2018 July; 24(7): pp. 527-535. doi: 10.1089/tmj.2017.0166. Epub 2017 December 7.

${ }^{336}$ Banerjee, Abhijit and Duflo, Esther (2019) Good Economics for Hard Times. PublicAffairs, a division of Perseus Books, a subsidiary of Hachette Book Groups (Nov 12, 2019) ISBN-13: 978-1610399500 ${ }^{337}$ Howes, Anton. Arts and Minds: How the Royal Society of Arts Changed a Nation. Princeton University Press, 2020. ISBN-13: 978-0691182643

${ }^{338}$ Y. Rong, A.V. Padrona , K. J. Hagerty, N. Nelson, S. Chic, N. O. Keyhani, J. Katz, S.P.A. Datta, C. Gomes, and E.S. McLamore (2018) Post Hoc Support Vector Machine Learning for Impedimetric Biosensors Based on Weak Protein-Ligand Interactions. The Analyst, vol. 143, no. 9, pp. 2066-2075 doi:10.1039/C8AN00065D https://pubs.rsc.org/en/content/getauthorversionpdf/C8AN00065D 
${ }^{339}$ Cassie A. Giacobassi, Daniela A. Oliveira, Cicero C. Pola, Dong Xiang, Yifan Tang, Shoumen Palit Austin Datta, Eric S. McLamore and Carmen Gomes (2020) Sense-Analyze-Respond-Actuate (SARA) systems span nanoscale and macroscale actuation for detection of Escherichia coli in water (in press) ${ }^{340}$ Nassauer, Sarah. “WSJ News Exclusive | Walmart Scraps Plan to Have Robots Scan Shelves.” Wall St J, 2 Nov 2020. www.wsj.com/articles/walmart-shelves-plan-to-have-robots-scan-shelves-11604345341 ${ }^{341}$ Bejan, Teresa (2017) Mere Civility: Disagreement and the Limits of Toleration. Harvard University Press, 2017. ISBN-13: 978-0674545496

${ }^{342}$ Sen, Amartya (1999) Development as Freedom. Alfred A. Knopf, New York, 1999. ISBN-13 : 978-0385720274

${ }^{343}$ Sen, Amartya (2009) The Idea of Justice. Belknap Press of Harvard University Press; 1 st edition (September 30, 2009) ISBN-13: 978-0674036130

${ }^{344}$ Datta, Shoumen. APPENDIX Figure 1: Description of Major Software Components https://github.com/shoumendatta/ADD-DIGITAL and James Lamb https://github.com/jameslamb ${ }^{345}$ Message Queueing using an open lightweight broker, such as, Message Queueing Telemetry Transport, MQTT (https://mqtt.org/) or RabbitMQ (https://www.rabbitmq.com/) or heavy-duty Apache Kafka (https://kafka.apache.org/). Self-managed or run behind a managed IoT service from cloud providers: AWS IoT Core (https://aws.amazon.com/iot-core/) or Azure IoT Hub (https://azure.microsoft.com/en-us/services/iot-hub/) or related services provided by other vendors (https://www.zdnet.com/article/the-top-cloud-providers-of-2020-aws-microsoft-azure-google-cloudhybrid-saas/).

${ }^{346}$ Operational Data Store choices include InfluxDB (https://www.influxdata.com/), Apache Cassandra (https://cassandra.apache.org/) or Prometheus (https://prometheus.io/). Managed cloud database from Amazon https://docs.aws.amazon.com/amazondynamodb/latest/developerguide/Introduction.html. ${ }^{347}$ Amazon S3 Glacier https://aws.amazon.com/glacier/

${ }^{348}$ Enterprise Resource Planning (ERP) - Master Data Management: Architecture and Technology https://www.element61.be/en/resource/master-data-management-mdm-architecture-technology ${ }^{349}$ Vesna Vučković (2008) Image and its Matrix, Matrix and its Image. Преглед НЦД (NCD Review) 12 (2008) 17-31 http://elib.mi.sanu.ac.rs/files/journals/ncd/12/ncd12017.pdf

${ }^{350}$ H3: Uber's Hexagonal Hierarchical Spatial Index https://eng.uber.com/h3/

${ }^{351}$ Liu J, Ranka S, Kahveci T. Classification and feature selection algorithms for multi-class CGH data. Bioinformatics. 2008 July 1; 24(13): i86-95. doi: 10.1093/bioinformatics/btn145 https://www.ncbi.nlm.nih.gov/pmc/articles/PMC2718623/pdf/btn145.pdf

${ }^{352}$ Bommert, Andrea, et al. "Benchmark for Filter Methods for Feature Selection in High-Dimensional Classification Data." Computational Statistics \& Data Analysis, vol. 143, March 2020, p. 106839. doi:10.1016/j.csda.2019.106839.

${ }^{353}$ Chen, R., Dewi, C., Huang, S. et al. Selecting critical features for data classification based on machine learning methods. Journal of Big Data 7, 52 (2020). https://doi.org/10.1186/s40537-020-00327-4 https://journalofbigdata.springeropen.com/track/pdf/10.1186/s40537-020-00327-4 
${ }^{354}$ Object stores: Amazon https://aws.amazon.com/s3/; Google Cloud https://cloud.google.com/storage; Microsoft Azure Blob https://azure.microsoft.com/en-us/services/storage/blobs/); Apache Cassandra https://medium.com/walmartglobaltech/building-object-store-storing-images-in-cassandra-walmartscale-a6b9c02af593

${ }^{355}$ Query-Over-Files Engines: Presto (https://prestodb.io/), Apache Drill (https://drill.apache.org/) or Apache Spark SparkSQL (https://spark.apache.org/sql/). If using application-specific custom code that directly reads files, orchestrated with batch-scheduling engine: Apache Airflow (https://airflow.apache.org/) or Prefect (https://www.prefect.io/)

${ }^{356}$ Lechner, M., Hasani, R., Amini, A. et al. Neural circuit policies enabling auditable autonomy. Nature Machine Intelligence 2, 642-652 (13 October 2020). https://doi.org/10.1038/s42256-020-00237-3 ${ }^{357}$ Analytical Data Store: Traditional relational database PostgreSQL (https://www.postgresql.org/) or hosted relational database products provided by cloud providers (https://aws.amazon.com/rds/). If intelligent caching of repeated queries is needed, data warehouse technologies (managed cloud service) include: Snowflake (https://www.snowflake.com/), Amazon Redshift (https://aws.amazon.com/redshift) or Google BigQuery (https://cloud.google.com/bigquery). For on-premises option: Teradata (https://www.teradata.com/).

${ }^{358}$ Machine Learning (see the cartoon on the last page of this article) model training tools: Apache Spark (https://spark.apache.org/), Dask (https://dask.org/) or Ray (https://rise.cs.berkeley.edu/projects/ray/). If application specificity does not require high degree of customization - use "autoML" tools - DataRobot (https://www.datarobot.com/), h2o (https://docs.h20.ai/h2o/latest-stable/h2o-docs/automl.html), Amazon SageMaker Autopilot (https://aws.amazon.com/blogs/aws/amazon-sagemaker-autopilot-fullymanaged-automatic-machine-learning/) or Google Cloud AutoML (https://cloud.google.com/automl). ${ }^{359}$ Tauro, C.J., Ganesan, N., Mishra, S.R., \& Bhagwat, A. (2012). Object Serialization: A Study of Techniques of Implementing Binary Serialization in C++, Java \& .NET. Intl J of Computer Applications, 45, 25-29. https://citeseerx.ist.psu.edu/viewdoc/download?doi=10.1.1.685.1077\&rep=rep $1 \&$ type $=$ pdf ${ }^{360}$ Common Object Request Broker Architecture (CORBA) https://www.corba.org/

${ }^{361}$ Container: Docker https://www.docker.com/resources/what-container

${ }^{362}$ Developer's language of choice may include (but the "menu" is not limited to): Java jar (https://en.wikipedia.org/wiki/JAR_(file_format)), Python pickle file (https://docs.python.org/3/library/pickle.html), $\mathrm{R}$ rds file (https://stat.ethz.ch/R-manual/R-devel/library/base/html/readRDS.html) or a precompiled executable which can read in input data from "stdin" (standard input is a stream from which a program reads its input data) or from a file, created with $\mathrm{C} / \mathrm{C}++$ or language-agnostic description of a model: Predictive Model ML (https://en.wikipedia.org/wiki/Predictive_Model_Markup_Language) or Portable Format for Analytics (http://dmg.org/pfa/) 
Cartoon for Reference \# 358: Machine Learning Algorithms - ML makes better sense without the nonsense of AI

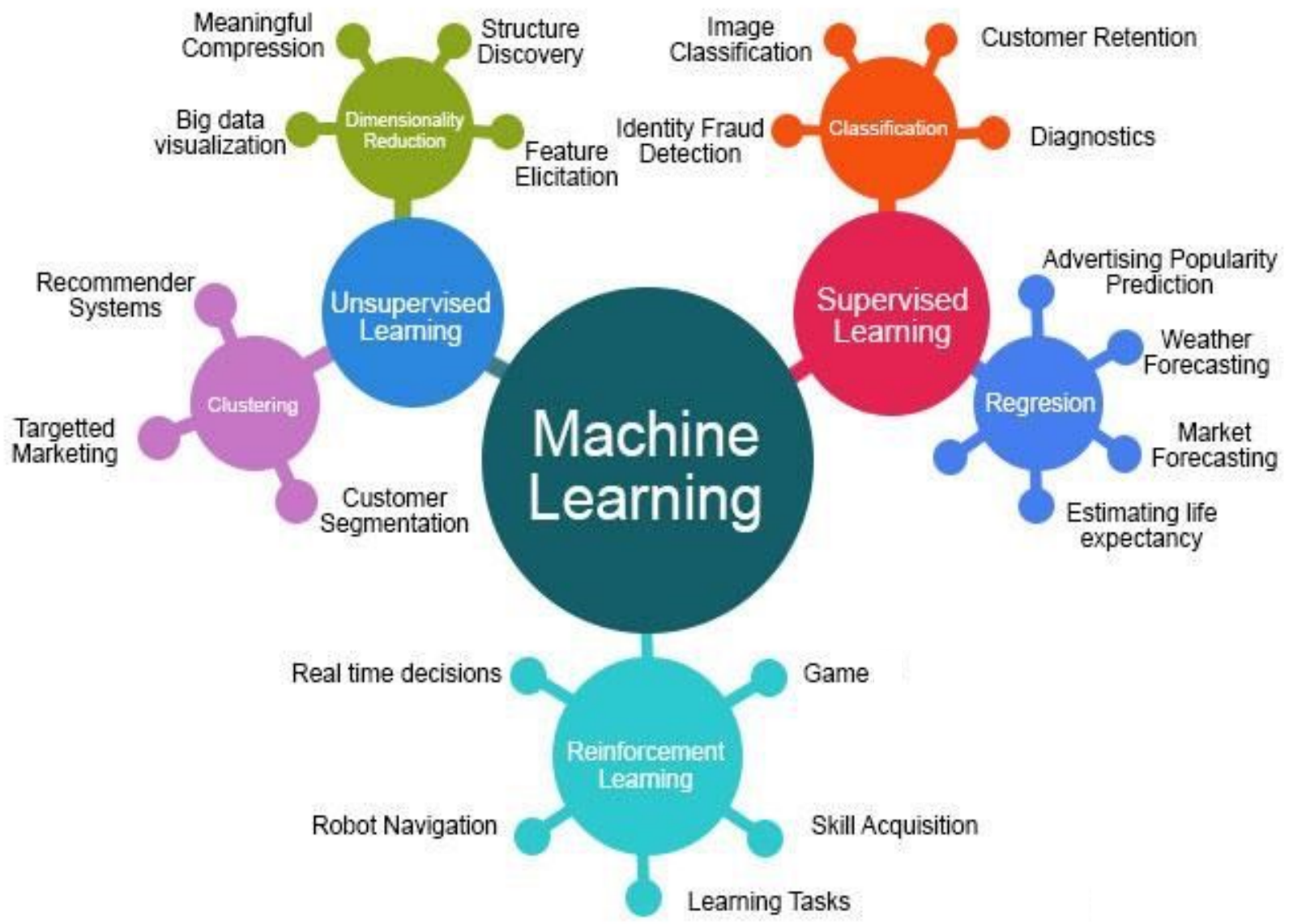




\section{ACKNOWLEDGEMENTS}

The author is thankful to Brittany Newell (section 2), Larry Gold (section 5), Andrew Fire and

Greg Winter (for section 6) as well as Britt Glaunsinger and Sanjay Sarma (for general review).

This note is only a suggestion and a proposal from Shoumen Datta based on published scientific research. It is not new and copyright free. It may be used by anybody for any purpose without any need to cite or credit the author.If you have questions please emailshoumen@mit.eduand/orsdatta8@mgh.harvard.edu 